\title{
a. MASTER
}

PROGRESS REPORT

TO

THE UNITED STATES ENERGY RESEARCH AND DEVELOPMENT ADMINISTRATION

CONTRACT EE-77-S-02-4268-*002

BIOMEDICAL RESEARCH AND APPLICATION UTILIZING

CYCLOTRON PRODUCED RADIONUCLIDES

Contract Period:

Report Period:

Principal Investigator:

Co-Principal Investigator:

Co-Principal Investigator:

Department:
January 1, 1977 to December 31, 1977.

October 1, 1976 to September 30, 1977

John S. Laughtin, Ph.D., Member

Richard S. Benua, M.D., Associate Member

Roy S. Tilbury, Ph.D., Associate Member

Biophysics Laboratory

5501

Sloan-Kettering Institute for Cancer Research

410 East 68th Street

New York, New York 10021

\section{NOTICE $\because$.}

PORTIONS OF THIS REPORT ARE ILLEGIBLE." I'

has been reproduced from the best avallable

copy to permit the broadestpossible avall-

ability.....

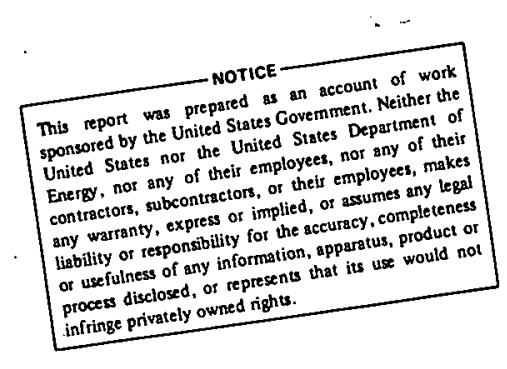

September $30, \cdot 1977$ 


\section{DISCLAIMER}

This report was prepared as an account of work sponsored by an agency of the United States Government. Neither the United States Government nor any agency Thereof, nor any of their employees, makes any warranty, express or implied, or assumes any legal liability or responsibility for the accuracy, completeness, or usefulness of any information, apparatus, product, or process disclosed, or represents that its use would not infringe privately owned rights. Reference herein to any specific commercial product, process, or service by trade name, trademark, manufacturer, or otherwise does not necessarily constitute or imply its endorsement, recommendation, or favoring by the United States Government or any agency thereof. The views and opinions of authors expressed herein do not necessarily state or reflect those of the United States Government or any agency thereof. 


\section{DISCLAIMER}

Portions of this document may be illegible in electronic image products. Images are produced from the best available original document. 


\section{NOTICE}

This report was prepared as an account of work sponsored by the United States Government. Neither the United States nor the United States Energy Research and Development. Administration, nor any of the ir employees, nor any of their contractors, subcontractors, or the ir employees, makes any warranty, express or implied, or assumes any legal liability or responsibility for the accuracy, completeness, or usefulness of any information apparatus, product or process disclosed or represents that its use would not infringe privately owned rights. 
TABLE OF CONTENTS

Page

1. OBJECTIVE

2. SUMMARY OF CYCLOTRON USE

3. PRODUCTION OF RADIONUCLIDES AND LABELED COMPOUNDS $\ldots \ldots$

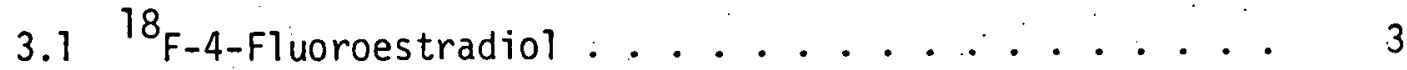

3.2 Enzymatic Synthes is of ${ }^{13} \mathrm{~N}$-Compounds of Biological

Significance ................... 7

3.3 Preparation of ${ }^{11} \mathrm{C}$ Labeled Precursors...... .9

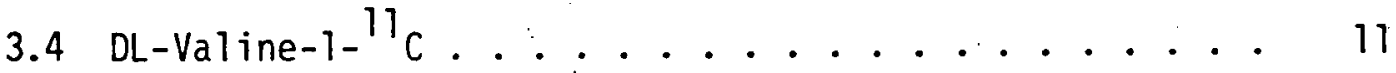

3.5 Potassium-38 Production . . . . . . . . . . . 15

3.6 Selenium-73 ......................... 19

3.7 Process Equipment Remote Control System (PERCS) . . . . 20

3.8 N-13 Species Formed by Proton Irradiation of Water . . 22

4. METABOLIC ISOTOPE STUDIES . . . . . . . . . . . . . . . 31

$4.1^{13}{ }_{N-A m m o n i a *}$ Metabolism in Hepatic Encephalopathy : . 31

4.2 Regional 0xygen Extraction in Cerebral Ischemia . . . 41

4.3 Development of New Pancreatic Scanning Agents . . . . 44

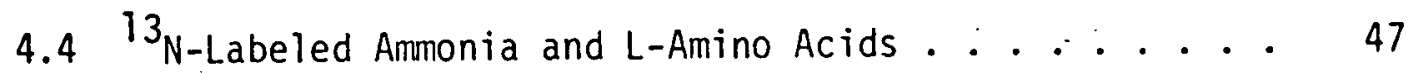

5. INSTRUMENTATION AND DATA HANDLING . . . . . . . . . . 52

5.1 Positron Coincidence Imaging with the TOKIM System ${ }^{\circ}$

5.2 Modeling and Data Analysis . . . . . . . . 60

6. DOSIMETRY FOR INTERNALLY DEPOSITED ISOTOPES IN ANIMALS
AND MAN ...
.

7. CYCLOTRON RESEARCH AND DEVELOPMENT . . . . . . . . . . . 84

8. PUBLICATIONS AND IN PRESS . . . . . . . . . . . . . . . . 87 
BIOMEDICAL RESEARCH AND APPLICATION UTILIZING

CYCLOTRON PRODUCED RADIONUCLIDES

1. OBJECTIVE

The operation of the cyclotron has the following objectives:

(a) Research on nuclear reactions and target design for production of radionuclides.

(b) Research on labeling of biologically important compounds with cyclotron produced radionuclides.

(c) Production of radionuclides and labeled compounds for metabolic isotope research in patients and in animals carried out by the metabolic i sotope study section.

(d) Development of improved cyclotron operation and beam handing technology.

\section{SUMMARY OF CYCLOTRON USE}

Table 1 is a summary of runs performed with the cyclotron during this report period. A run is used here to mean a separate request for cyclotron time, usually for several hours duration, and may include many short runs of a few minutes duration. Beam on time is the time the anode or DEE voltage was on and represents $37 \%$ of the available working hours (2008). The oscillator filament meter registered 1031 hours or $51 \%$ of the available working hours. 
TABLE 1

Summary of Cyclotron Use

October 1, 1976 - September 30, 1977

\begin{tabular}{|c|c|c|c|}
\hline Type of Run & $\begin{array}{l}\text { No. } \\
\text { of Runs }\end{array}$ & $\begin{array}{c}\text { Beam on Time } \\
\text { (Hrs.) }\end{array}$ & Use \\
\hline $\begin{array}{l}\text { Machine Research and } \\
\text { Development }\end{array}$ & 21 . & 17.5 & \\
\hline Modifications & 28 & & \\
\hline Beam Test & 13 & 20.5 & \\
\hline Operator Training & 4 & 2.4 & \\
\hline \multicolumn{4}{|l|}{ Radioisotope Production } \\
\hline $18_{F}$ & 96 & 160.0 & $\begin{array}{l}\text { Bone Scanning } \\
\text { 18F Labeling. }\end{array}$ \\
\hline .150 & 3 & 19.3 & Steady-State Studies \\
\hline${ }^{11} \mathrm{C}$ & 26 & 96.9 & Labeling \\
\hline $13 \mathrm{~N}$ & 90 & 293.8 & $\begin{array}{l}\mathrm{NH}_{3} \text { Production Amino } \\
\text { Acid Synthesis } \\
\text { BCNU, etc. }\end{array}$ \\
\hline${ }^{52} \mathrm{Fe}$ & 13 & 50.3 & Erythropoietic (Patients) \\
\hline${ }^{38} \mathrm{~K}$ & 3 & 7.0 & Production Studies \\
\hline${ }^{206} \mathrm{Bi}$ & 1 & 7.3 & Animal Studies \\
\hline${ }^{73} \mathrm{Se}$ & 6 & 10.2 & Production Studies \\
\hline${ }^{48} \mathrm{Cr}$ & 2 & 7.1 & Production Studies \\
\hline \multicolumn{4}{|l|}{ Neutron Studies } \\
\hline Activation Analysis & $\begin{array}{l}2 \\
3\end{array}$ & $\begin{array}{r}6 \\
8.2\end{array}$ & $\begin{array}{l}\text { Dogs } \\
\text { Bones }\end{array}$ \\
\hline Dosimetry & 11 & 33.1 & Calorimeter \\
\hline Cells. & 1 & 6 & Radiation Biology \\
\hline Target Development & 10 & 18.7 & \\
\hline TOTALS & 334 & 764.3 & \\
\hline
\end{tabular}




\section{PRODUCTION OF RADIONUCLIDES AND LABELED COMPOUNDS}

$3.1 \quad{ }^{18}$ F-4-FLUOROESTRADIOL

\section{OBJECTIVE:}

To prepare 4-fluoroestradiol labeled with fluorine-18.

\section{SCOPE OF INVESTIGATION:}

About $40 \%$ of breast tumors are hormone dependent, and an in vitro test has been developed in this Institute to measure the estrogen receptivity of biopsy samples and to use this as a diagnostic aid in the management of patients with breast cancer (1).. Estrogen receptive tumor tissue takes up tritiated estradiol in vitro about ten times more than normal breast tissue. Experiments at the estrogen receptor protein laboratory in Memorial Hospital, as reported in last. year's progress report, have shown 4-F-estradiol to have comparable physiological activity to estradiol itself. If we are successful in labeling estradiol with $18 \mathrm{~F}$ in the four-position, this compound can be evaluated as a scanning agent for breast cancer or metastases which are hormone dependent. Since estrone is in reversible equilibrium with estradiol, 4-fluoroestrone will be synthesized also.

The synthesis of non-radioactive 4-f7uoroestradiol and 4-fluoroestrone has been reported by Utne (2). A modification of Utne's method to the synthesis of these estrogens iabeled with 18F has been made in this laboratory.

${ }^{18} \mathrm{~F}$-fluoroestrone and ${ }^{18} \mathrm{~F}-4$-fluoroestradiol can be made by the following scheme utilizing an adaptation of the Schiemann reaction for the introduction of fluorine into an aromatic ring $(3,4)$.

\section{RESULTS AND CONCLUSIONS:}

Estrone was used as a starting material rather than estradiol. because the diazotization reaction on 4-aminoestradiol-3-methyl ether gave no solid fluoroborate salt but dark oils only (2). Attempts will be made to use estradiol as a starting material by protection of the 17-hydroxy group prior to diazotization.

At present, details of the method are being worked out for the ${ }^{18} \mathrm{~F}$ exchange and pyrolysis reactions. The procedure described below permits the production of $18 \mathrm{~F}-4$-fluoroestrone methyl ether at specific activities of about $600 \mu \mathrm{Ci} / \mathrm{ing}$ in about 120 minutes. However, only one run has been made at this writing. 
Page 4<smiles>CCC1C(c2ccc(O)cc2CCOC(C)(F)F)CCC2(C)C(=O)CCC12</smiles>

$\underset{\text { Nitration }}{\longrightarrow}$<smiles>C=Nc1c(O)ccc2c1CCC(C(C)CC)C2C</smiles>
$\mathrm{CH}_{3} \mathrm{O}$<smiles>Cc1ccc2c(c1N)CCC1C2CCC2(C)C(=O)CCC12</smiles>

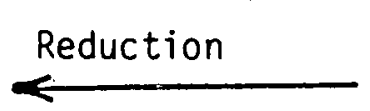<smiles>[X][N+]([O-])([O-])c1c(OC)ccc2c1CCC1C2CCC2(C)C(=O)CCC12</smiles>
Diazotization $\mathrm{CH}_{3} \mathrm{O}$ $\mathrm{NH}_{2}$

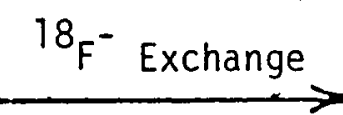

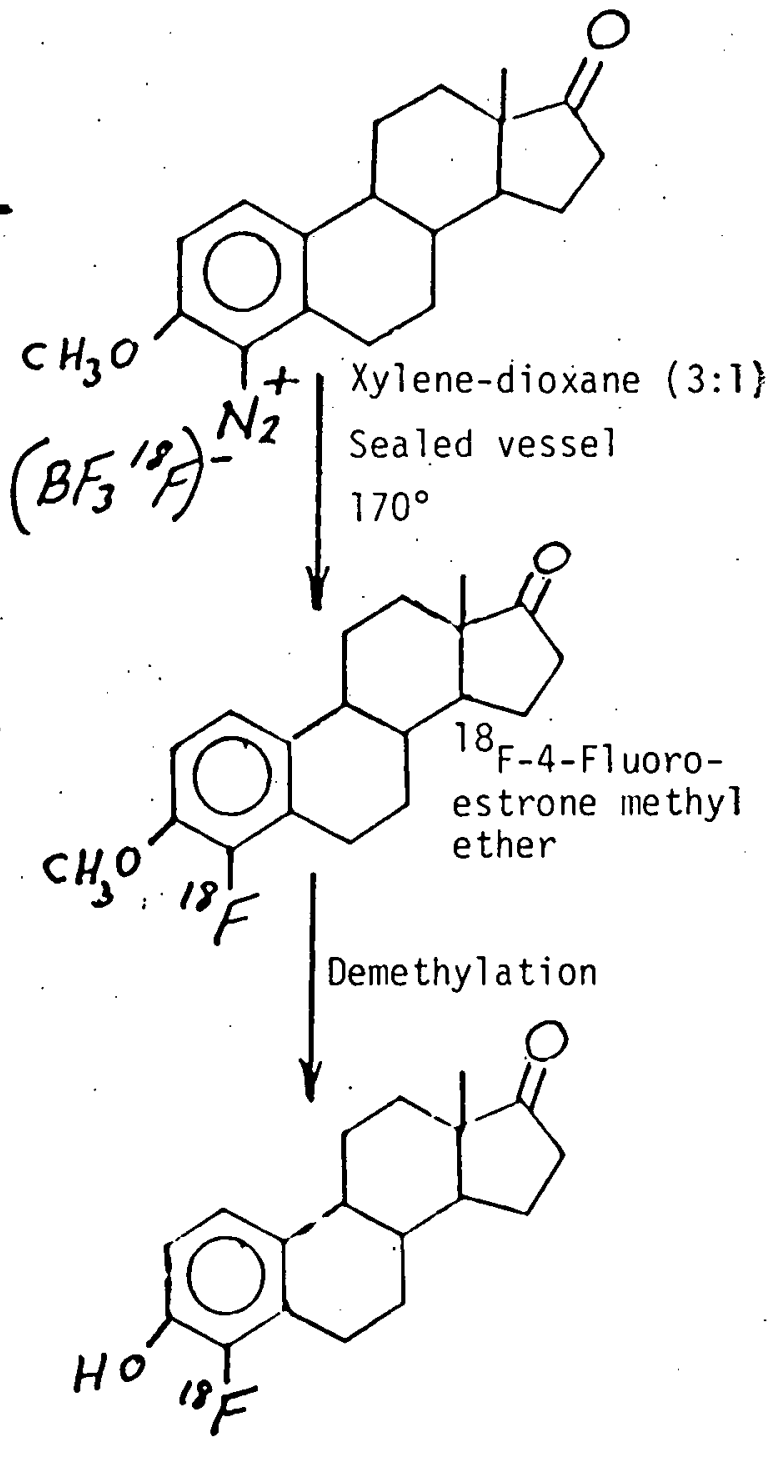

${ }^{18}$ F-4-Fluoroestradiol

${ }^{18} F-4-F i u o r o e s t r o n e$ 
$18 \mathrm{~F}^{-}$was produced by cyclotron through the ${ }^{16} \mathrm{O}\left({ }^{3} \mathrm{He}, \mathrm{p}\right){ }^{18} \mathrm{~F}$. reaction and about $200 \mathrm{mCi}$ of $18 \mathrm{Fe}$ in $30 \mathrm{ml}$ of water was obtained. The volume. of the water was reduced to about $1 \mathrm{ml}$ by heating under nitrogen. The $18 \mathrm{~F}^{-}$solution was transferred to the reaction vessel which contained $9 \mathrm{mg}$ of the diazonium tetrafluoroborate salt and $2 \mathrm{ml}$ of acetone. The reaction mixture was allowed to stand for 10 minutes to enhance the incorporation of $18 \mathrm{~F}$ into the tetrafluoroborate moiety. The solvents were evaporated to dryness at 500 under nitrogen. The dried residue was subjected to high vacuum for 5 minutes and subsequently pyrolyzed (1700) ( $5 \mathrm{ml}$ microflex tube equipped with a microflex valve) in $1 \mathrm{ml}$ of xylene-dioxane (3:1) for 30 minutes. The solvents were evaporated to dryness at $50^{\circ}$ under nitrogen. The dried pyrolysate was dissolved in $2 \mathrm{ml}$ of chloroform and washed with water to constant activity. The chloroform solution had a total activity of about $3 \mathrm{mC}$. The identity of the product was determined by mass spectrometry. Analysis indicated that 4-fluoroestrone methyl ether was the major component of the solution. Generally, yields of about $50 \%$ have been obtained for pyrolyses in the solvent mixture xylene-dioxane $(3: 1)$. By this method, the production of 18F-4-fluoroestrone methyl ether at specific activities of about $600 \mu \mathrm{Ci} / \mathrm{mg}$. in about 120 minutes is projected.

In subsequent runs, pure product will be obtained by chromatography on acid-washed alumina (2). The assumption that labeling with $18 \mathrm{~F}$ was achieved will be confirmed by radioscans of thin-layer plates (alumina). About 30 minutes was allowed for the pyrolysis of the fluoroborate salt in xylene-dioxane $(3: 1)$, in contrast to Utne's dry pyrolysis method ( 3 hours).

Details of the reduction and demethylation steps have to be worked out. Reduction of 4-fluoroestrone methyl ether with sodium borohydride gives 4-fluoroestradiol methyl ether in nearly quantitative yield. Utne's procedure for the demethylation of 4-fluoroestradiol methyl ether by pyridine hydrochloride requires a long reaction period ( 4 hours at 1800). and produces 4-fluoroestradiol in $40 \%$ yield. However, the time for this reaction may be considerably reduced at higher temperatures. Estrone methyl ether can be demethylated to estrone in less than one hour at temperatures above $240^{\circ}$. A number of novel reagents are available for the cleavage of ethers, and the problem can be completely circumvented by using protecting groups which are more easily removed. The benzoate, valerate, and dipropionate esters of estradiol are current therapeutic agents $(5)$. It would be interesting to synthesize similar esters of 4-fluoroestradiol for diagnostic purposes and for subsequent hydrolysis to 4-fluoroestradiol, which should occur easily and in high yield.

\section{REFERENCES :}

1. Nisselbaum, J.S., et al. Estrogen receptors in human breast tissue. 65th Ann. Mtg. American Association for Cancer Research, March 27-30, 1974, Houston, Texas. (Abstract) 
2. Utne, T., Jolson, R.B. and Babson, R.D. The synthesis of 2- and 4fluoroestradiol. J. Org. Chem. 33:246j-73, 1968.

3. Firman, G., Nahinias, C.., and Garnett, S. The preparation of ${ }^{18} \mathrm{~F}-5-$ fluoro-dopa with reactor-produced fluorine-18. Int. J. Appl. Radiat. Isotopes 24:182, 1973.

4. Kook, C.S., Reed, M.F. and Digenis, G.A. Preparation of ${ }^{18}$ F-haloperidol. J. Med. Chem. 18:533, 1975.

5. AMA Drug Evaluations, Third Edition. Publishing Sciences Group, Inc., Littleton, Massachusetts, 1977, p. 560. 


\subsection{ENZYMATIC SYNTHESIS OF ${ }^{13}$-COMPOUNDS OF BIOLOGICAL SIGNIFICANCE}

\section{OBJECTIVE:}

To synthesize ${ }^{13} \mathrm{~N}$-labeled compounds that will be used in metabolic studies and as tumor and/or organ scanning agents:

\section{SCOPE OF INVESTIGATION:}

The enzymatic synthesis of ${ }^{13} \mathrm{~N}$ amino acids yields a product with the following attributes:

1: The amino acid is synthesized as the biologically active L-isomer.

2. The amino acid is labeled with ${ }^{13} \mathrm{~N}$, an isotope of a natural constituent of the compound.

3. ${ }^{13} \mathrm{~N}$ is a positron emitter which permits use of singles or coincidence detection techniques.

Amino acids are involved in numerous biological processes. Our particular interests in $13 \mathrm{~N}$-amino acids are: (1) as tools to study tumor metabolism; (2) as organ imaging agents and (3) as potential agents for studying brain metabolism.

\section{RESULTS:}

Ammonia, L-glutamic acid, L-glutamine and L-valine labeled with ${ }^{13} \mathrm{~N}$ are routinely produced for a number of collaborative studies that are discussed in other sections of this report. $13 \mathrm{~N}$-ammonia is produced for the hepatic encephalopathy studies in collaboration with the Neurology Department of Cornell University Medical College. The labeled amino acids are tested as tumor imaging agents in spontaneous canine tuniors in cases supplied by the Animal Medical Center. The use of $13 \mathrm{~N}$-amino acids as indicators of response to drug therapy has been studied in a few canine tumors. The efficacy of labeled amino acids as organ imaging agents in rats and in normal dogs and monkeys is under continuous investigation.

The ${ }^{13} \mathrm{~N}$-ammonia generating system has been modified so that the proton-irradiated water is transported under pressure directly to the hot cells in the radiochemistry laboratory where the $13 \mathrm{~N}-n$ itrate is reduced to $13 \mathrm{~N}$-ammonia. This modification permits us to set up our chemical procedures while the cyclotron beam is on. Thus we have been able to carry out more experiments and there has been a significant decrease in radioactive exposure to the chemists. 
Progress Report.

page 8

Last year we reported that ${ }^{13} \mathrm{~N}$-glutamic acid was made by inmobilizing glutamic acid dehydrogenase on derivatized silica beads. Enzyme immobilization is preferred over the "batch method". because the product is free of potentially antigenic enzyme protein. Unfortunately the derivatized silica beads are no longer available commercially. We thus have changed our solid support of the enzyme to activated Sepharose. With this system we have been able to synthesize as much as $110 \mathrm{mCi}$ of $13 \mathrm{~N}$-glutamic acid and $10 \mathrm{mCi}$ of $13 \mathrm{~N}$-valine.

$13 \mathrm{~N}$ L-aspartic acid, L-tyrosine and L-phenylalanine have recently been synthesized by transaminating oxaloacetic acid, hydroxyphenylpyruvic acid and phenylpyruvic acid respectively, with $13 \mathrm{~N}$ glutamic acid in a reaction catalyzed by glutamic-oxalacetate transaminase. The products were identified by separation on a Partisil S.A.X. column using high pressure liquid chromatography. Approximately $80 \%$ of glutamic acid was converted to aspartic acid, $40 \%$ to tyrosine and slightiy less to phenylanine under our incubation conditions. We have not been able to rapidly separate $13 \mathrm{~N}$-aspartic acid from $13 \mathrm{~N}$-glutamic acid by several elution procedures from Dowex- 1 or Alumina columns. $13 \mathrm{~N}$-tyrosine and $13 \mathrm{~N}-$ phenylalanine have been separated from the labeled glutamate by differentially eluting the aromatic amino acids off a Dowex-1 column.

Glutamine doubly labeled with $13_{N}$ in the amine and amide positions has been synthesized by incubating $\alpha$-ketoglutarate $13 \mathrm{~N}$-ammonia and cofactors in the presence of glutamic acid dehydrogenase and glutamine synthetase. The products were identified by high pressure. liquid chromatography. We hope to utilize the labeled amino position of glutamine as a donor in specific glutamine-amino transferase reactions.

The water target in use at this laboratory since 1968 has been modified by the installation of a Fluorocarbon model SP-3000 teflon pump, and a two-way and a three-way air operated teflon valve. Use in conjunction with the Process Equipment Remote Control System, allows filling, pump control, and draining of the target, proton irradiations of water at beam currents up to $50 \mu \mathrm{A}$ and up to $600 \mathrm{mCi} 13 \mathrm{~N}$ produced EOB.

\section{CONCLUSIONS:}

The synthesis of ${ }^{13} \mathrm{~N}$-labeled L-tyrosine, L-phenylalanine, L-aspartic acid and $13 \mathrm{~N}$-amido- $13 \mathrm{~N}$-amino-L-glutamine has been demonstrated for the first time. $13_{N}-g$ Tutamic acid has been prepared with an enzyme immobilized on an activated Sepharose column. Evaluation of $13 \mathrm{~N}$-ammonia, L-glutamic acid, L-glutamine and L-valine as tumor and organ scanning agents continues.

Attempts to purify asparagine synthetase from extracts of a mutant strain of Escherichia coli have not been successful. We have found the enzyme to be extremely labile to the usual purification procedures such 
as Sephadex gel chromatography, calcium phosphate gel elution and ammonium: sulfate salt precipitation. We thus have not been able to separate asparagine synthetase activity from other enzymes such as asparaginase which interfere with synthesis of $13 \mathrm{~N}$-asparagine.

To date, nine amino acids labeled with ${ }^{13} \mathrm{~N}$ have been synthesized enzymatically and are at various stages of development and evaluation in in vivo studies. $13 \mathrm{~N}$-Ammonia, L-glutamic acid and L-glutamine are being evaluated as tumor scanning agents in spontaneous canine tumors. $13 \mathrm{~N}-\mathrm{L}-$ valine and $L$-glutamic acid are being tested in rats and monkeys as pancreatic scanning agents. $13 \mathrm{~N}$-L-tyrosine, L-phenylalanine and Laspartic acid are in the developmental stages of optimizing yields. $13 \mathrm{~N}-$ L-alanine leucine and asparagine have been synthesized.

\subsection{PREPARATION OF ${ }^{11} \mathrm{C}$ LABELED PRECURSORS}

\section{OBJECTIVE:}

The object of this work is to develop apparatus for the routine supply of Curie amounts of HIICN, H $11 \mathrm{CHO}$, and other $11 \mathrm{C}$ materials for use in labeling organic compounds of clinical interest with carbon-11.

\section{SCOPE OF INVESTIGATION:}

Carbon-11 has been produced at this laboratory and used for the preparation of $11 \mathrm{C}$-dilantin and $11 \mathrm{C}$-valine (1). H $1 \mathrm{C}_{\mathrm{CHO}}$ has been used to label compounds such as chloropromazine (2). Formaldehyde and methyl iodide labeled with carbon-11 have been produced in useful amounts as well as $11 \mathrm{CO}, 11 \mathrm{CO}_{2}, 11 \mathrm{CH}_{4}, 11 \mathrm{CH}_{3} \mathrm{OH}(3,4,5,6)$. All of these processes begin with $\mathrm{IiCO}_{2}$, produced either by the proton bombardment of nitrogen $(90-99 \%)$ oxygen $(10-1 \%)$ mixtures, $(3 ; 5,6)$ or the deuteron bombardment of boric oxide. (4).

The method used here to produce $\mathrm{H}^{11} \mathrm{CN}$ was to irradiate $95 \%$ nitrogen-5\% hydrogen mixtures, producing $11 \mathrm{CH}_{4}$ which after purification was mixed with ammonia traces and converted to $H^{\prime l} \mathrm{CN}$ by passage over $\mathrm{Pt}$ at $10000 \mathrm{C}$. Experience in this laboratory has shown that efficient removal of $11 \mathrm{C}$ from the target requires an intense ( $>35 \mu \mathrm{Amp}$ ) beall focused to pass through a $1 \mathrm{~cm}$ collimator. These conditions are difficult to achieve and require extreme care in target set-up and cyclotron tuning.

Since ${ }^{11} \mathrm{CH}_{4}$ may be produced from ${ }^{11} \mathrm{CO}_{2}$ without added carrier, by catalytic reduction over a supported nickel catalyst, in a hydrogen. atmosphere (3) the irradiation of nitrogen oxygen mixtures would appear 
Progress Report

Page 10

to overcome this problem. Also, ${ }^{11} \mathrm{CO}_{2}$ can be reacted with LiAlH4 and when the resulting salt is hydrolyzed with water, $17 \mathrm{CH} 3 \mathrm{OH}$ is obtained $(5,6)$. ${ }^{11} \mathrm{CH}_{3} \mathrm{OH}$ is oxidized by $\mathrm{H}^{\top} \mathrm{CHO}_{\mathrm{H}}$ by passage over silver catalyst at $4500 \mathrm{C}$. Yields of $50-60 \%$ have been reported $(6) . \quad 11 \mathrm{CH}_{3} \mathrm{I}$ is prepared in $80 \%$ yield by passing $1 \mathrm{CH}_{3} \mathrm{OH}$ into hydroiodic acid and refluxing.

\section{RESULTS AND CONCLUSIONS:}

11 Due to the difficult operating conditions the method of producing $\mathrm{H}^{11} \mathrm{CH}$ by the irradiation of nitrogen containing $5 \%$ hydrogen will be abandoned when this work is complete. However numerous runs have been made this year, producing 0.5 to $1.5 \mathrm{Ci}$ of $\mathrm{H}^{11} \mathrm{CN}$ for subsequent use.

A single run has been performed in which $9.5 \% \mathrm{~N}_{2}-5 \% \mathrm{O}_{2}$ was irradiated with protons, the $11 \mathrm{CO}_{2}$ being converted to $8 \mathrm{mCi}$ of $\mathrm{H} / 7 \mathrm{CHO}$. This was a pilot run made to gain familiarity with problems of technique and equipment prior to design of a single system for the production of $\mathrm{H}^{11} \mathrm{CN}$, ${ }^{11} \mathrm{CH}_{3} \mathrm{OH},{ }^{11} \mathrm{CH}_{3} \mathrm{I}, \mathrm{H}^{11} \mathrm{CHO}$, or ${ }^{11} \mathrm{CO}_{2}$, from a single target. Use of this target eliminates the need for small collimators and the consequent precise cyclotron beam tuning.

The new system, currently under construction, will trap the ${ }^{11} \mathrm{CO}_{2}$ produced on chromatographic quality molecular sieve $5 \mathrm{~A}$ at $-78^{\circ} \mathrm{C}$.

After sufficient ${ }^{11} \mathrm{CO}_{2}$ is trapped, the molecular sieve will be heated and the $11 \mathrm{CO}_{2}$ either mixed with hydrogen for $\mathrm{H} 11 \mathrm{CN}$ production or reduced with $\mathrm{LiAlH}_{4}$ for ${ }^{11} \mathrm{CH}_{3} \mathrm{OH}$, $11 \mathrm{CH}_{3} \mathrm{I}$ or $\mathrm{H}^{17} \mathrm{CHO}$. The HIICN synthesis. will pass the $11 \mathrm{CO}_{2}$-hydrogen mix over Raney nickel pellets at $350^{\circ} \mathrm{C}$, through liquid ammonia at $-78^{\circ} \mathrm{C}$, and finally the mix will be converted to $\mathrm{H}^{1} \mathrm{CN}$ by platinum at $10000 \mathrm{C}$. The $\mathrm{LiATH}_{4}$ will be in a tetrahydrofuran

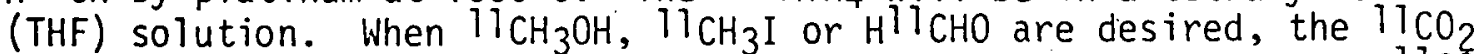
will be bubbled through the $\mathrm{LiAlH}_{4}$ in the THF at $\mathrm{OO}^{\circ} \mathrm{C}$. After the $11 \mathrm{CO} 2$ has reacted, the THF will be evaporated. A small amount of water is added to convert the lithium salt to $11 \mathrm{CH} 30 \mathrm{H}$. The $11 \mathrm{CH}_{3} \mathrm{OH}$ can be used directly, or converted to either $11 \mathrm{CH}_{3} \mathrm{I}$ or $\mathrm{H}^{\mathrm{T}} \mathrm{CHO}$ by the methods of Marazano et al. (6). As mentioned previously, this system is under construction at this writing. Experimental results will. be given in a later report.

\section{REFERENCES :}

1. Progress Report to National Cancer Institute for Grant No. CA 18153-01, Cancer Studies with New Radioactive Scanning Compounds, 1976-1977.

2. Maziere, M., Sainte-Laudy, J.L., Crouze1, M., and Comar, D. Synthesis and distribution kinetics of $C-11$ chlorpromazine in animals. In:

Radiopharmaceuticals, Subramanian, G., Rhodes, B.A., Cooper, J.F. and Sodd, U.S. (Eds.), New York, Soc. Nucl. Med. pp. 139-195, 1975. 
3. Christman, D.R., Finn, R.D., Karlstrom, K.I., Wolf, A.P. The production of ultra-high activity $11 \mathrm{C}$-labeled hydrogen cyanide carbon dioxide, carbon monoxide, and methane, via the $14 \mathrm{~N}(p, r)$ 11C reaction (XV). International J. Appl. Radiation \& Isotopes $26: 435-442$, 1975 .

4. Straatman, M.G. and Welch, M.S. A method for labeling proteins with 11C. N. Nucl. Med. $16: 425,7975$.

5. March, P., Marazano, C., Maziere, M., Morgat, J.L., De La Llosa, P., Comar, D., Fromageot, P. llC-Tabeling of ovine leuthinizing hormone by reductive methylation. Radiochem. \& Radioanal. Ltrs. 21: $53-59 ; 1975$.

6. Marazano, C., Maziere, M., Berger, $G_{i}$, and Comar, D. Synthesis of methyl iodide-11C and formaldehyde 11 C. Int. J. Appl. Rad. \& Isotopes 28:49-52, 1977.

3.4 DL-VALINE-1- ${ }^{11} \mathrm{C}$

\section{OBJECTIVE:}

To synthesize $\mathrm{DL}-\mathrm{valine}-\mathrm{l}-{ }^{11} \mathrm{C}$ and evaluate it as a pancreatic scanning agent.

\section{SCOPE OF INVESTIGATION:}

Since pancreatic tissue synthesizes protein it is expected that carbon-11 labeled amino acids would be taken up in the pancreas.

Busch et al. (1) have measured the uptake of various carbon-14 labeled amino acids in the pancreas and other tissues and have found that valine has one of the highest pancreatic uptakes. Experiments with transplantable animal tumors have demonstrated that carbon-14 labeled amino acids are incorporated into tunior tissue at a greater rate than into normal tissue (2). The synthesis of valine-11C would provide an agent which has a demonstrated high degree of localization in the pancreas. This localization is almost twice that of $75 \mathrm{Se}-$ selenomethionine the agent currently in use. This should provide improved visualization of the pancreas, leading to detection of smaller lesions, with acceptance of greatly reduced radiation exposures. 
Carbon-11 has been made in our laboratory in amounts up to $1: 5$ Curies by proton irradiation of nitrogen either as methane-11C when. hydrogen is added to the target gas, or as carbon dioxide-11C when. oxygen is present in the target gas. The methane-1.1C was converted to hydrogen cyanide-11C by reaction with ammonia on a platinum catalyst at $1000^{\circ} \mathrm{C}$, according to the method of Christman et al. (3). We have used the HIICN so produced to synthesize DL-valine-l-11C as shown below by a modification of the hydantoin procedure developed by Hayes et al. (4) for $11 \mathrm{C}$-amino cyclopentane carboxylic acid.
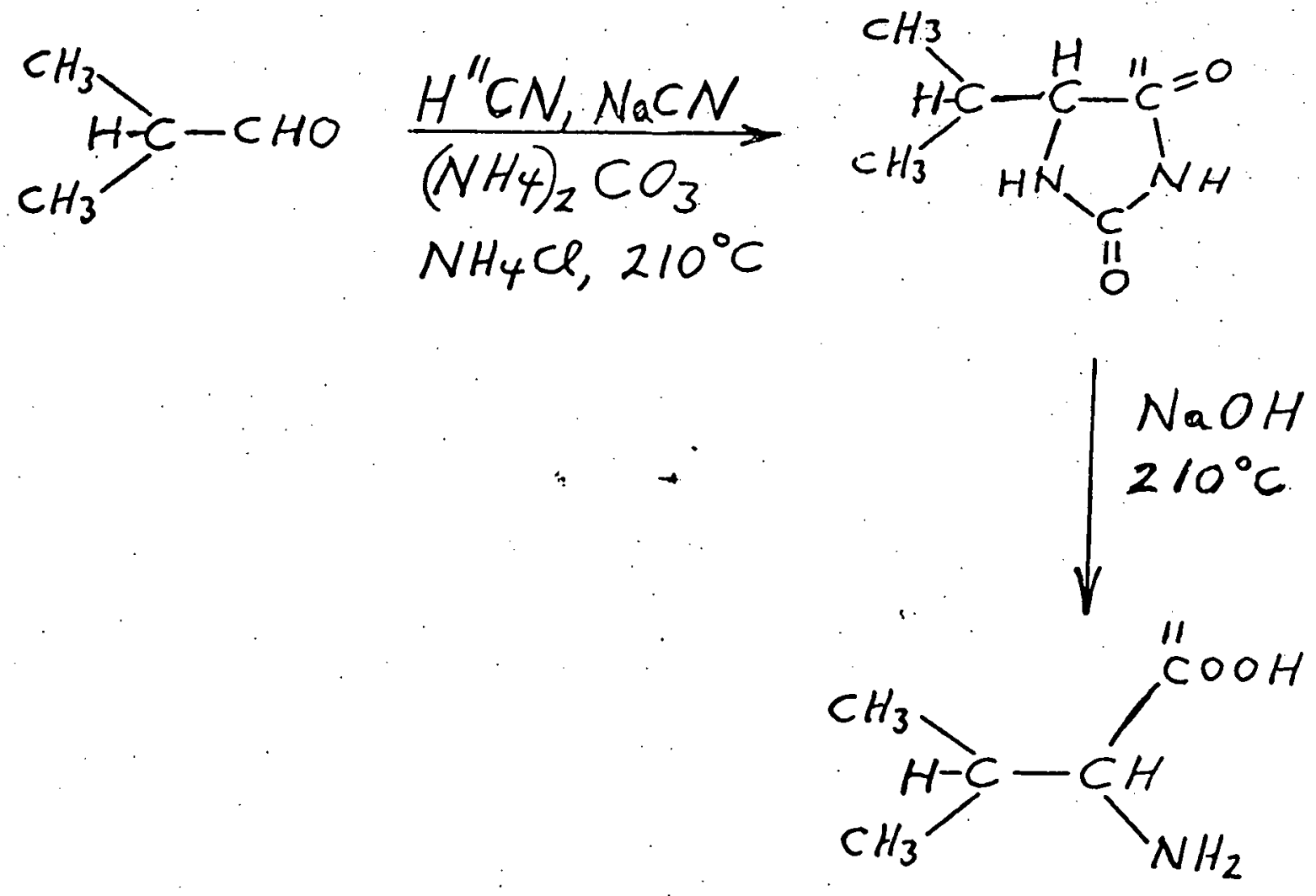

\section{RESULTS AND CONCLUSIONS:}

By this procedure, DL-valine labeled with carbon- 11 has been synthesized in eight separate batches in amounts up to $25 \mathrm{mCi}$ in about one hour. The product was purified by ion exchange chromatography on Bio-Rad AG- 1 and $A G-50$ resins. Assay of the product by thin layer chromatography showed the radiopurity to exceed $95 \%$. The purified product has been administered to normal rats and a positive uptake in the pancreas has been noted. The concentration in the pancreas is about. four times that of liver. 
$\mathrm{H}^{11} \mathrm{CN}$ is bubbled into a glass gas absorption column containing $3 \mathrm{ml}$ of $0.005 \mathrm{~N} \mathrm{llaOH}$. This solution (containing $\mathrm{Na} 11 \mathrm{CN}$ ) is drained through a stopcock at the base of the column into a stainless steel pressure. vessel having an internal volume of $20 \mathrm{ml}$. The reaction vessel is charged with a mixture of $85.7 \mathrm{mg}$ isobutyraldehyde, $216 \mathrm{mg}\left(\mathrm{NH}_{4}\right)_{2} \mathrm{CO}_{3}$, $\mathrm{CO}_{3}, 20.1 \mathrm{mg} \mathrm{NH} 4 \mathrm{Cl}$ and $18.6 \mathrm{mg} \mathrm{NaCN}$, prior to introduction of the. HTICN.. The closed vessel is rapidly heated to $2100 \mathrm{C}$ and maintained at that temperature for 10 minutes after which it is rapidly cooled. Three $\mathrm{ml}$ of $6 \mathrm{~N} \mathrm{NaOH}$ is then introduced and the vessel is again heated at $210^{\circ} \mathrm{C}$. for another period of 10 minutes. The cooled reaction mixture is filtered and then loaded directly onto a $1.5 \mathrm{~cm}$ (diameter) $\times 5 \mathrm{~cm}$ (length) prewashed $A G$ 1-X2, 100-200 mesh, anion exchange bed (Bio-Rad Laboratories, Rockville Center, N.Y.) in the hydroxide form. Anionic components, including $11 \mathrm{C}-\mathrm{valine}$ are retained by the column while cationic and nonionic components pass through. After washing repeatedly with distilled water ( $\sim 50 \mathrm{ml})$ the column is then eluted with $1 \mathrm{~N} \mathrm{HCl}$, the process being monitored by means of an ion chamber. This eluate ( $15 \mathrm{ml})$ is then loaded onto a prewashed $1.0 \mathrm{~cm}$ (diameter) $\times 15 \mathrm{~cm}$ (length) $A G 50 W-X 2,50-100$ mesh, cation exchange bed (Bio-Rad Laboratories) in the hydrogen form. Cationic material (11C-valine) is retained while anionic material passes through the column. After being washed repeatedly with distilled water ( $50 \mathrm{ml})$, the column is slowly eluted with $0.2 \mathrm{~N}$ $\mathrm{NaOH}$, the process again being monitored with an ion chamber to minimize the volume of eluate containing the product $(\sim 10 \mathrm{ml})$. The purified ${ }^{11} \mathrm{C}$-valine solution can then be adjusted to physiologic $\mathrm{pH}$ with $\mathrm{HCl}$ and sterilized by microfiltration for investigational use. Generally overall chemical yields of about $50 \%$ were obtained. The purity of the 11C-valine product was assessed by thin layer chromatography (tlc) using Eastman silica gel chromagram sheets (13179) developed in butanol: water: acetic acid (100: $10: 5 \mathrm{v} / \mathrm{v})$.

At present, specific activities of ${ }^{11} \mathrm{C}$-valine up to $1 \mathrm{mCi} / \mathrm{mg}$ have been obtained. About a three-fold increase in specific activity can be realized by reducing the amounts of materials charged to the reaction vessel. A pressure vessel having an internal volume of $3 \mathrm{ml}$ will be used. Also, the synthesis of $11 \mathrm{C}$-valine up to $45 \mathrm{mCi}$ is projected. The increase in radiochemical yield will further increase the specific activity by a factor of two. Specific activities of 3 to $6 \mathrm{mCi} / \mathrm{mg}$ will improve visualization of the pancreas and give more favorable pancreas to liver ratios.

Complete tissue distribution studies in rats will be continued and dynamic scans to prove the effectiveness of this agent for localizing the pancreas will be performed on Rhesus monkeys. Pyrogenicity tests of IIC-valine using standard U.S.P. techniques will be conducted.

Tissue distribution studies in rats have shown that $L-v a l i n e-{ }^{13} \mathrm{~N}$ has twice the relative concentration in pancreas at 30 minutes postinjection tha DL-valine-l-11C. The preparation of L-valine-1-IlC will 
be attempted and results of tissue distribution studies will be compared to those obtained with the racemate. Separation of the racemate is projected in reactions catalyzed by the specific actions of D- and L-amino acid oxidases $(5,6)$. We have demonstrated the feasibility of this procedure with unlabeled $\mathrm{OL}$-valine. Resolution of $\mathrm{DL}-\mathrm{val}$ ine by this method leads to the formation of one-half equivalent of a-keto-isovaleric acid. Since $\alpha$-keto acids undergo transamination reactions in vivo to L-amino acids, tissue distribution studies with a-keto-isovaleric acid-1-.. 11C are of interest.

\section{REFERENCES :}

1. Busch, H. et al. Amino acid uptake in nuclear proteins. Cancer Research 19:1030, 1959.

2. Quastel, J.H. and Bickis, I.J. Metabolism of normal tissues and neoplasms in vitro. Nature 183:281-286, 1959.

3. Christman, D.R., Finn, R.D., Karlstrom, K.I.; and Wolf, A.P. The production of $11 \mathrm{C}-\mathrm{HCN}-\ldots$. Int. J. Appl. Rad. Isotopes 26: 435-442, 1975.

4. Hayes, R.L., Washburn, L.C., Wieland; B.W., Sun, T.T., TurtTe, R.R., and Butler, T.A. Carboxyl-labeled ${ }^{1} \mathrm{C}-1$-aminocyclopentanecarboxylic acid, a potential agent for cancer detection. J. Nucl. Med. 17:748-751, 1976.

5. Cooper, A.J.L., Stephani, R.A., and Meister, A. Enzymatic reactions of methionine sulfoximine. J. Biol. Chem. 251:6674-6682, 1976.

6. Worthington Enzyme Manual, ed. L.A. Decker, Worthington Biochem. Corp., Freehold, N.J. 07728, 1977, p. 51. 


\subsection{POTASSIUM-38 PRODUCTION}

\section{OBJECTIVE:}

38 To investigate various methods of production of ${ }^{38} K$ and to prepare $\mathrm{KCl}$ suitable for use as a myocardial or tumor scanning agent.

\section{SCOPE OF INVESTIGATION:}

Potassium is a very important element of biology since it is actively taken up by living cells. The short half-life of $38 \mathrm{~K}$ ( 7.7 minutes) is long enough to study the uptake of potassium in the myocardium since this is very rapid, reaching its maximum one minute after IV injection. In human use the short half-life is advantageous in reducing the radiation dose. The $100 \%$ positron emission of $38 \mathrm{~K}$ is useful for positron tomographic scanning, but the high energy $x$-ray of $2.17 \mathrm{MeV}$ is not needed.

The purpose of this investigation is to try various nuclear reactions, and target materials for its production, to measure yields and impurities, and to evaluate the feasibility of producing $38 \mathrm{~K}$ in a yield, and form suitable for human use. The nuclear reactions investigated have been:

$$
\begin{array}{ll}
\text { (1) }{ }^{40} \mathrm{Ca}(d, \alpha) & { }^{38} \mathrm{~K} \\
\text { (2) }{ }^{35} \mathrm{Cl}(\alpha, n) & { }^{38_{\mathrm{K}}} \\
\text { (3) }{ }^{37} \mathrm{Cl}\left({ }^{3} \mathrm{He}, 2 \mathrm{n}\right) & { }^{38_{\mathrm{K}}}
\end{array}
$$

\section{RESULTS AND CONCLUSIONS:}

We reported last year on reactions (1) and (3) above, and this year we have concentrated on reaction (2).

Several batches of ${ }^{38} \mathrm{~K}$ have been made by $14.7 \mathrm{MeV}$ alpha particle irradiation of solid sodium chloride. The highest thick target yield was found to be $1.1 \mathrm{mCi} / \mu \mathrm{A}$ at the end of a saturation bombardment, as shown in Table 2 . The targets consisted of $90 \mathrm{mg}$ sodium chloride evaporated onto a $30^{\circ}$ inclined surface of a solid cylindrical block of aluminum or mild steel 2 inches in diameter. The salt was in the shape of an ellipse about $0.7 \times 1.2$ inches in minor and major axes, and was exposed directly to the beam in vacuo at the end of the external beam tube of the cyclotron. The tube containing the target block was water cooled on the outside and sealed by a circular plate and a rubber $0-r i n g$. After the irradiation, air was admitted to the target chamber, the end plate removed and the target block withdrawn with tongs. The sodium 
Potassium-38 Yields by $\mathrm{NaCl}+$ a Particles of $14.7 \mathrm{MeV}$

Run No. Beam Current $\begin{gathered}\text { Irradiation } \\ (\mu \mathrm{A})\end{gathered}$
1
1


chloride, which turned a deep blue color during irradiation, was washed off with $10 \mathrm{ml}$ of water and sterile filtered into a vial.

The decay-rate of the whole sample was measured in a gammaionization chamber from 4 to 66 minutes after irradiation and the decay curve plotted on semi-log paper showed a straight line of half-life 7.7 minutes. No radioactive contaminants were observed by measuring the gamma-ray spectrum of an aliquot of the sample at decay times of 17. and 36 minutes. After 20 hours decay the whole sample contained a small unidentified contaminant with a 511 Kev $\gamma$-ray which was approximately $0.08 \mu \mathrm{Ci}$ when counted relative to a $22 \mathrm{Na}$ standard.

After run \#2 about an equal amount of radioactivity was measured in the target holder, thought to be $38 \mathrm{~K}$ which had sublimed onto the inside of the beam tube, but little could be recovered by washing. Two runs were tried with $1 / 4$ mil Havar foil over the sodium chloride to collect any sublimate but the yields were low. It is thought that higher yields could be obtained by improving cooling of the target block.

Otherwise the method is very convenient, and there is little extraneous induced activity.

One batch of ${ }^{38} K(3.3 \mathrm{mCi})$ was injected into a normal dog, anesthetized with pentabarbitol, and imaged with the TOKIM using a high energy lead collimator. A good image of the heart was obtained 2 minutes after injection, at which time the activity in the heart was a maximum. However when $3.0 \mathrm{mCi}$ was injected into a human volunteer the heart was not well visualized. There is no explanation for this at present.

Table 3 lists the Q-values $\left(E_{0}\right)$ and minimum energies ( $E_{\min }$ ) for reactions of alpha particles on sodium chloride. Emin is calculated as

$$
E_{Q} \cdot \frac{\text { Mass of compound nucleus }}{\text { Mass of product } 38 \mathrm{~K}}
$$

and is the minimum energy for a nuclear reaction to occur allowing for the conservation of momentum. It can be seen from this table that $38 \mathrm{~K}$ is the only radionuclide produced with a half-life of a few minutes. Chlorine-34m is not formed because the alpha particle energy $14.7 \mathrm{MeV}$ is too low. 40K, $37 \mathrm{Ar}$ and $26 \mathrm{Al}$ would be expected to be formed but $40 \mathrm{~K}$ and $26 \mathrm{Al}$ have very long half-lives and so would be produced in very small amounts, and $37 \mathrm{Ar}$ being a gas would be lost in the vacuum system. $22 \mathrm{Na}$ would not be formed unless there is any quantum mechanical tunneling through the energy barrier. 


\section{TABLE 3}

Energetics of He-4 Reactions on $\mathrm{NaCl}$

\begin{tabular}{|c|c|c|c|c|c|}
\hline $\begin{array}{l}\text { Target } \\
\text { Nuclide }\end{array}$ & $\begin{array}{l}\text { Nuclear } \\
\text { Reaction }\end{array}$ & Product & Half-Life & $\begin{array}{l}\text { Q value } \\
\text { ( MeV) }\end{array}$ & $\begin{array}{l}E_{\min } \\
(\mathrm{MeV})\end{array}$ \\
\hline \multirow[t]{4}{*}{$C 1-35$} & $\alpha, n$ & $k-38$ & $-7.7 \mathrm{~m}$ & 5.88 & 6.03 \\
\hline & $\alpha, d$ & $A r-37$ & $34 d$ & 8.77 & 9.24 \\
\hline & $\alpha, \alpha n$ & $C 7-34 m$ & $32 \mathrm{~m}$ & 12.68 & 14.50 \\
\hline & $\alpha, 2 n$ & $K-37$ & $1.2 \mathrm{~s}$ & 17.93 & - \\
\hline \multirow[t]{2}{*}{$C 1-37$} & $\alpha, n$ & $k-40$ & $10^{9} \mathrm{y}$ & 3.88 & 3.99 \\
\hline & $\alpha, 2 n$ & $K-39$ & stable & $i 1.68$ & - \\
\hline \multirow[t]{3}{*}{$\mathrm{Na}-23$} & $\alpha, n$ & A $1-26$ & $7 \times 10^{6} y$ & 2.96 & 3.07 \\
\hline & $\alpha, 2 n$ & A $1-25$ & $7.2 \mathrm{~s}$ & 14.31 & - \\
\hline & $\alpha, \alpha n$ & $\mathrm{Na}-22$ & $2.6 y$ & 12.42 & 15.24 \\
\hline
\end{tabular}




\subsection{SELENIUM-73}

\section{OBJECTIVE:}

The aim of this work is to provide carrier-free ${ }^{73}$ Se for animal and clinical studies as required.

\section{SCOPE OF INVESTIGATION:}

The remaining area of work was the reduction of processing time and development of a method to produce $\mathrm{H}_{2}{ }^{73} \mathrm{Se}$. Reliability of the target preparation method required proof.

\section{RESULTS AND CONCLUSIONS:}

Six preparations of ${ }^{73} \mathrm{Se}$ sodium selenite, the average batch being about $10 \mathrm{mC} i$ EOB. The previously developed procedures (1) have been adequate for the requirements at this laboratory. Processing time is about four to five hours. From end of bombardment to delivery of product. The electroplating of the target is reliable, both targets are only barely sufficient to stop the useable $3 \mathrm{He}^{++}$beam. The calculated required thickness to reduce the $23 \mathrm{MeV}$ incident $3 \mathrm{He}$ to $14 \mathrm{MeV}$ is $4.15 \mathrm{mg} / \mathrm{cm}^{2}$ for a beam incidence angle of 40 . The usual germanium target thickness obtained is $\sim 6 \mathrm{mg} / \mathrm{cm}^{2}$ after plating from $6.5 \% \mathrm{GeCl} 4$ anhydrous 1,2 propanediol under dry conditions for 3 to 4 hours at 15-20 V, 0.4 to $0.6 \mathrm{~A} \mathrm{\mu p} / \mathrm{cm}^{2}$ and 500 to $60^{\circ} \mathrm{C}$.

\section{REFERENCES:}

1. ERDA Progress Report E(11-1)-3521 for period October 1, 1975 to September 30,1976 , p. 22. 


\subsection{PROCESS EQUIPMENT REMOTE CONTROL SYSTEM (PERCS)}

\section{OBJECTIVE:}

The aims of this work were to reduce personnel radiation exposure by reducing the requires of direct manipulation of irradiated targets especially in nitrogen-13 and fluorine-18 production, and enable the control of heating/cooling, liquid flow and other devices from the control console.

\section{SCOPE OF INVESTIGATION:}

This work was limited in time and funding in that it had to be completed without interfering with on-going research with materials bought with expense funds. The investigation was confined to a search for the cheapest parts and construction and installation at odd times.

\section{RESULTS AND CONCLUSIONS:}

A schematic diagram of the system in shown in Figure 1. At the control console an instrument panel was fitted with 8 SPST switches and indicator lights, and a 24 volt DC power supply. A.9-conductor coaxial cable installed several years ago and no longer in use was used to connect the switches to the output panel in the target room. The output panel, installed on the beam terminal vacuum cart consists of 8 sets of one 24 VDC relay with 4 DPDT 115 VAC 5 Amp contacts, two 115 VAC 3-way solenoid valves, and a duplex 115 VAC outlet. Power is supplied to the coil of each relay at all times from the 24 VDC supply at the console. Closing a switch at the console causes the relay to energize by completion to ground.

Energizing a relay causes 115 VAC at the matching duplex outlet to be turned off or on (four are normally on, four, normally off) and instrument air at 2 swagelock quick-connects to change from pressure to vent. The fourth relay contact set switches 24 VDC supplied at "banana" connectors on the panel. This can be used to power additional relays, or to interlock the relays. The system has proven useful by allowing remote draining of liquid containing targets and the accomplishment of certain chemical procedures remotely (e.g. solutions evaporated, target, heating after irradiation). By use of the system $F-18$ and nitrogen-13 are now produced, delivered to the hot cells in the Hot Lab and the target refilled without entering the cyclotron vault. Because economy grade solenoid valves are used, and require clean instrument air, several have failed due to dirt, moisture and corrosion caused by low-quality house air. Filters and drying apparatus are now being installed. 


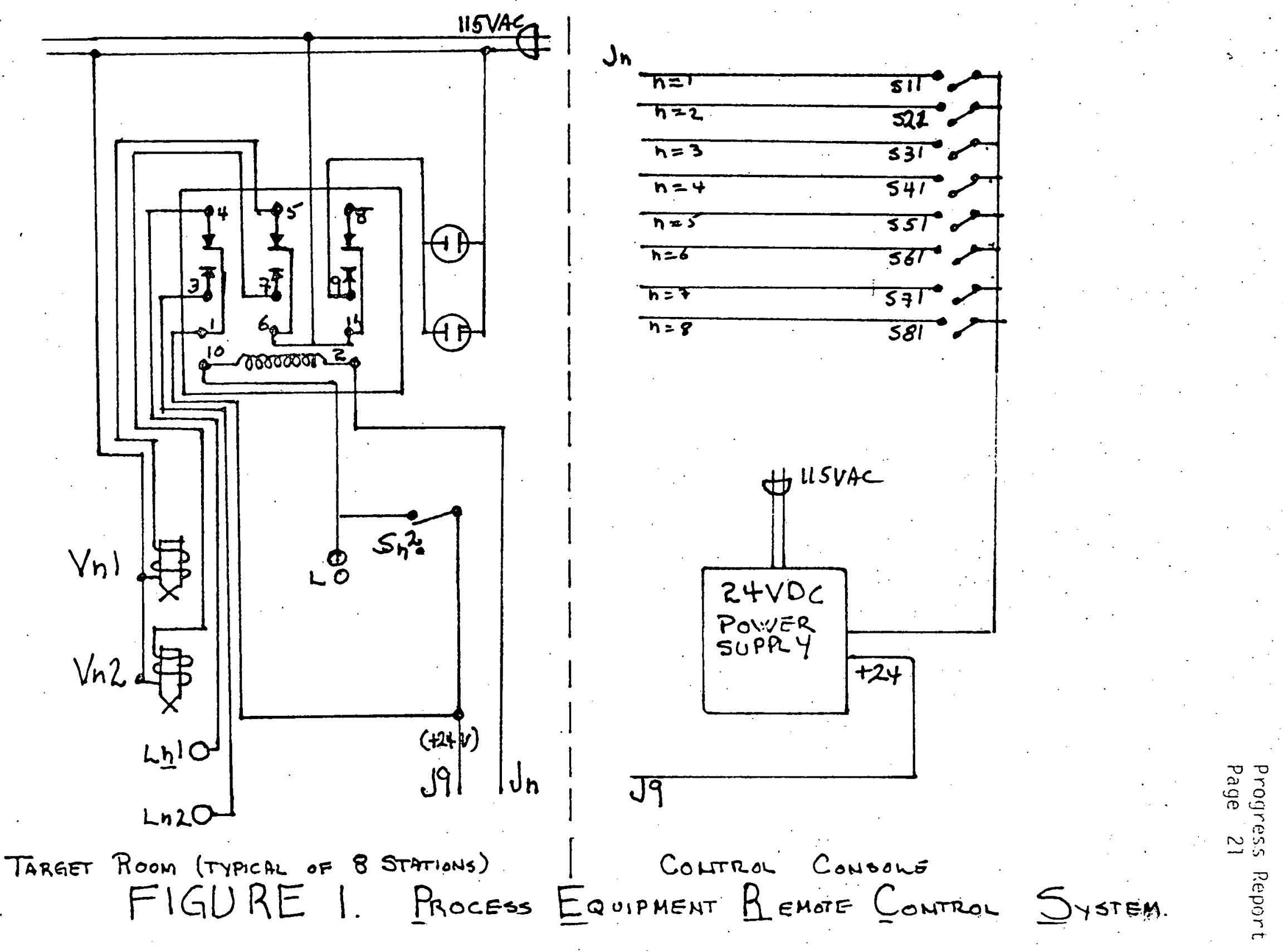


Progress Report

Page 22

\subsection{N-13 SPECIES FORMED BY PROTON IRRADIATION OF WATER}

\section{OBJECTIVE:}

The purpose of this investigation was to determine the chemical species formed by the irradiation of water with 14.5 MeV protons: this is a continuation of the work begun last year..

\section{SCOPE OF INVESTIGATION:}

Several cyclotron laboratories are using the proton irradiation of water to produce nitrogen-13 $(1,2,3,4)$. In our laboratory nitrogen-13 is used as ammonium ion for heart or brain studies (5), or enzymatic synthesis of $13 \mathrm{~N}$ labeled amino acids $(6,7)$, or incorporated into other compounds such as bis- chloroethyl nitrosyl urea.(BCNU) (8). Welch and Straatman have studied the fate of $13 \mathrm{~N}$ recoil atoms in water and various organic compounds (9). Gersberg, Krohn, and coworkers report the production of $99.6 \%$ pure $13 \mathrm{NO}_{3}^{-}$by irradiation water with $14.5 \mathrm{MeV}$ protons in a quartz beaker, with no measurable $13 \mathrm{NO}_{3}^{-}$or $13 \mathrm{NHt}(1)$. The first indication that we were producing $13 \mathrm{NH}_{3}$ by direct irradiation of water occurred while comparing. the distribution of $13 \mathrm{~N}-\mathrm{BCNU}$ to that of $13 \mathrm{NO}_{3}^{-}$which displayed unusual accumulation in the heart and brain.

Simple in-vitro tests such as bubbling air through the solution to detect gaesous products, addition of $\mathrm{NH}_{4} \mathrm{OH}$ and $\mathrm{NaOH}$ to detect $\mathrm{NH}_{4}^{+}$; precipitation with Nesslers Reagent to confirm the $\mathrm{NH}_{4}^{+}$; detection of $13 \mathrm{NO}_{2}$ by the addition of $\mathrm{NaNO}_{2}$, urea, and hydrochloric acid; precipitation of $\mathrm{NO}_{3}^{-}$and $\mathrm{NO}_{2}^{-}$with "Nitron," indicated about $5 \%$ gaseous activity, $5 \% \mathrm{NH}_{3}, 4 \% \mathrm{NO}_{2}^{-}$and $86 \% \mathrm{NO}_{3}^{-}$, but were difficult and inconvenient to perform on a single sample. Gas chromatography on poropak QS also showed the presence of gaseous activity and ${ }_{3} \mathrm{NH}_{3}$ but could not detect inorganic ions. Acquisition of a high pressure liquid chromatograph enabled a more systematic study of the $13 \mathrm{~N}$ species produced.

\section{RESULTS AND CONCLUSIONS:}

More than 70 irradiations of pure water were made at beam currents from 0.14 to $25 \mu \mathrm{A}$ and irradiation periods from 0.4 to 48 minutes. The results, although scattered did permit a qualitative description. It was shown that at doses less than $0.3 \mathrm{ev} / \mathrm{molecule}$ we produced primarily anmonia, some nitrate, and a lesser amount of nitrite. At lowest doses we produced pure $13 \mathrm{NH}_{3}$. Greater than 0.75 ev/molecule, the nitrate ion increased to $80 \%(8)$. 
Progress Report

Page 23

Table 4 lists results of the proton irradiation of solutions containing hydroxyl radical scavengers. These were done with increasing beam current for each successive run. Integrated beam currents of less than $5 \mu$ Ah produced very little nitrate ion and no detectable nitrite ion; the primary species being ammonium ion present at greater than $99 \%$. Doses sufficient to reduce the ammonium ion concentration. were marked by the appearance of nitrite and nitrate. Notice that doubling the ethanol concentration did not return the ammonium concentration to its previous level. The irradiation of formic acid solutions yields data similar to that obtained with ethanol. The dose at which the ammonia concentration begins to decrease is close to the corresponding dose for ethanol. A hundred-fold increase in the formic acid concentration causes a 50\% increase in the dose required to reduce the $\mathrm{NH}_{4}^{+}$concentration.

The results of the proton irradiation of ascorbic acid solutions, which can act both as a hydroxyl radical scavenger and to reduce peroxide, are shown in Table 5. The irradiation of $10^{-3} \mathrm{M}$ ascorbic acid solutions did not yield large percentages of ammonion ion even at low dose. The ascorbic acid was probably oxidized by residual oxygen in the water used. Increasing the ascorbic acid by a factor of 5 raised the dose required to cause nitrite-nitrate formation to 6 or $8 \mu A h$.

Comparing equal concentrations of ethanol, formic acid, and. ascorbic acid, ethanol provides the highest ammonium ion yield. At low dose only NHt is produced in all of these solutions. At a higher dose, depending on the nature and concentration of the solute nitrate and nitrite are produced. Table 6 shows data obtained when the target water is purged with oxygen and an oxygen over pressure applied during irradiation. Very little ammonium ion is produced and larger amounts of nitrite are observed. The major species is nitrate.

13 Suzuki and Iwata (10) have reported the production of $99.9 \%$ pure $13 \mathrm{NN}$ by the proton irradiation of $10^{-1}$ to $3 \times 10^{-3} \mathrm{M}$ ammonia soiutions while passing helium gas through the solution. Our data, in Table 7 , show an increasing $13 \mathrm{NH}_{4}^{+}$yield as the target ammonia concentration decreases. Notice also the decreasing yield of total $13 \mathrm{~N}$ is a constant $24.8 \mathrm{mCi} / \mu \mathrm{A} \cdot \mathrm{h}$ at end of a saturation bombardment (EOSB) with a standard deviation of $\pm 7.55 \mathrm{mCi} / \mu A$ A EOSB. The decreased value is probably due to gaseous products lost during irradiation.

Connecting a Partisil SCX column in series with the Partisil SAX column effected a separation of $\mathrm{NH}_{4}^{+}, \mathrm{NO}_{2}^{-}, \mathrm{NO}_{3}^{-}$, and gaseous products. Only in the run ( $\# 4)$ where the target was shown to leak gas was any gaseous activity present. Data in parentheses, calculated from Suzuki and Iwata, are presented for comparison. Table 8 shows the effect of dose. on the $13 \mathrm{NH}_{4}^{+}$concentration in very dilute ammonia solutions. 


\section{TABLE 4}

Proton Irradiation of Aqueous Solutions Containing Hydroxyl Radical Scavengers

\begin{tabular}{|c|c|c|c|c|}
\hline \multirow{2}{*}{$\begin{array}{c}\text { Dose } \\
(\mu A \cdot h)\end{array}$} & \multirow{2}{*}{$\begin{array}{l}\text { Target } \\
\text { Solution }\end{array}$} & \multicolumn{3}{|c|}{$13 \mathrm{~N}$ Species $\left(\begin{array}{l}n \\
\cdots\end{array}\right)$} \\
\hline & & $\mathrm{NH}_{4}^{+}$ & $\mathrm{NO}_{2}^{-}$ & $\mathrm{NO}_{3}^{-}$ \\
\hline 1 & $10^{-3} \mathrm{M} \mathrm{ETOH}$ & 100 & -- & -- \\
\hline 2 & $"$ & 99.8 & -- & 0.2 \\
\hline 3 & $"$ & 99.8 & -- & 0.2 \\
\hline 4 & $"$ & 99.9 & -- & 0.1 \\
\hline 5 & $"$ & 99.3 & $\cdots$ & 0.7 \\
\hline 6 & '" & 71.0 & 4.2 & 24.7 \\
\hline 7 & $"$ & 11.0 & 15.9 & 73.0 \\
\hline 3 & $2 \times 10^{-3} \mathrm{M}$ ETOH & 85.8 & 1.8 & 12.3 \\
\hline 7 & $"$ & 7.5 & 13.8 & 78.6 \\
\hline 2 & $10^{-3} \mathrm{M} \mathrm{HCOOH}$ & 97.5 & - & 2.5 \\
\hline 4 & $"$ & 99 & -- & 1 \\
\hline 6 & $"$ & 68 & 4 & 28 \\
\hline 8 & $"$ & $86^{\circ}$ & 3 & 11 \\
\hline 10 & ." & 7 & 12 & 81 \\
\hline 2 & $10^{-1} \mathrm{M} \mathrm{HCOOH}$ & 100 & - & -- \\
\hline 4 & " & 100 & -- & -- \\
\hline 8 & $"$ & 96 & -- & 4 \\
\hline 10 & $"$ & 17 & 4.5 & 78.5 \\
\hline
\end{tabular}


TABLE 5

Proton Irradiation of Ascorbic Acid Solutions

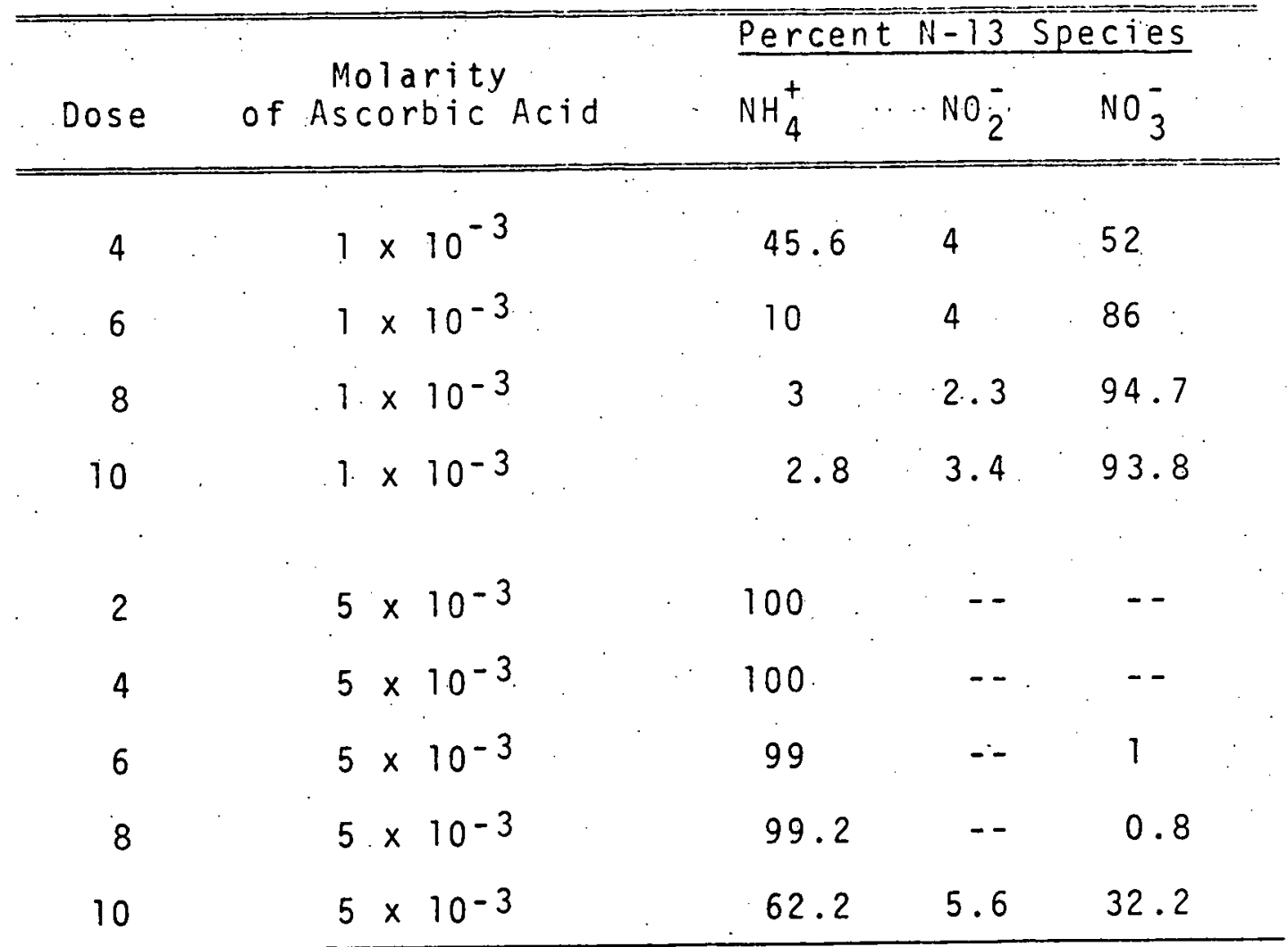


TABLE 6

Proton Irradiation of $\mathrm{H}_{2} \mathrm{O}$ with 10 psi $\mathrm{O}_{2}$ Overpressure

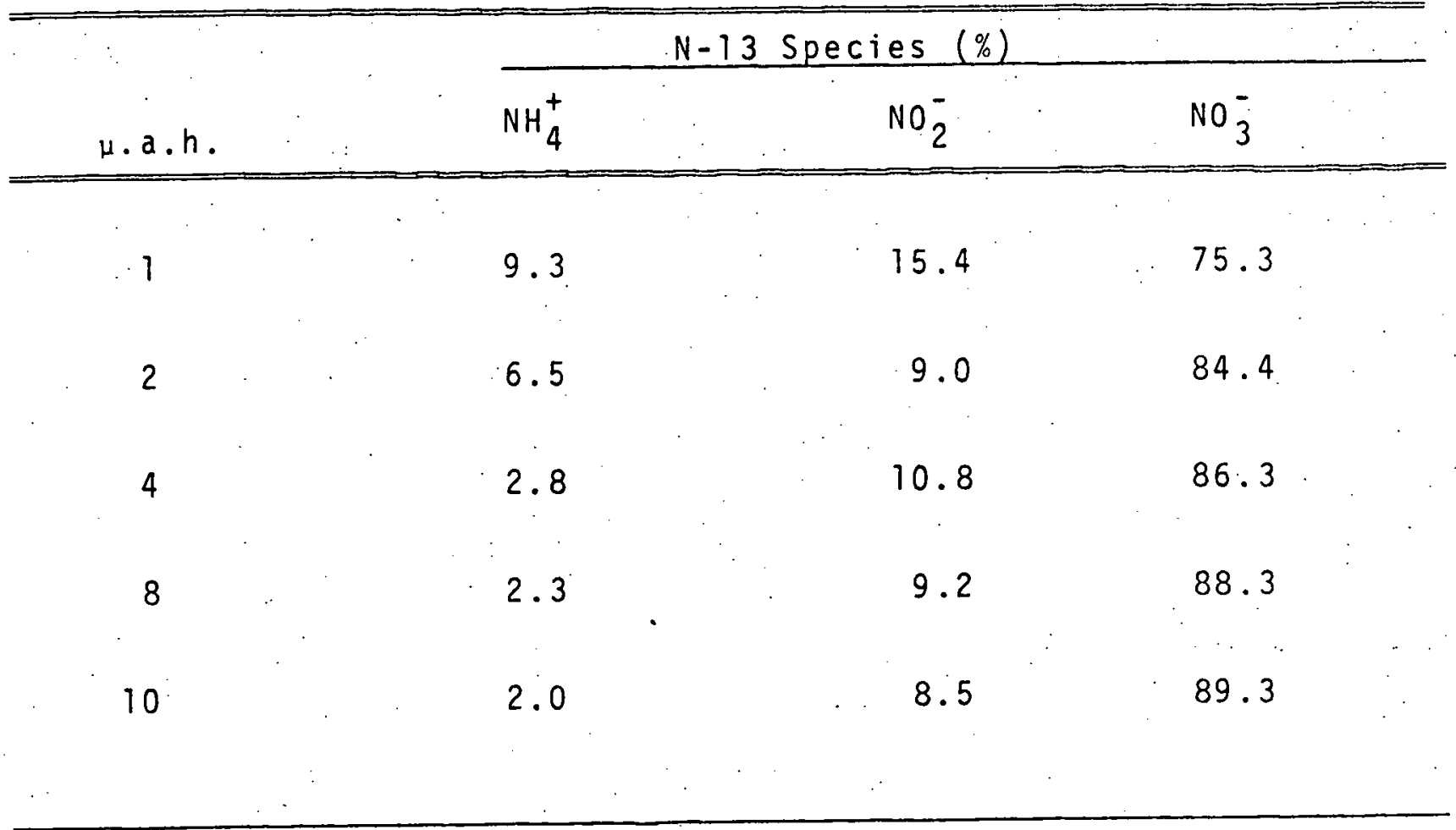




\section{TABLE 7}

Proton Irradiation of Aqueous Ammonia

$$
\text { (Dose }=3.3 \mu \mathrm{A} \cdot \mathrm{h} \text { ) }
$$

\begin{tabular}{|c|c|c|c|c|c|}
\hline \multirow[b]{2}{*}{$\begin{array}{c}\text { Target } \\
\text { Solution }\end{array}$} & \multirow[b]{2}{*}{$\begin{array}{c}\text { Total } \mathrm{N}-13 \\
(\mathrm{mCi} / \mu \mathrm{Ah}, \text { EOSB })\end{array}$} & \multicolumn{4}{|c|}{ Percent N-13 Species } \\
\hline & & $\mathrm{N}_{2}$ & $\mathrm{NH}_{4}^{+}$ & $\mathrm{NO}_{2}^{-}$ & $\mathrm{NO}_{3}^{-}$ \\
\hline $\mathrm{H}_{2} \mathrm{O}$ & 24.7 & - & 8 & 14 & .78 \\
\hline $10^{-1} \mathrm{MNH}_{4} \mathrm{OH}$ & $22.4(15)$ & $-(99)$ & $7.5(-)$ & $6.9(-1)$ & $85.6(-)$ \\
\hline $10^{-2} \mathrm{M} \mathrm{NH}_{4} \mathrm{OH}^{\star}$ & 12.4 & 4.6 & 2.6 & 9.8 & 82.9 \\
\hline $10^{-2} \mathrm{MNH}_{4} \mathrm{OH}$ & 19.5 & - & 8.7 & 11.9 & 79.4 \\
\hline $10^{-3} \mathrm{M} \mathrm{NH}_{4} \mathrm{OH}$ & 16.5 & - & 24.8 & 13.4 & 61.8 \\
\hline
\end{tabular}

* = Gas leaked from target during irradiation.

() = Data calculated from Suzuki and Iwata. 
Proton Irradiation of $5 \times 10^{-5} \mathrm{M} \mathrm{NH}_{4} \mathrm{OH}$ Solution

\begin{tabular}{|c|c|c|c|}
\hline \multirow[b]{2}{*}{$\mu . a . h}$. & \multicolumn{3}{|c|}{$\mathrm{N}-13$ species $(\%)$} \\
\hline & $\mathrm{NH}_{4}^{+}$ & $\mathrm{NO}_{2}^{-}$ & $\mathrm{NO}_{3}^{-}$ \\
\hline 2 & 100.0 & 0 & 0 \\
\hline 3 & 39.9 & 14.5 & 45.5 \\
\hline 4 & 16.4 & 12.0 & 71.5 \\
\hline 5 & 18.2 & 11.3 & 70.3 \\
\hline 6 & 16.1 & 13.5 & 70.3 \\
\hline
\end{tabular}


One characteristic of the data occurs when a series of runs is made increasing the dose by sequential increments to a given dose, and then decreasing the dose in a series of reverse increments. The data fails to return over the original path. This effect is a primary cause of scatter in these measurements. A second characteristic is the detection of $\mathrm{NO}_{3}^{-}$before $\mathrm{NO}_{2}^{-}$in sequences where the $\mathrm{NH}_{4}^{+}$decreases due to increased dose. The first irradiation of the day produces a higher yield of $\mathrm{NH}_{4}^{+}$than subsequent runs. We believe the induced activity, in the target foil is producing by radiolysis sufficient $\mathrm{H}_{2} \mathrm{O}_{2}$ and $\mathrm{O}_{2}$ to produce $\mathrm{NO}_{2}{ }^{-}$and $\mathrm{NO}_{3}{ }^{-}$. The $\mathrm{G}$ value for $\mathrm{H}_{2} \mathrm{O}_{2}$ production with 10 W LET

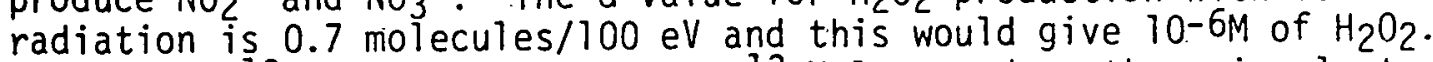
$100 \mathrm{mC} i$ of $13 \mathrm{~N}$ is equivalent to $10^{-13}$ Moles, and so there is plenty of $\mathrm{H}_{2} \mathrm{O}_{2}$ formed by radiolysis to react. with a 11 the $13 \mathrm{~N}$ hot atoms produced. Also we observe $13 \mathrm{NH}_{4}$ is reduced by the addition of $\mathrm{H}_{2} \mathrm{O}_{2}$, and $\mathrm{NO}_{2}{ }^{-}$is decreased by the addition of $\mathrm{NH}_{2} \mathrm{OH}$ or $\mathrm{TiCl}_{2}$

The following reaction scheme is proposed.

$$
\begin{aligned}
& { }^{16} \mathrm{O}+{ }_{\mathrm{H}} \rightarrow{ }^{13} \mathrm{~N}+{ }^{4} \mathrm{He} \\
& 13 \mathrm{~N}+\mathrm{H}_{2} \mathrm{O} \rightarrow{ }^{13} \mathrm{NH}+\mathrm{OH} \\
& 13 \mathrm{NH}+\mathrm{H}_{2} \mathrm{O} \rightarrow{ }^{13} \mathrm{NH}_{2}+\mathrm{OH} \cdot \\
& 13 \mathrm{NH}_{2}+\mathrm{H}_{2} \mathrm{O} \rightarrow{ }^{13} \mathrm{NH}_{3}+\mathrm{OH} \cdot \\
& 13 \mathrm{NH}_{3}+\mathrm{OH} \cdot{ }^{13} \mathrm{NH}_{2}+\mathrm{H}_{2} \mathrm{O} \\
& 13 \mathrm{NH}_{2}+\mathrm{O}_{2} \rightarrow{ }^{13} \mathrm{NH}_{2} \mathrm{O}_{2} \\
& 13 \mathrm{NH}_{2} \mathrm{O}_{2}+\mathrm{OH}^{13} \rightarrow \mathrm{H}^{3} \mathrm{NO}_{2}+\mathrm{H}_{2} \mathrm{O} \\
& \mathrm{H}^{13} \mathrm{NO}_{2}+\cdot \mathrm{HO}_{2}+\mathrm{H}^{13} \mathrm{NO}_{3}+\mathrm{OH} \cdot \\
& \mathrm{H}^{13} \mathrm{NO}_{2}+\mathrm{H}_{2} \mathrm{O}_{2} \rightarrow \mathrm{H}^{13} \mathrm{NO}_{3}+\mathrm{H}_{2} \mathrm{O}
\end{aligned}
$$


Progress Peport

Page 30

The ${ }^{13} \mathrm{~N}$ ion born at an energy of $5-10 \mathrm{MeV}$ slows to about $5 \mathrm{eV}$. It then sequentially abstracts hydrogen from water, producing $\mathrm{OH}$. The $\mathrm{NH}_{2}$ may decompose directly, or pass through a hydrazine like confiquration, to form $13 \mathrm{NN}$ and ammonia. Ammonia may be oxidized to nitrite by steps IV, $V$, and VI.

The radiolysis of water is known to produce as the end products $\mathrm{H}_{2}$ and $\mathrm{H}_{2} \mathrm{O}_{2}$. $\mathrm{O}_{2}$ is also formed by decomposition of $\mathrm{H}_{2} \mathrm{O}_{2}$. . Intermediate free radicals of $\mathrm{H} \cdot, \mathrm{OH} \cdot, \mathrm{HO}_{2}$, and the solvated electron are believed to be formed. The first two steps in the proposed mechanism seem reasonable in view of the observation by Suzuki and Iwata that $13 \mathrm{NN}$ can be collected by gas purge of a target containing carrier $\mathrm{NH}_{4}^{+}$ion. Nitrogen and $\mathrm{NH}_{3}$ are known products of the radiolysis of hydrazine. The formation of 13NN in irradiated ammonia solution suggests the existence of either $\mathrm{NH}_{2}$ or hydrazine. Suzuki and Iwata report the observation of hydrazine in proton irradiated aqueous ammonia solutions. The addition of ammonia to the target solution will increase reaction IV, increasing the $\mathrm{NH}_{2}$ concentration. The second half of the reaction scheme was proposed by Rigg, Scholes, and Weiss in 1952 to explain the action of $x$-rays on aqueous ammonia solutions. Nitrite can be oxidized to nitrate by a variety of mechanisms. Steps I through III are further suggested by the observed increase in $13 \mathrm{NH}_{3}$ production when hydroxyl radical scavengers are added to the target water.

In conclusion we have shown at least three nitrogen-13 species are produced when water is irradiated with protons. A reaction sequence has been suggested that is consistent with our observations which accounts for the production of these species and the effects of various solutes. The difficulty of obtaining consistent results with acceptable error, a long known characteristic of the hot atom chemistry of water serve as a warning to those attempting to prepare pure $13 \mathrm{NO}_{3}^{-}$or $13 \mathrm{NO}_{2}^{-}$by the proton irradiation of water. 
Progress Report

Page 31

\section{METABOLIC ISOTOPE STUDIES}

\section{$4.1 \quad 13$ N-AMMONIA* METABOLISM IN HEPATIC ENCEPHALOPATHY}

\section{OBJECTIVE:}

The objective is to use ${ }^{13} \mathrm{~N}$-labeled ammonia to study the uptake and metabolism of ammonia in the brains of norma rats and rats made chronically hyperammonemic by means of a portacaval shunt. This work will entail the development of rapid isolation techniques for the quantitation of various labeled brain metabolites. Understanding the rate of uptake and metabolism of ammonia in the brain in greater detail should lead to more effective methods for the treatment of patients with liver disease.

\section{SCOPE OF INVESTIGATION:}

Liver disease ranks as the sixth most common cause of death in the United States. A common treatment involves the construction of a portacaval shunt. However, this operation is not.ideal and the long term survival rate of such patients is low. These patients always develop neuropathological symptoms. Exactly why the brain is most sensitive to the effects of liver disease is not known. A number of substances that are known to be elevated in the plasma of patients with liver disease have been implicated as being toxic to the CNS and some are thought to act synergistically. Nevertheless, ammonia is widely regarded as the most neurotoxic agent in hepatic encephalopathy. Therefore, a detailed understanding of the metabolic fate of ammonia in the brain should provide a clue as to the causes of hepatic encephalopathy.

Studies involving the metabolic fate of ammonia in the brain in vivo have been 1 imited. $15 \mathrm{~N}$-Labeled ammonia has been used as a tracer, but the use of $15 \mathrm{~N}$ has several drawbacks. In order to detect low levels of incorporation of label into metabolites very high

* What we refer to as ammonia or $\mathrm{NH}_{3}$ is of course actually a mixture of $\mathrm{NH}_{4}^{+}$ions and $\mathrm{NH}_{3}$ gas in solution fpredominantly $\mathrm{NH}_{4}^{t}$ at physiological $\mathrm{pH}$ values). If any process upsets this equilibrium, such as depletion of number $\mathrm{NH}_{4}^{+}$ions through metabolism, the equilibrium is quickly reestablished (ammonium dissociation rate constant is $\sim 3 \times 10^{10} \mathrm{sec}^{-1}$, and the recombination constant is $\left.\sim 6 \times 10^{5} \mathrm{sec}^{-1}\right)$. 
concentrations of ${ }^{15} \mathrm{NH}_{3}$ have commonly been employed with a concomitant disruption of the steady state (1). Furthermore, quantitation requires the use of a mass spectrometer which is tedious and time consuming: We have begun to use $13 \mathrm{NH}_{3}$ to study the fate of ammonia in the brains of normal and chronically hyperammonemic rats. $13 \mathrm{~N}$-Labeled ammonia has advantages over $15 \mathrm{~N}$-labeled ammonia in that (a) it can be administered with a very high specific activity so that disruption of the metabolic steady state does not occur, and (b) it can be readily quantitated by means of standard radiation detectors. The ma in drawback with using $13 \mathrm{~N}$ as a tracer is its short half-life ( $t / 2=10$ minutes). Nevertheless, we have developed methods for the rapid isolation of labeled metabolites from the brain that involve high pressure liquid chromatography (HPLC) and chromatography on very small cation and anion exchange columns that largely circumvent this limitation.

At the present time we have administered ${ }^{13} \mathrm{NH}_{3}$ to six normal rats via the common carotid artery (with external carotid ligated) in order to determine the steady state distribution of $13 \mathrm{~N}$ among various brain metabolites. After ten minutes of infusion the animals were sacrificed by decapitation or by a "freeze-blowing" technique and the brain tissue analyzed. We have also analyzed the steady state incorporation of label into metabolites after administration of $13 \mathrm{NH}_{3}$ via the right lateral cerebral ventricle in five rats. The label was infused for 14 minutes; the rats were sacrificed by decapitation and the brains analyzed for various labeled metabolites.

\section{RESULTS AND CONCLUSIONS:}

\section{a) Separation of ${ }^{13} \mathrm{~N}$-Labeled Metabolites}

The first part of the project was to devise a method for the rapid quantitation of $13 \mathrm{~N}-1$ abeled brain metabolites. The following procedure was adopted. The brain tissue was homogenized by means of a motor driven pestle in three volumes of $1 \%$ picric acid. The homogenate was then centrifuged for 1 minute in a bench top Beckman microfuge. An aliquot $(20 \mu l)$ was then subjected to HPLC. Another aliquot was counted and the percent uptake of label was calculated. The HPLC system consisted of a minipump with pulse dampener (Laboratory Data Control, Model L 711-31), rheodyne injection valve, Whatman SAX column $(10 \mu 1,25 \mathrm{~cm}$ length) and $20 \mu 1$ injection loop. Pressure was maintained at $750 \mathrm{psi}$. The eluting buffer was $5 \mathrm{mM}$ potassium phosphate-HCl buffer, $\mathrm{pH} 3.5 ; 22^{\circ}$. $13 \mathrm{~N}$-Labeled metabolite fractions were collected in liquid scintillation vials. In order to minimize geometry errors each sample was made up to $20 \mathrm{ml}$ with distilled water. Samples were counted in a Packard auto gamma scintillation counter. The following $13 \mathrm{~N}-1$ abeled metabolites were used as standards: ammonia, L-glutamate, L-glutamine and L-aspartate. Non-labeled metabolites used as standards included arginine, $\gamma=$ aminobutyrate, urea, asparagine, alanine, glutathione, 2-pyrrolidone-5-carboxylate, $\mathrm{N}$-acetylaspartate and $\alpha$-keto-glutaramate. 
An aliquot of a cold brain picrate supernatant fluid was made approximately $10 \mathrm{mM}$ with each standard and subjected to HPLC. Table 9 lists the retention times of 13 nitrogen containing metabolites. It may be noted that picric acid is eluted from the column between 21 and 30 minutes. This was the main reason for choosing picric acid as the deproteinizing agent since its yellow color is easy to visualize when the run is over.

Six fractions were collected from the HPLC system at the time indicated in minutes: (1) $1.50-2.67$; (2) $2.67-5.00$; (3) 5.00-9.00; (4) $9.00-15.00$; (5) $15.00-20.00$; (6) $20-30.00$. Fractions 4,5 , and 6 , were not treated any further. Fractions 1,2, and 3 were subjected to further analysis on small Dowex columns. A flow diagram of the procedure is given in Figure $I A$.

b) Distribution of Label Among Various Brain Metabolites After Infusion of $13 \mathrm{NH}_{3}$ for 10 Minutes via the Internal Carotid Artery

Rats were anesthetized with $2.5 \%$ halothane and the right lateral and external carotid arteries were surgically exposed. The external carotid was ligated and a cannula was inserted into the right common carotid. The other end of the tubing was threaded through. a hole punched in the skin covering the back of the animal. The rats were placed in restraining cages and were allowed to recover for 2 hours before infusion of isotope. $3 \mathrm{~N}$-Labeled ammonia was bubbled into $3 \mathrm{ml}$ of physiological saline. Typically, at the beginning of each experiment the total activity was in the range $20-120 \mathrm{mCi}$. A fluorometric analys is of small aliquots taken at random revealed that the concentration of ammonia was $138( \pm 49) \mu \mathrm{M}$. Two $\mathrm{ml}$ of the labeled ammonia solution was injected over a period of 10 minutes. Table 10 summarizes the data obtained for the distribution of labeled metabolites in six rat brains. The data represent the averages of four brains removed by "freeze-blowing" (2) and two by decapitation. (At first we were concerned that ischemic changes after decapitation would alter the pattern of $13 \mathrm{~N}-1$ abeled metabolites. However, we have found that although it takes about $90 \mathrm{sec}$ to remove a rat brain by dissection and homogenize it, there is essentially no difference in the pattern of labeled metabolites to that obtained by a "freeze-blowing" brain removal technique. It should also be noted that in a separate experiment the ratio of label in right to left halves was 5:1 indicating that the label was not completely mixed in the Circle of Willis, and preferentially enters the right cerebral hemisphere. This was also demonstrated by injection of $2 . \%$ Evans blue dye in physiological saline into the right common carotid artery after the injection of isotope. The right half of the brain was much more heavily stained than the left. It was also found that the recovery of counts within the brain after the 10 minute infusion was $4.8: 1.8 \%$ (S.E.M., 6 determinations). In one experiment the counts in a whole brain homogenate were compared to the 
TABLE 9

Retention Times for Various Nitrogen-Containing Metabolites

on Whatman SAX

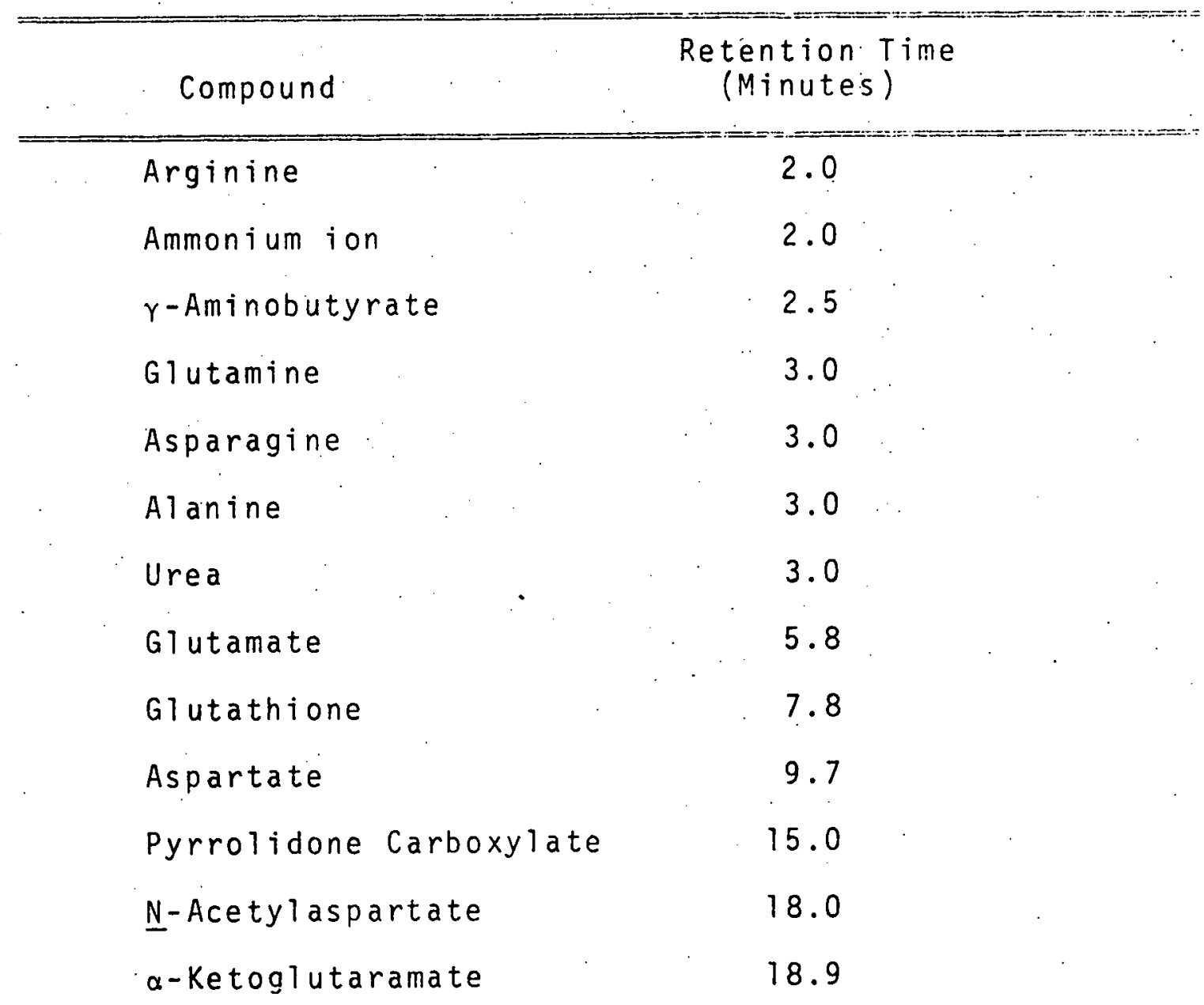




\section{Figure 1A: Rapid Separation of ${ }^{13} \mathrm{~N}$-Labeled Brain Metabol ism}

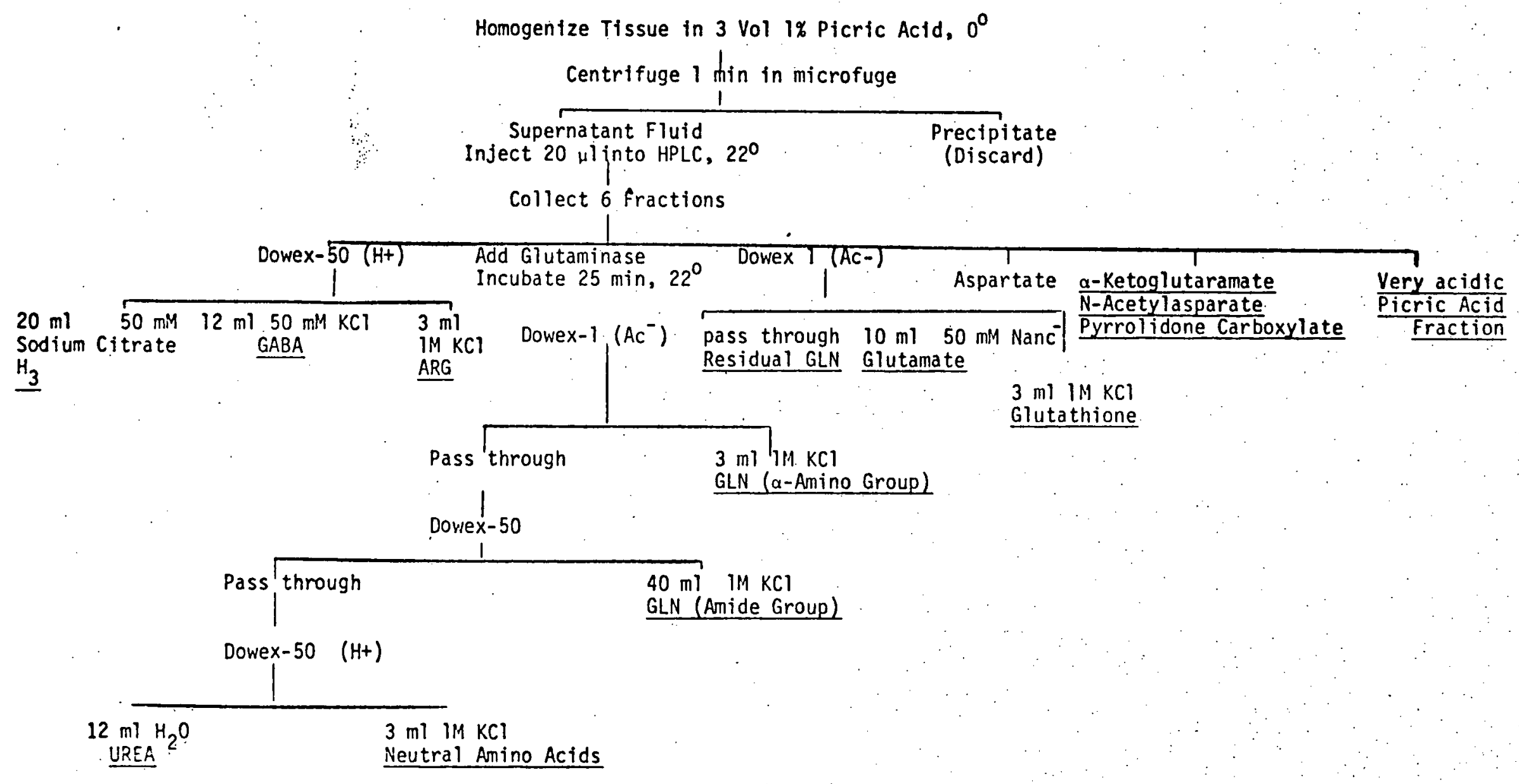


TABLE 10

Distribution of ${ }^{13} \mathrm{~N}$ among Various Brain Metabolites after Infusion of ${ }^{13} \mathrm{NH}_{4}^{+}$for 10 Minutes: Carotid Artery Route

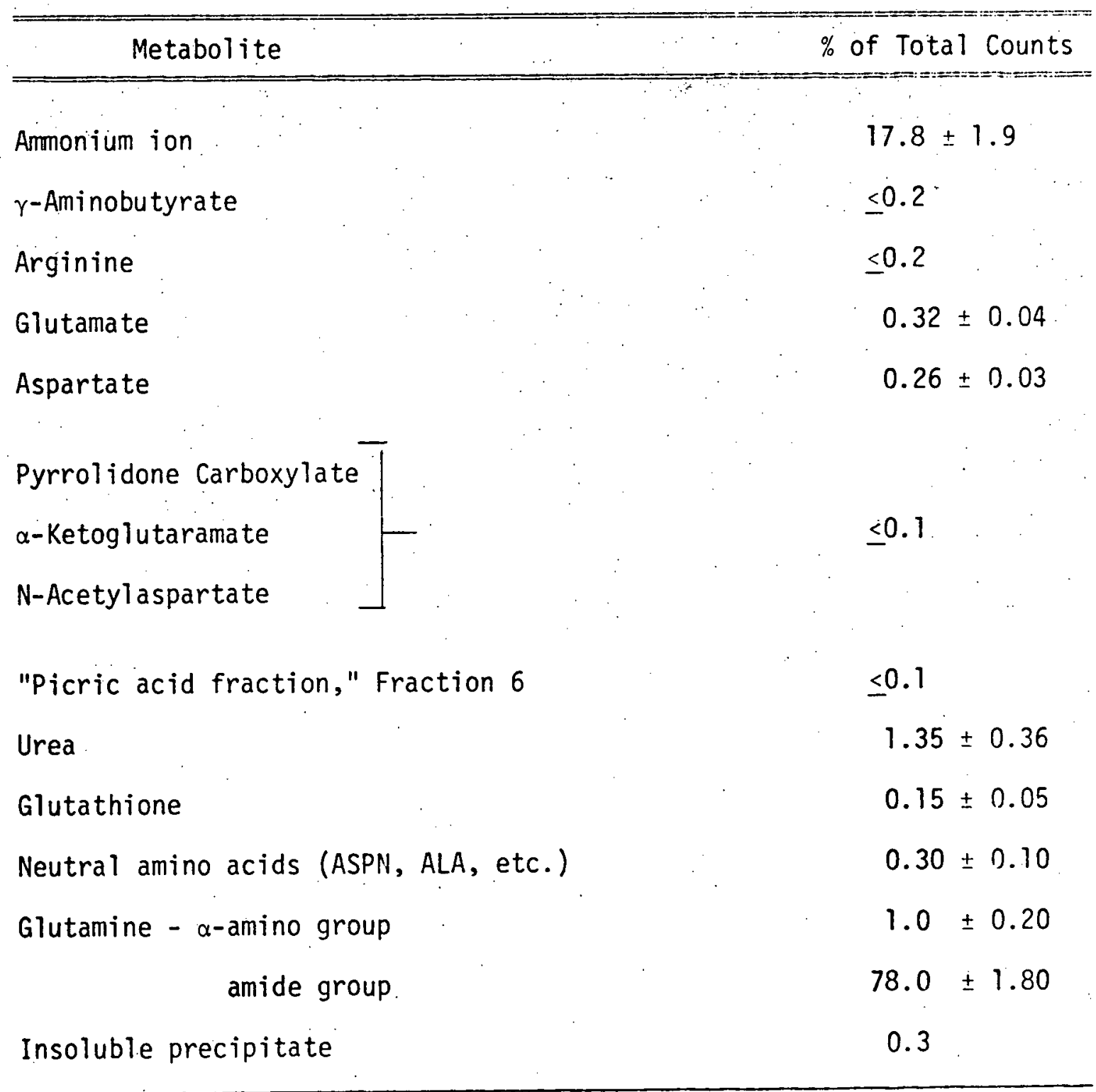


counts in the remainder of the rat carcass which was homogenized in 3 volumes of water. The amount of label in the brain was found to be $5 \%$ of the whole.

Our results are in general agreement of those of Berl et al. (1) who infused $15 \mathrm{~N}$-labeled ammonia into cats. However, in the experiments of Berl et al. about 42 and $46 \%$ of $15 \mathrm{~N}$-ammonia was present in an unmetabolized form in the cat brain after a carotid artery infusion for 20 and 25 minutes, respectively. In our experimerits in the rat only $18 \%$ of the ammonia remained unmetabolized after a ten minute infusion. We have also verified that there is more incorporation of label into the $\alpha$-amino group of glutamine than into the $\alpha$-amino group of glutamate. However, the absolute values in our experiment are much lower. Berl et al. found that after 20 minutes the relative incorporation of label into the a-amino group of glutamate, $\alpha$-amino group of glutamine and amide group of glutamine was 1:8.4:29.5. In our experiments, after ten minutes, the relative incorporation was found to be 1:3:244 (see Figure 2). These differences may be due to the different species involved or, more likely, to the very high concentrations of ammonia employed in the experiments of Berl et al. Our data emphasize the importance of the glutamine synthetase reaction as the major route for arterial-borne ammonia metabolism in the brain. It is well known that rat brain contains twice as much glutamate as glutamine. Therefore, we can calculate that the relative specific activities of the $\alpha$-amino group of glutamate to the amide group of glutamine is approximately 1:500. One explanation for these data is that put forward by Berl et al. i.e., ammonia entering the brain comes into contact with a relatively small rapidly turning over glutamate pool. However, one cannot exclude the possibility that a glutamate synthase type reaction (GLN $+\alpha-K G \rightarrow 2$ GLU) is responsible, at least in part for the labeling patterns observed. Although this enzyme has not as yet been observed in mammalian systems, glutamate synthase is now well established as a means of assimilation of low concentrations of ammonia in certain prokaryotes. A glutamate synthase reaction would account for the much higher label in the amide group of glutamine than that of the a-amino group of glutamate but would not account for the higher activity in the a-amino group of glutamine over that of glutamate. It is conceivable that a glutamate synthase reaction competes with the GDH reaction for the formation of glutamate, or alternatively, that both glutamine synthetase and glutamate synthase reactions occur within the small rapidly turning over pools. Whatever the detailed mechanism for ammonia assimilation in rat brain the first step appears to involve entry into a small pool with high glutamine synthetase activity. 


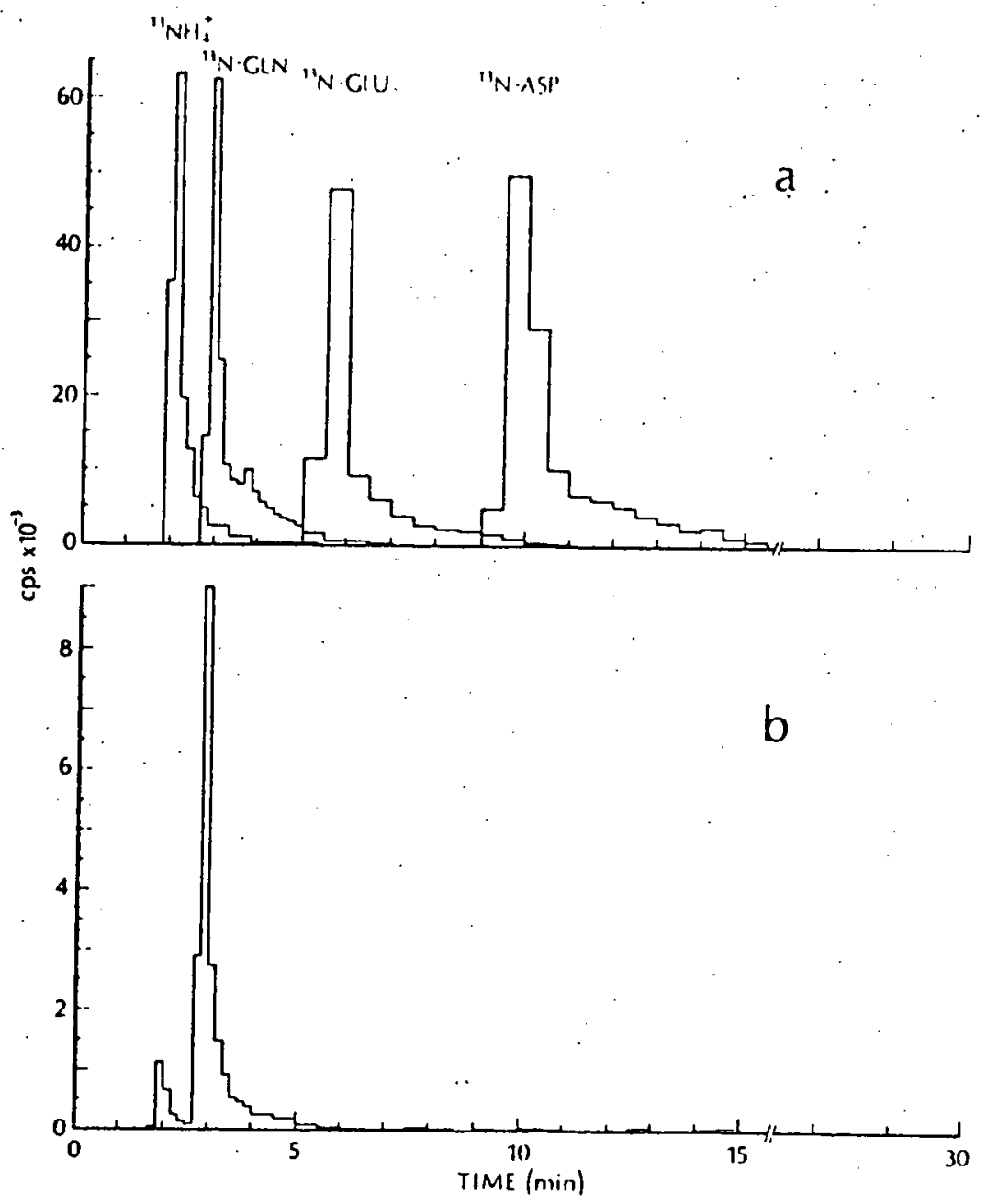

Figure 2. a) HPLC of ${ }^{13} \mathrm{~N}$-labeled standards. b) HPLC of a $20 \mu 1$ aliquot of the brain picrate supernatant fluid. $13 \mathrm{NH}_{4}^{+}$was infused into the right common carotid artery of a rat for 10 minutes. The rat was sacrificed by "freeze-blowing" the brain. The brain was homogenized in $7 \%$ picric acid and an aliquot subjected to HPLC as described in the test. Note the absence of detectable peaks for glutamate and aspartate and the virtually complete incorporation of metabolized $13 \mathrm{NH}_{4}^{+}$in the glutamine peak. 
c) Distribution of Label Among Various Brain Metabolites After Infusion of $13 \mathrm{NH}_{3}$ via the Right Lateral Cerebral Ventricle

The technique of placing a cannula into the right lateral cerebral ventricle has been successfully used in this laboratory in the past for the infusion of neurotoxins (3). The procedure was adapted for the infusion of $13 \mathrm{~N}$ ammonia. Table 11 summarizes the data obtained for the distribution of labeled metabolites in brain tissue after infusion via the right lateral ventricle. Fourteen minutes was chosen as the infusion time since for an isotope with a $t_{1 / 2}$ of 10 minutes maximum counts would be obtained after 214.43 minutes of infusion. The rate of infusion was set at $3.4 \mu 1 / \mathrm{min}$ because this rate is close to the rate at which CSF is produced and readsorbed in the rat (4) and will not induce hydrocephalus. The recovery of counts in the total brain was found to be $61.2 \pm 6.2 \%$. That some label was indeed escaping into the general circulation was shown in one experiment in which after infusion the radioactivity in various organs was determined. It was found that recovery of counts in the liver, kidneys, lungs, heart and spleen was $0.84,0.36,0.17,0.11$ and $0.05 \%$ respectively.

Even though ammonia is readily diffusible there is apparently little passage of $13 \mathrm{~N}$-ammonia into the left ventricle. Thus, splitting the brain into right and left hemispheres before analysis revealed that the ratio of radioactivity in the right half to that in the left half was $12.2 \pm 3.6$. Analysis of the left hemisphere revealed essentially no differences in the pattern of metabolites to that of the right hemisphere.

An unexpected finding of the present work was the high rate of incorporation of $13 \mathrm{NH}_{4}^{+}$into various metabolites via the intraventricular route. The label converted into metabolites via the intraventricular route represented about one-third that of the carotid artery route even though the volume infused was only one-fortieth. Thus, there appears to be a very active uptake of $13 \mathrm{~N}$ ammonia of the CSF. This is borne out by the findings that $\mathrm{CSF} \mathrm{NH} 4{ }^{+}$concentrations are much lower than those of brain as a whole or of blood plasma. Ammonia is actually taken up against the gradient by conversion to glutamine in an energy utilizing process.

It may be noted (Table 10 and 11 ) that very little activity was found in $\mathrm{N}$-acetylaspartate, glutathione, $r$-aminobutyrate and urea. The amount of activity in urea was so low that it may have been due solely to blood-borne urea. These findings again emphasize that the urea cycle is of very little importance in detoxifying ammonia in the brain. 
TABLE 11

Distribution of ${ }^{13} \mathrm{~N}$ among Various Brain Metabolites after Infusion of $13 \mathrm{NH}_{4}^{+}$for 14 Minutes: Right Lateral Ventricle Route

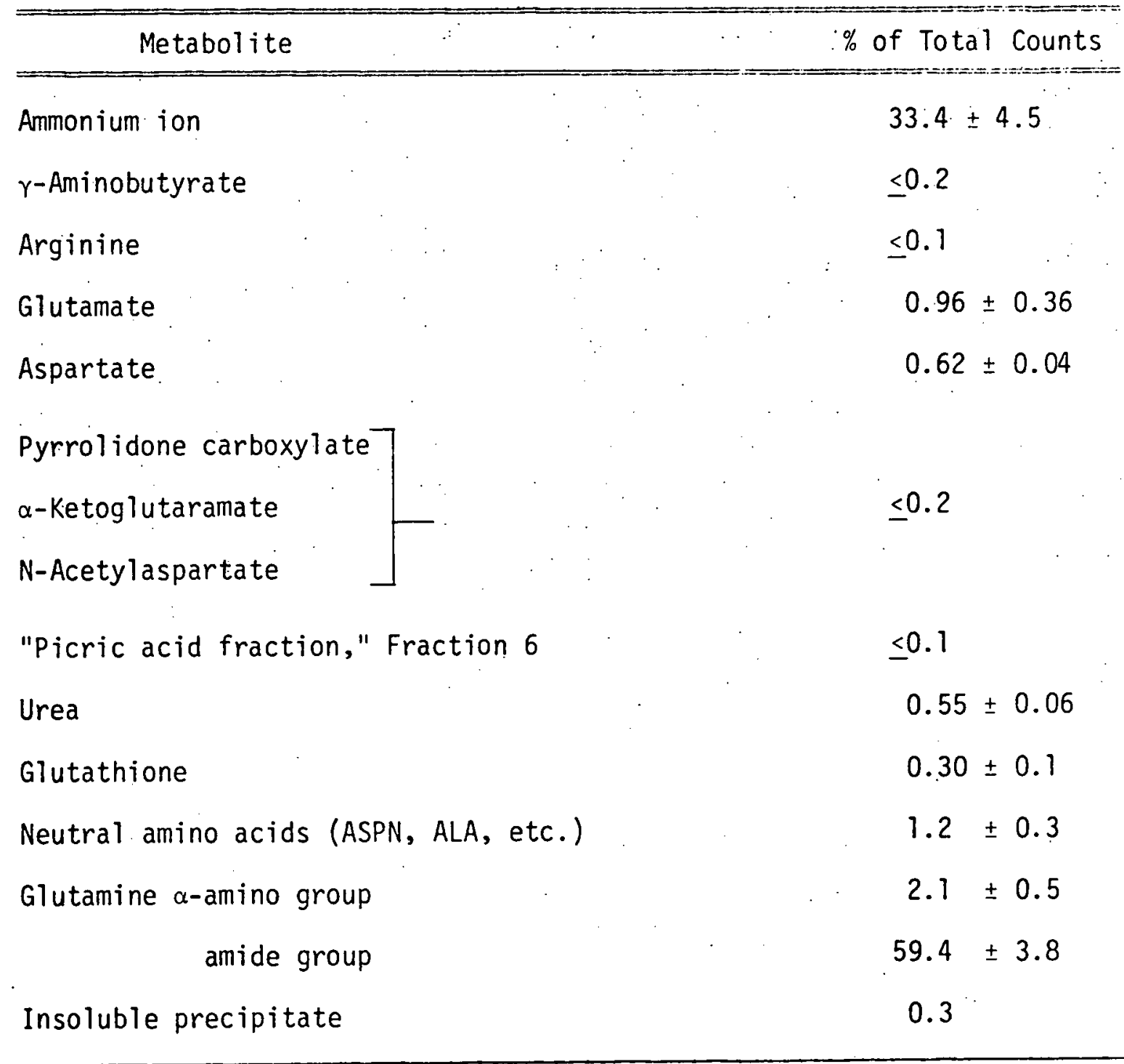




\section{REFERENCES:}

1. Berl, S., Takagaki, G., Clarke, D.D., and Waelsch, H. Metabolic compartments in vivo. J. Biol. Chem. 237:2562-2569, 1962.

2. Veech, R.L., Harris, R.L., Veloso, D., and Veech, E.H. Freezeblowing: A new technique for the study of brain in vivo.

J. Neurochem. 20:183-188, 1973:

3. Vergara, F., Plum, F., and Duffy, T.E. a-Ketoglutaramate: increased concentrations in the cerebrospinal fluid of patients with hepatic coma. Science 183:8183, 1974.

4. Duzinski, D.S. and Cutler, R.W.P. Spinal subarachnoid perfusion in the rat: Giycine transport from spinal fluid. J. Neurochem. 22: 355-361, 1974.

\subsection{REGIONAL OXYGEN EXTRACTION IN CEREBRAL ISCHEMIA}

\section{OBJECTIVE:}

This is an investigation utilizing cyclotron-produced oxygen-15 to assess changes in brain metabolism and blood flow caused by transient cerebral ischemia. The underlying hypothesis is that transient cerebral ischemia may cause a secondary disruption of the normal coupling between brain blood flow and metabolism. The specific question to be answered is whether blood flow falls at a time of increased metabolic need, a situation that could produce additional ischemia and thus secondary brain damage. The techniques being developed for this study will ultimately be applicable to human stroke since they are minimaliy invasive and might in time prove useful in assessing the course and effects of therapy in individual patients.

\section{SCOPE OF INVESTIGATION:}

As it will take a number of years for all aspects of the general objectives to be met, steps to be completed in each year have been formulated. The first aim is to develop techniques that will permit a comparison of oxygen-15 derived blood flow and metabolism determinations with standard results derived from Kety-Schmidt CBF and $A-V$ oxygen difference measurements. Since this phase involves measurements of whole brain blood flow and metabolism, the following specific goals were set: 
Progress Report

Page 42

(1) Acquire standard techniques for measuring blood flow and metabolism.

(2) Develop a model of global brain ischemia in baboons.

(3) Adapt the TOKIM cameras and supporting equipment for the imaging of baboon brains after introduction of oxygen-15.

During this time, attention has also been directed toward the simultaneous development of a model of regional brain ischemia in. baboons that could be introduced after validation of oxygen-15 derived blood flow and metabolism.

\section{RESULTS AND CONCLUSIONS:}

In conjunction with Dr. R. A. R. Fraser, neurosurgeon at Cornell, Dr. Levy has developed a model for producing global brain ischemia in baboons. The baboon (papio papio) has a brachio-cephalic trunk from which most of the arteries supplying the brain originate (both common carotid arteries, the right vertebral artery, as well as the right subclavian artery). As both the brachio-cephalic trunk and the left vertebral artery are accessible via a supra-sternal incision, it is possible to interrupt completely the circulation to the head without performing a major thoracotomy. In a preliminary operation, a reservoir is placed over the superior sagital sinus, and epidural EEG leads are positioned. Several days later, ventilated animals with indwelling arterial and venous cannulae and continuous EEG monitoring are subjected to simulatneous occlusion of the left vertebral artery and the brachiocephalic trunk. Ischemia of variable duration (2-12 minutes) has been produced, the animals are permitted to recover, EEG and clinical status are assessed, and the animals are then perfusion-fixed for pathological examination. We have found thus far that 6-8 minutes of circulatory interruption produce clinical and morphological abnormalities. This then would be a suitable model for comparison of cerebral blood flow and oxygen uptake with standard techniques and with oxygen-15 since all necessary sampling sites are available and variable-duration ischemia can be produced.

The standard methods to be used in determining cerebral blood flow and oxygen utilization is the xenon-133 method developed in our. laboratory by Gjedde et al. (1975). Within the past year, Dr. Levy has acquired this technique in small laboratory animals (rats and dogs) so that it can subsequently be applied to baboons. As noted above, all sampling sites necessary for this method are available in the preparation of global brain ischemia already being used. 
Several modifications have been made in the TOKIM imaging methodology to permit reproducible tomographic imaging of the baboon brain. Dr. Levy has designed a head holder that will permit reproducible positioning of unanes thetized, paralyzed, mechanically-ventilated baboons. This head holder is constructed of plexiglass and Teflon, and none of the supports are located between the animal's brain and the two heads of the TOKIM system in order that there be no: interference with imaging. He have developed software for the improvement of the uniformity of sensitivity of the TOKIM system in the coincidence mode, and for the removal of blurred image contribution from activity located off the focal plane. In addition, graded absorbers have been constructed which will produce some improvement in the count rate capabilities of the system (see Section 5.1 of this Report).

Progress has also been made within the past year in preparing for experiments on regional brain ischemia. Dr. Brierley in England has prepared 6 baboons subjected to unilateral common carotid artery occlusion and systemic hypoxia. All of these have been spontaneously-breathing baboons, and cardiorespiratory collapse intervened before any brain danage developed. Dr. Levy at Cornell has produced unilateral common carotid artery occlusion and systemic hypoxia in one mechanically-ventilated, unanesthetized baboon. Though focal EEG abnormalities developed, the brain of this animal showed no morphological abnormalities. Additional experiments involving longer and more profound hypoxia are planned. Also within the past year, Dr. Levy has developed a regional cerebral blood flow method that could be applied to baboons undergoing oxygen-15 studies. This is a modification of Goldman and Sapirstein's (1973) indicatorfractionation technique that utilizes 14 -butanol. Though developed primarily for small laboratory animals and despite the fact that the method requires sacrifice of the animal, it could be used after a oxygen-15 determination to obtain an independent measure of regional cerebral blood flow.

\section{REFERENCES:}

1. Gjedde, A., Caronna, J.J., Hindfelt, B., and Plum, F. Whole-brain blood flow and oxygen metabolism in the rat during nitrous oxide anesthesia. Am. J. Physiol. 229:113-118, 1975.

2. Goldman, H. and Sapirstein, L.A. Brain blood flow in the conscious and anesthetized rat. Am. 1. Physiol. 224:122-126, 1973. 
Progress Report

Page 44

\subsection{DEVELOPMENT OF NEW PANCREATIC SCANNING AGENTS}

\section{OBJECTIVE:}

The development of compounds labeled with short-lived cyclotronproduced radionuclides which will be clinically useful in the detection of pancreatic cancer.

\section{SCOPE OF INVESTIGATION:}

The amino acid valine, which has been reported to concentrate selectively in pancreas, has been synthesized and labeled in our laboratory in two forms. L-Valine is produced by enzymatic amination of alphaketoisovaleric acid with $3 \mathrm{~N}$-labeled ammonia. DL-Valine, Tabeled with Tic in the carboxyl group, is produced by organic synthesis. The pancreatic uptake and general tissue distribution of these agents, as well as commercially available L-valine uniformly labeled with $14 \mathrm{C}$, are being studied in adult male Sprague-Dawley rats. Under pentabarbitol anesthesia, the animals are injected in the femoral vein and sacrificed at intervals from 2 to 60 minutes after injection by heart puncture. Whote organs, specimens of tissue (including blood), bladder and urine are removed from each animal and assayed for activity. Results are expressed as $\%$ injected dose per whole organ divided by \% body weight (Relative Concentration).

\section{RESULTS AND CONCLUSIONS:}

While these studies have not yet been completed, some conclusions may be drawn from the data available to date. The mean relative concentration of the three agents studied, for these tissues, in the interval 20 to 60 minutes after injection, are listed in Table 12 . The DL form of valine is cleared more slowly from the blood, and is taken up more slowly to a lower concentration in the pancreas than the two $L$ forms studied. Initial uptake in the kidney is higher from the DL form. The maximum urine excretion of activity observed was $1.5 \%$ dose at 50 minutes for the $13 \mathrm{~N}$ label and $16.6 \%$ dose at 60 minutes with the $11 \mathrm{C}-\mathrm{DL}$ form. After an initial distribution period of about 20 minutes, tracer concentration in several tissues remains fairly constant for the next 30 to 40 minutes. The measurements clearly indicate significant differences in distribution for the two L forms, probably due to deanination of the $13 \mathrm{~N}$ label. One result is a higher concentration of activity in liver for the $13 \mathrm{~N}$ label, producing a somewhat lower pancreas/liver ratio than that found for the uniformly labeled compound. Nevertheless, the ratio of pancreas to liver and to surrounding muscle background is significantly greater for the $13 \mathrm{~N}$ label than for the II $\mathrm{C}-\mathrm{DL}$ form: "This, coupled with the shorter half-life of the former nuclide suggests that it 
would be the preferred imaging agent, particularly where radiation dose must be kept to a minimum. The $\{1 \mathrm{C}-l$ abeled compound may find application in studies where longer periods of observation are required. Further study is necessary to determine whether the relative concentration observed for labeled valine in rats will predict the distribution in larger animals and in humans. 


\section{TABLE 12}

Tissue Distribution of Valine with Various Labels in

Male Sprague-Dawley Rats (I.V. Injection)

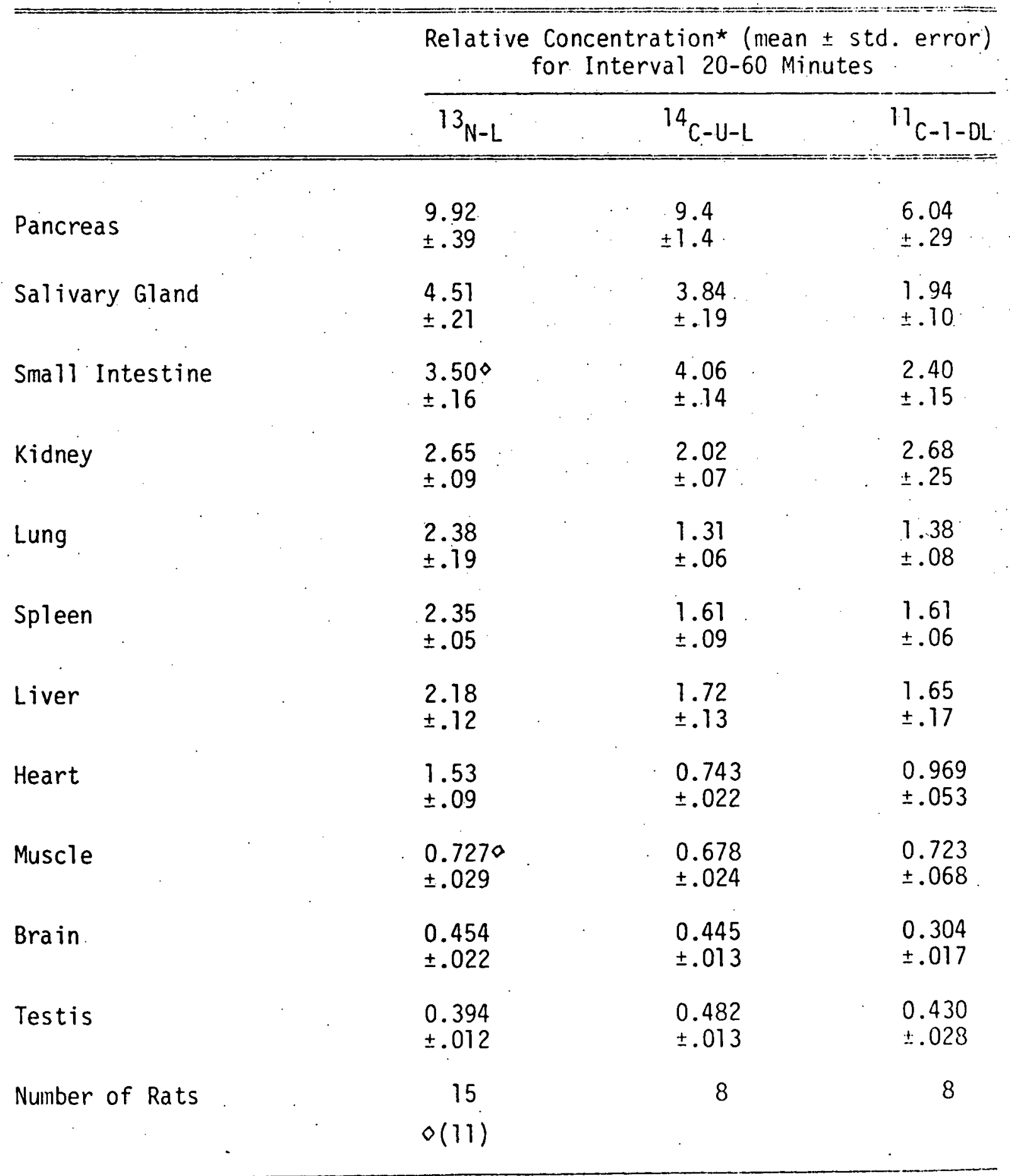


Progress Peport

Page 47

\section{$4.4 \quad 13$ N-LABELED AMMONIA AND L-AMINO ACIOS}

\section{OBJECTIVE:}

To evaluate ${ }^{13} \mathrm{~N}$-labeled compounds as tumor and organ imaging agents, and to use these compounds to study the metabolism of tumor and normal. tissues.

\section{SCOPE OF INVESTIGATION:}

$13 \mathrm{~N}$-Ammonia and a number of enzymatically synthesized $13 \mathrm{~N}$-1abeled L-amino acids have been produced in our cyclotron and hot lab facilities for our tumor imaging and tissue distribution studies. These amino acids are (a) glutamic acid, glutamine, and valine, (b) asparagine, leucine, and alanine, and (c) tyrosine, phenylalanine, and aspartic acid. The group (a) amino acids have received most of our attention during this past year, while the (c) group amino acids have just recently been synthesized and have not been administered to any animal subjects (see section 3 for details of the synthesis of these $13 \mathrm{~N}$ compounds).

Two types of studies were.carried out extensively during this period, with the first few preliminary measurements of a third type performed just prior to the preparation of this report. They are as follows: (a) the detection or visualization in vivo of spontaneous primary and metastatic tumors in canine subjects, (b) the in vitro measurement of $13 \mathrm{~N}$ tissue distribution in rats, following IV administration of the labeled compound, and (c) determination of the metabolic fate of the labeled compounds in tumor and normal tissues.

The subjects of our tumor imaging studies were spontaneous canine tumor cases referred to us by the oncology group at the New York Animal Medical Center (AMC). This private veterinary hospital has collaborated with our group for the past several years; in addition to supporting services provided to us by the AMC, one of their veterinarians works closely with us in the selection of appropriate cases and in the execution of each study. Each dog was injected intravenously with $25 \mathrm{mCi}$ of each $13 \mathrm{~N}$-compound and tumor imaging was begun 5 minutes after injection; where appropriate other agents (e.g. 67 Ga-citrate) were also administered as a comparison with the $13 \mathrm{~N}$-compound. The results from the radionuclide images were also compared with radiographic and post-mortem findings. For most of these imaging studies, namely for the static whole body distribution images, a dual-detector high energy gamma ray (HEG) rectilinear scanner, equipped with constant response collimators was employed. The uniformity of response of this systell permits quantitative determination of the amount of $1.3 \mathrm{~N}$ activity present in the organ or tumor of interest. The Total Organ Kinetic Imaging Monitor (TOKIM) gamma camera system was used for dynamic studies covering. 
smaller areas of the subject's body. Digital image data from the TOKIM were stored in serial form on magnetic tape for subsequent analyses. These analyses included integration of counts within an area of interest as a function of time. Both HEG and TOKIM images were displayed as alphanumeric character lineprinter output or as a dot-density format output on a storage oscilloscope.

Extensive tissue distribution studies were performed in normal male Sprague-Dawley rats following IV administration of $13 \mathrm{~N}$-ammonia and $13 \mathrm{~N}-\mathrm{labeled} \mathrm{L}-\mathrm{gl}$ tutamic acid and $\mathrm{L}-\mathrm{val}$ ine, completing these measurements for the first two of these compounds (approximately 30 rats per $13 \mathrm{~N}$ compound and over one dozen tissues per rat). On the order of $100 \mathrm{iC} i$ of each compound was injected into a femoral vein under pentabarbitol anesthesia and the rats were sacrificed at times ranging from 2 to 50 minutes after injection. Tissue specimens were assayed for $13 \mathrm{~N}$ activity in a Packard scintillation spectrometer with dual $\mathrm{NaI}$ (TI) crystals and. automatic sample changer. Nitrogen-13 content was expressed as relative concentration (RC), which is defined as percent injected dose over percent body weight for a given tissue sample or whole organ. A tissue distribution comparison was also performed in rats between $13 \mathrm{~N}$-L-valine, $11 C-D L-v a l i n e$, and $14 C$ uniformly labeled $L$-valine (see section 4.3 ).

We have recently developed techniques (see section 4.1 ) which will enable us to study some of the labeled metabolites formed in tumor and normal tissues following IV administration of $13 \mathrm{~N}$-ammonia or an $13 \mathrm{~N}$-amino acid. These rapid separation methods involve high pressure liquid chromatography, enzyme treatment, and ion exchange chromatography. Subject tissues for our preliminary measurements have been rat heart and kidney, with $13 \mathrm{~N}$-ammonia, and one canine mammary (metastatic lung) tumor following $13 \mathrm{~N}$-glutamic acid injection.

\section{RESULTS AND CONCLUSIONS:}

During this past year we have performed $22^{13} \mathrm{~N}$-amino acid studies, plus seven $13 \mathrm{~N}$-ammonia studies, in 14 spontaneous canine tumor cases. The tumor types available included 2 osteogenic sarcomas, 7 mammary cancers (adenocarcinoma and fibrosarcoma), 3 liver cases, and one each hemangiosarcoma and lymphosarcoma. Most of the mammary cases also involved metastases to the lungs and in one case a suspected metastatic brain tumor. Confirming our previous results with a smaller number of mammary tumors, $13 \mathrm{~N}$-glutamic acid was generally found to be a good imaging agent for these primary and metastatic manmary tumors. Figures 3 and 4 show two of these mamimary cases imaged with $33 \mathrm{~N}$-glutamic acid using a rectilinear scanner, with the activity distribution displayed in a dot density format on a storage oscilloscope; both are A-P, summed, whole body images with the animal's head oriented towards the top of the image. Figure 3 shows a case with the primary visualized in the lower left abdomen, and a metastatic tumor in the center of the lung field, just above the liver and to the right of the (non-visualized) heart. $13 \mathrm{~N}$-ammonia poorly visualized this primary, and the metastatic tumor was not seen, perhaps 
Progress Report

Page 49

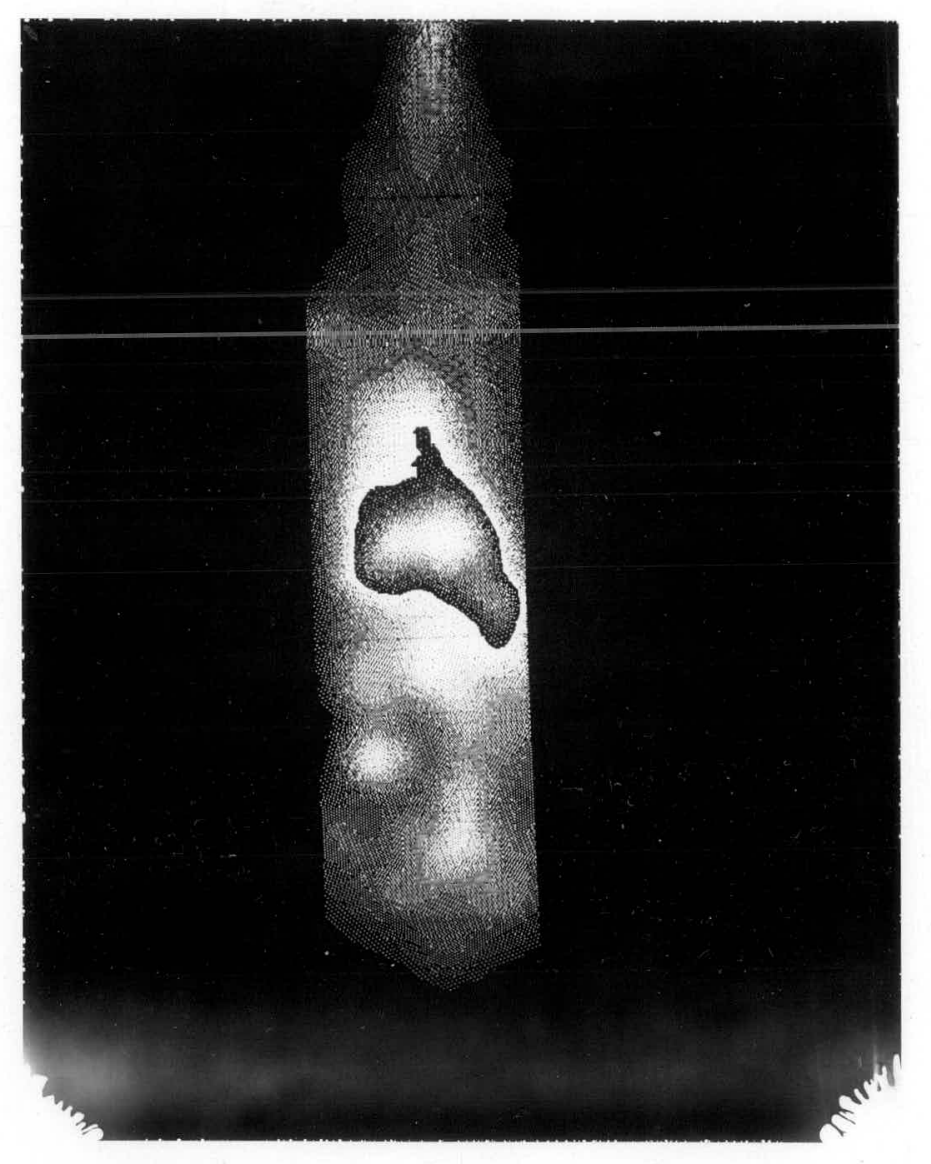

Figure 3. Rectilinear scan of a dog with mammary $\mathrm{Ca}$ using $13 \mathrm{~N}$-glutamate. 
Progress Report

Page 50

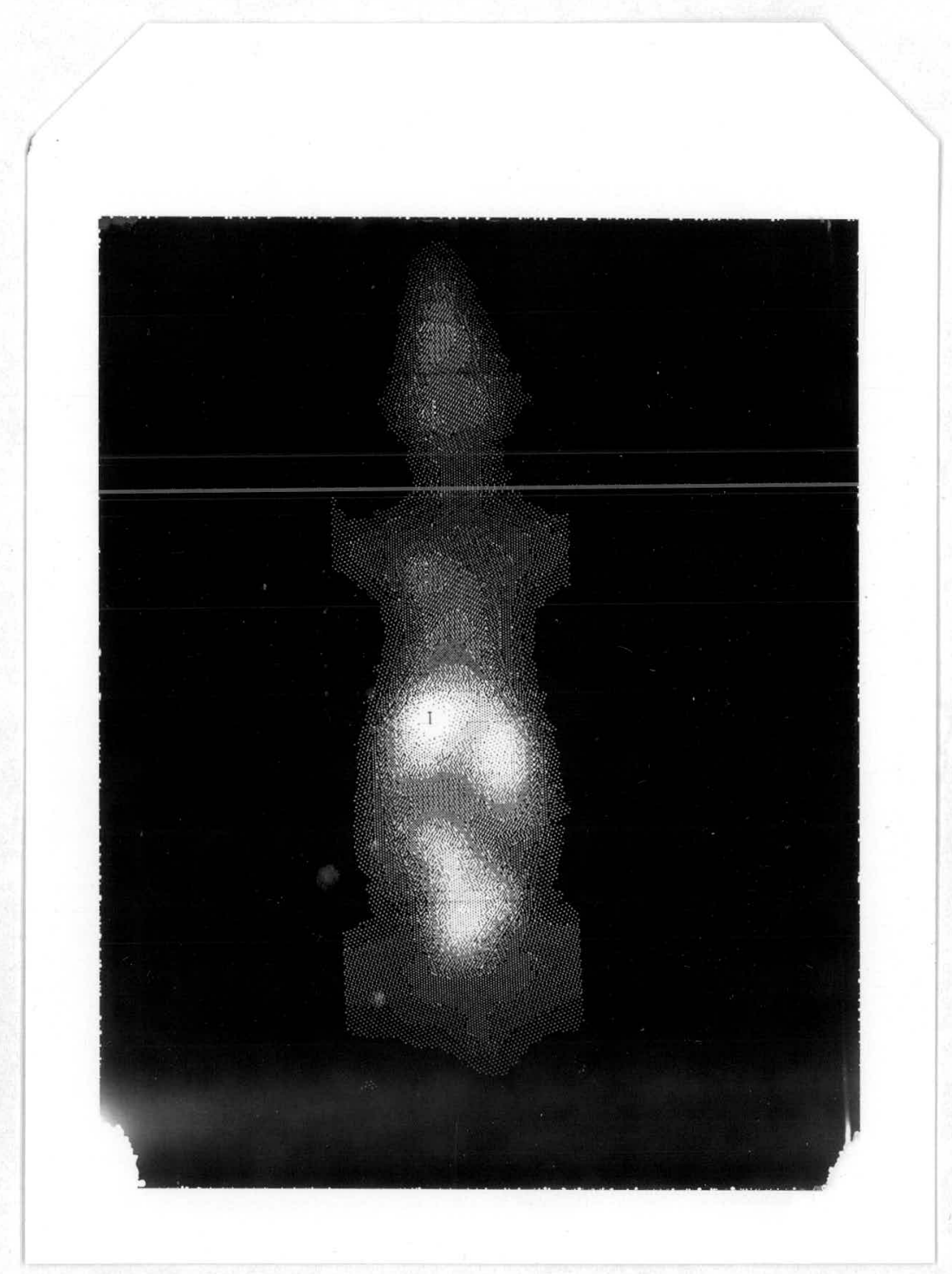

Figure 4. Rectilinear scan of dog with metastatic mammary Ca using $13 \mathrm{~N}-\mathrm{g}$ lutamate. 
Progress Report

Pàge 51

due to the higher uptake of ${ }^{13} \mathrm{~N}$-ammonia in the dog's heart. Figure 4 is of a mammary case where the primary had been previously removed and tumor had subsequently been found in the abdominal lymphatics; here the tumor can be seen displacing the urinary bladder to the right.

Also of interest is a series of $13 \mathrm{~N}$-amino acid scans performed on a canine osteogenic sarcoma case before and during a course of chemotherapy. In this study scans were performed with $13 \mathrm{~N}-\mathrm{val}$ ine and $13 \mathrm{~N}-$ glutamic acid pretherapy and one week post initiation of methotrexate therapy. The $13 \mathrm{~N}$ activity in four regions in the tumor. $1 \mathrm{eg}$ and corresponding regions in the contralateral leg, were obtained using a rectilinear scariner. For all contralateral regions the activity decreased or remained constant between the pretherapy and post therapy study, while the activity increased in the tumor leg for most regions. The most significant increases were noted in the regions proximal to the tumor, which increased approximately $170 \%$ and $3.00 \%$ for $13 N-v a l i n e$ and $13 \mathrm{~N}$-glutamic acid respectively. Unfortunately, the animal died and further studies could not be performed.

Our results this past year and in previous studies, particularly with $13 \mathrm{~N}$-glutamic acid in colon cancers, osteogenic sarcomas, and mammary cancers, have encouraged us as to the potential value of these amino acids in human diagnostic applications and in helping us to understand tumor metabolism. We intend to begin evaluation of $13 \mathrm{~N}-L-g l u t a m i c$ acid in human cancer patients shortly, upon completion of prerequisi.te pyrogenicity testing. Some batches tested have been pyrogenic.

For ${ }^{13} \mathrm{~N}$-ammonia and ${ }^{13} \mathrm{~N}$-labeled L-glutamic acid and L-valine administered by IV injection in rats, the major features of the resulting $13 \mathrm{~N}$ activity distributions are as follows. Ammonia produces high concentrations of activity in lungs, kidneys and heart within 2 minutes after injection. At 50 minutes, the highest concentrations are in salivary glands, heart and lungs. Pancreas, gut, kidneys and liver show moderately high concentrations throughout this time period. Glutanic acid concentrates mainly in kidneys, lungs, liver and salivary glands at 2 minutes, with moderately high levels in pancreas, salivary glands, lungs and kidneys at 50 minutes. Liver and spleen maintain moderately high levels throughout. For valine, the highest concentrations are attained in pancreas and salivary glands throughout the period of study, the pancreas showing remarkably high concentrations of activity within 2 minutes of injection. The lowest concentrations were observed in testes for ammonia and valine, and in brain for glutamic acid. . The time course of activity in blood is similar in character for the three compounds, with a distinct minimum occurring between 20 and 30 minutes after injection. Relative concentrations in blood are in the order: valine $>$ glutamic acid > ammonia at 2 minutes, ammonia > glutamic acid > valine at 20 minutes, glutamic acid = ammonia > valine at 50 minutes. 
Progress Report

Page 52

\section{INSTRUMENTATION AND DATA HANDLING}

\subsection{POSITRON.COINCIDENCE IMAGING WITH THE TOKIM SYSTEM}

\section{OBJECTIVE:}

To improve the imaging capabilities of our dual-detector Total Organ Kinetic Imaging Monitor (TOKIM) gamma-camera system in the positron coincidence mode of operation.

\section{SCOPE OF INVESTIGATION:}

The TOKIM system is equipped with two stationary, opposed Angertype gamma cameras which may be operated in coincidence without collimation. It is thus possible to obtain focal plane tomographic images with three-dimensional spatial resolution and high detection sensitivity using positron emitting isotopes. This method, however, suffers from certain inherent limitations:

1) Due to the variation of the geometric coincidence aperture in the plane of the detectors, the sensitivity of the system as a function of radial distance from the axis of the detector pair is highly nonuniform;

2) The reconstructed image of a given focal plane.contains blurred contributions from activity in neighboring planes superimposed on the contribution from activity in the plane of interest;

3) The photopeak coincidence efficiency is relatively low compared to the total single photon efficiency, which includes a large contribution from low-energy photons arising from Compton scatter in the subject.

In the past year we have made efforts to overcome these 1 initations and hence improve the TOKIM imaging capability in the tomographic mode. The following approaches have been taken: the removal of out-of-focus contributions via a computerized iterative correction procedure, the temporary use of a software-based coincidence aperture limitation system to achieve more uniform sensitivity across a portion of the detector pair diameter and the application of Muehllehner's graded filter approach to increase the ratio of usable coincidence events to single photon events. 
Progress Report

Page 53

RESULTS AND CONCLUSIONS:

We have developed software for the IBM 1800 which will remove, from a given plane of interest, the out-of-focus contributions from activity located in other planes in the canera's field of view. At the time of data acquisition, the camera-computer interface records on magnetic tape the $x-y$ positions at the opposing crystals for each coincident pair. It is then possible to calculate the intersection points of the lines connecting such pairs with any desired focal plane. The resulting focal plane image matrix represents the true radioisotope distribution plus blurred contributions from all other planes. Let $A_{j}$ represent the observed image matrix in plane $i$, and $P_{i j}$ the blurring operator for activity in the $j \underline{\text { th }}$ plane contributing to the $\underline{i}$ th plane image. Then

$$
A_{i}^{\prime}=A_{i}+\sum_{i \neq j} P_{i j} * A_{j}
$$

The true distribution $A_{j}$ cannot be obtained directly from equation [1] since the true distributions $A_{j}$ are not known. However, the application of the following expression in an iterative fashion can yield an approximation to the true isotope distribution:

$$
A_{i}^{n}=A_{i}^{0}-\sum_{i \neq j} P_{i j} * A_{j}^{n-1},
$$

where $A_{j}^{0}$ is the original observed data for plane $i$ and $A_{i}^{n}$ is the $n$th iteration image, and $A_{i}^{D} \rightarrow A_{i}$ for sufficiently large $\underline{n}$.

For this procedure to be effective, the blurring functions $P_{i j}$ must be space-invariant, i.e. constant over the field of the detector. The uniformity may be improved by limiting the coincidence aperture. This is best achieved by mechanical collimation. Pending the design of an adequate collimator, we have chosen to limit the aperture via a flexible software-based method. The coincidence aperature is limited by having the algorithm reject those rays whose incident angle is greater than some preselected value. Figure 5 shows the effective field-flattening obtained when this technique is applied to data from a flood source acquired on the TOKIM in the positron coincidence mode. Note that while the severe non-uniformity is greatly.improved as the aperture is decreased, the number of accepted counts is also reduced, with a resulting decrease in the statistical quality of the inages.

The blurring functions $P_{i j}$ depend upon the aperture diameter, the relative positions of plane $i$ and plane $j$, and the detector separation. At first it was planned to measure $P_{i j}$ for $a 11 \quad i$ and $j$ and for several discrete values of detector separation. However, this quickly became impractical for more than a few planes, and it was found that theoretically computed values were in sufficiently good agreement with measured values so that calculated values could be used in all cases. As expected, the 


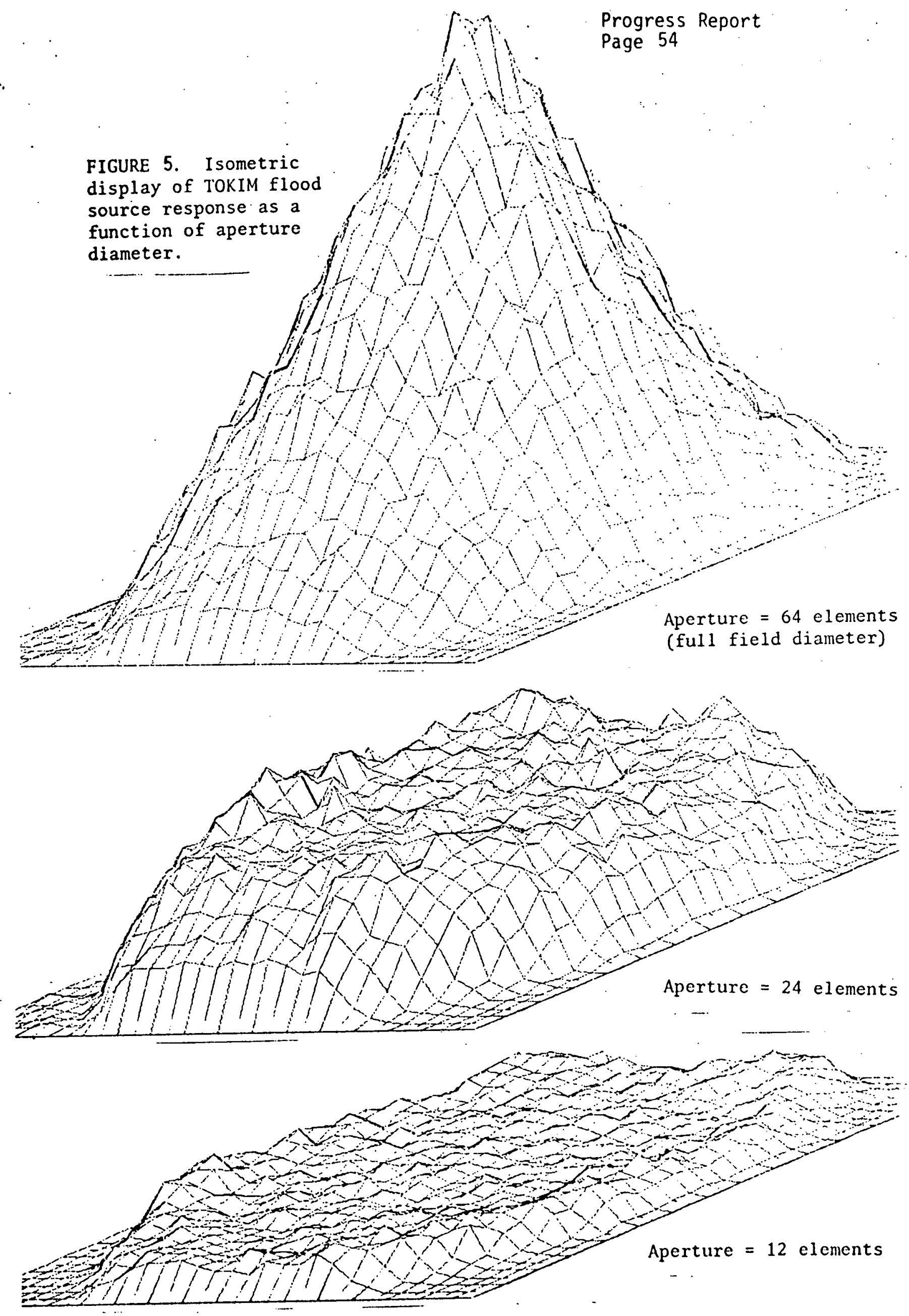


Progress Report

Page 55

width of $P_{j j}$ (which is approximately Gaussian-shaped) is a linear function of the distance between planes $i$ and $j$ for a constant aperture diameter, and also a linear function of aperture diameter for fixed $\underline{i}$ and $\underline{j}$.

The axial resolution (FlUHM of the point response function along a line perpendicular to the crystal faces) of the TOKIM system is a function of the crystal separation and the selected aperture limitation. Hence the number of principal reconstruction planes should be consistent with the axial resolution, i.e., the separation between planes should be on the order of the axial resolution. In the initial studies, the region between the detectors is divided into four regions (see Figure 6) by five principal planes. Division of the field into seven planes would be an improvement, but would require twice as many blurring and subtraction operations as the 5-plane case, resulting in impractical computing times for the IBM 1800. The algorithm works as follows:

1) The operator selects an aperture diameter. The coincidence pairs are read from a magnetic tape (generated at acquisition time), and pairs whose incident angle is greater than that specified are rejected. The accepted $x-y$ values are written to disk.

2) From the count pairs on disk, the image distributions $A_{j}$ are formed for the five principal planes. These distributions are databounded to decrease statistical fluctuations and are placed on disk.

3) Beginning with the first principal plane, the program evaluates expression (2). The original planes are blurred with a Gaussian function whose width is continuously variable and is dependent on the inter-plane distance. The blurred planes are added point-by-point and the sum is likewise subracted from $A_{i}^{\prime}$. This step is repeated for the next principal plane, and so forth. The resulting distributions are written to disk. When expression (2) has been evaluated for all 5 planes, the first iteration is complete.

4) The subtracted images obtained from step 3) are read from disk and are used as An- 1 in expression (2). This continues until the specified number of iterations has been performed.

The effectiveness of this algorithm in reducing off-plane contributions has been demonstrated using a point-source located midway between detectors (plane 3). The counts in the maximum image element are used to compute the percentages, which are relative to the maximum counts at plane 3. The results are shown in Table 13. 

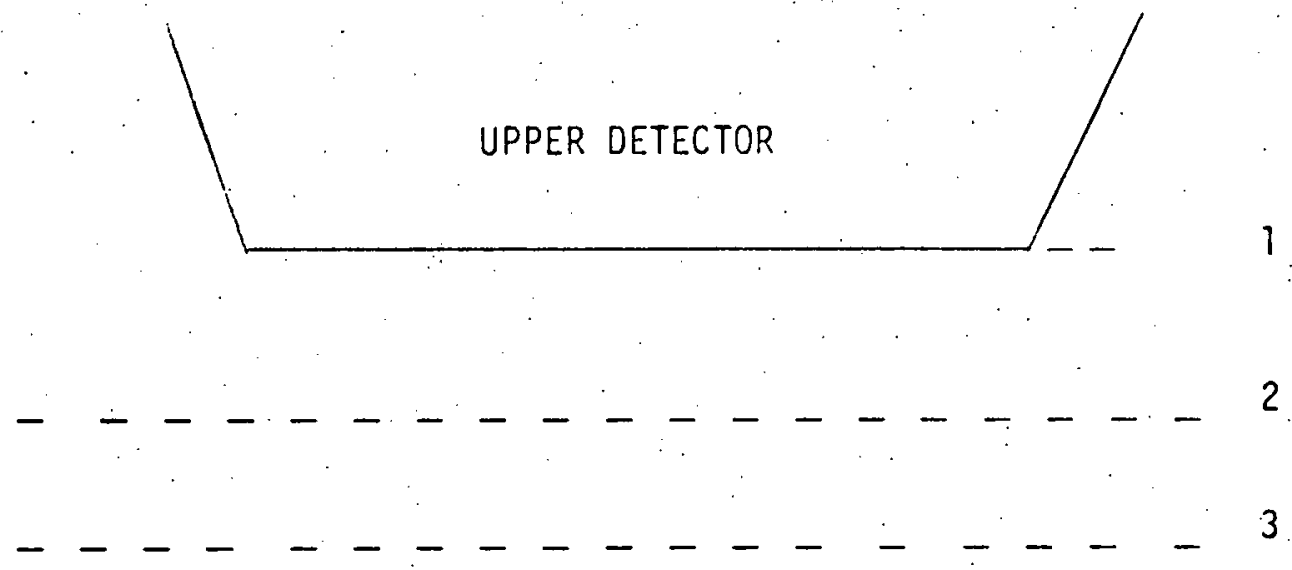

$--------------^{4}$

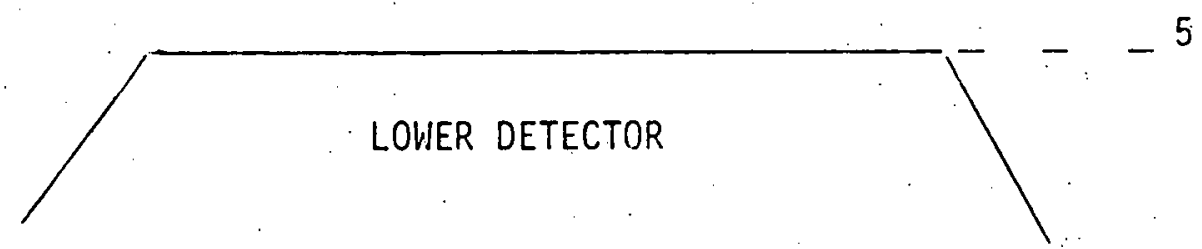

Figure 6 -- Arrangement of 5 principal reconstruction planes relative to TOKIM detectors. 
TABLE 13

\begin{tabular}{lccc}
\hline Plane & Original & After 1 Iteration & After 2 I terations \\
3 (Midplane) & $100 \%$ & $100 \%$ & $100 \%$ \\
2 & $38 \%$ & $35 \%$ & $18 \%$ \\
1 (Crystal) & $21 \%$ & $8 \%$ & $8 \%$ \\
\hline
\end{tabular}

Note the significant reduction in the amount of activity in those planes which are far from the point source. The reduction continues as more iterations are performed, but the amount of reduction per iteration is less dramatic than that of the first two iterations.

The evaluation of this software is continuing. New phantom studies, including distributed sources of radioactivity and voids within a radioactive background, can now be performed to determine the limitations of the system. The future implementation of this software on the newlyacquired PDP-11/70 should eliminate some of the problems associated with the limited core and speed of the IBM 1800.

The use of Muehllehner's graded filter approach was investigated; in particular, a filter consisting of $60 \mathrm{mils}$ of lead, 5 mils of tantalum and $10 \mathrm{mils}$ of copper was constructed and tested. The purpose of the lead is to preferentially shield the crystal from the lower energy photons arising from the scatter of $517-\mathrm{keV}$ gammas inside the subject, and the tantalum and copper are present to shield the crystal from excitation $x$-rays produced in the lead and tantalum filter components, respectively. The net result should be a reduction in the number of low-energy photons entering the detector, with minimum absorption of usable $511 \mathrm{keV}$ coincident photons. To test the filter, the upper detector of the TOKIM system was used to detect events in three energy ranges which were selected to include the $88 \mathrm{keV}$ lead $x$-ray, the region of Compton scatter of $517 \mathrm{keV}$ photons, and the $511 \mathrm{keV}$ photopeak. A point source of Ge-68 was placed $30 \mathrm{~cm}$ from the detector face on the central axis. Counts were taken with the source in air and with $10 \mathrm{~cm}$ of lucite to act as a scattering medium. The effectiveness of the Ta absorber was tested by performing measurements with $\mathrm{Pb}$ and $\mathrm{Cu}$ foil only. The results are shown in Table 14. Note the large increase in low energy photons, relative to the photopeak, which occurs when the scattering medium is introduced and no filter is in place. When the $\mathrm{Pb}-\mathrm{Cu}$ filter is added, the 50-100 keV and 100-400 $\mathrm{keV}$ regions are reduced about $80 . \%$ and $60 \%$ respectively, while the photopeak counts are reduced by only $21 \%$. The addition of the tantalum foil 
TABLE 14

Effect of Graded Filters on Singles Count Rate

\begin{tabular}{|c|c|c|c|c|c|c|}
\hline Energy Range (keV) & $\begin{array}{c}\text { Air, } \\
\text { Unfiltered }\end{array}$ & $\begin{array}{c}\text { TEM } \\
\text { Unfiltered }\end{array}$ & $\begin{array}{c}\text { TEM } \\
\mathrm{Pb}-\mathrm{Cu} \text { Filter }\end{array}$ & $R$ & $\begin{array}{l}\text { TEM, } \\
\text { Pb-Ta-Cu } \\
\text { Filter }\end{array}$ & $R_{\text {ta }}$ \\
\hline $50-100 \mathrm{keV}(\mathrm{Pb} x-$ ray $)$ & 0.458 & 1.066 & 0.223 & 0.209 & 0.172 & 0.161 \\
\hline $100-400$ (Compton) & 2.205 & 2.942 & 1.172 & 0.398 & 1.119 & 0.380 \\
\hline 400-600 (Photopeak) & 1.000 & 0.548 & 0.433 & 0.790 & 0.421 & 0.768 \\
\hline
\end{tabular}

TEl $=10 \mathrm{~cm}$ of Lucite to simulate Tissue Equivalent material.

$R=$ Reduction factor for the filter $=(T E M$, filtered $) /(T E M$, unfiltered $)$.

The values in the table are count values normalized to the counts in the unfiltered photopeak measured in.air. The source was a point source of Ge-68 located $30 \mathrm{~cm}$ from the crystal face. 
reduces the photopeak and Compton counts by an additional $2 \%$ and the counts in the $x$-ray region by an additional $5 \%$. We may conclude, then, that the graded absorber approach will be effective in reducing the scattered radiation which reaches the crystal relative to the photopeak events, and that the tantalum foil can provide a small but useful reduction in the number of lead $x$-rays reaching the crystal. The singles rate can thus be reduced without sacrificing useful coincidence events. In addition, it may be possible to increase the energy acceptance window and include Compton events which originate in the crystal, thus further increasing the number of coincidence events relative to the total singles rate. 
Progress Report

Page 60

\subsection{MODELING AND DATA ANALYSIS}

\section{OBJECTIVE:}

To study methods, such as modeling of dynamic processes and functional imaging, aimed at extracting more information from our garnma camera radionuclide images than simply isotope distribution.

\section{SCOPE OF INVESTIGATION:}

Our gamma camera system (TOKIM) has been used in a series of human studies on the metabolism of $13 \mathrm{NH}_{3}$ in hepatic encephalopathy. The TOKIM was used to image the distribution of $13 \mathrm{~N}$ in the heads of our normal subjects and 1 iver patients, for the first 10 minutes after IV injection of $210 \mathrm{mCi}$ of $13 \mathrm{~N}$-ammonia, and to determine the amount of $13 \mathrm{~N}$ present in the whole brain of each subject as a function of time during this initial 10 minute period. These TOKIM dynamic brain data, together with arterial blood $13 \mathrm{NH}_{3}$ and $13 \mathrm{~N}$-metabolite concentrations, have been used as input for a compartmental model of cerebral ammonia metabolism which we have been developing.

The TOKIM gamma camera acquires its data in list mode; that is, a buffer containing the $x-y$ coordinates of 1024 counts, along with the time at which the counts were acquired, is written to magnetic tape. This process continues during the course of the study. It is then possible to "frame" the data in a desired fashion at the time of analysis. This flexibility in the choice of time increments not only facilitates the usual region-of-interest type of dynamic analysis and also makes possible certain types of functional imaging. In functional imaging, the quantity displayed in the image matrix is not the usual accumulated count data but is rather some parameter which reflects the dynamic character of the biological system under study. For example, suppose a radioisotope accumulates in an organ according to the formula

$$
A=A_{0}(1-\exp (-\lambda t))
$$

where $A$ is activity, $t$ is time post-injection and $A_{0}$ and $\lambda$ are parameters which characterize the uptake curve. It may be possible to obtain values for $\lambda$ and $A_{0}$ for each resolution element in the image matrix. These values can be displayed and the spatial variation of the parameters can then be visualized. 
Progress Repurt:

Page 61

\section{RESULTS AND CONCLUSIONS:}

The computerized model of cerebral ammonia metabolism as it now stands consists essentially of three pools: pool $\$ 1$ : the blood present within the brain; pool $\# 2$ the brain free ammonia pool, from which the ammonia may participate in various (unspecified) metabolic processes; and pool \#3, the metabolite pool (e.g. glutamine). Pool \#1, or the cerebral blood volume (CBV) is further separated into the brain capillary volume, where ammonia exchange across the blood-brain-barrier (BBB) may occur with the contents of the brain free ammonia pool, and the arterial and venous volumes, where this exchange across the BBB does not take place. Parameters which describe the model (and therefore are the quantities varied to achieve best agreement with the experimental data) are: the rate constants for ammonia exchange across the $B B B$ in both directions, the rate constant for metabolism from the brain free ammonia pool into the metabolite pool, the rate constant for the return from the metabolite pool to the circulation and the total cerebral blood flow (CBF). Also required by the model, and input as variables, are the capillary fraction of the tota 1 CBV and the weighting factor determining where the capillary $13 \mathrm{NH}_{3}$ concentration falls between arterial and venous concentrations. A central assumption in the model is the availability for exchange across the $\mathrm{BBB}$ of all the $13 \mathrm{~N}$-ammonia present in the capillaries. What we have elected to refer to as $13 \mathrm{NH}_{3}$ or $13 \mathrm{~N}$-ammonia is; at typical blood $\mathrm{pH}$ values, actually predominantiy ammonium ion, $\mathrm{NH}_{4}^{+}$(i.e. $297-98 \% . \mathrm{NH}_{4}{ }^{+}$ versus $22-3 \% \mathrm{NH}_{3}$ gas in solution). However, since the rate constant for dissociation of $\mathrm{NH}_{4}^{+}$to the highly diffusible $\mathrm{NH}_{3}$ form is so great $\left(\sim 3 \times 1010 \mathrm{sec}^{-1}\right)$ relative to the cerebral blood transit time, that all of the $\mathrm{NH}_{4}^{+} / \mathrm{NH}_{3}$ mixture is available as $\mathrm{NH}_{3}$ if required. Reformation of the $\mathrm{NH}_{4}{ }^{+}$ion is also a rapid process once the BBB is crossed $\left(\sim 6 \times 10^{5}\right.$ $\mathrm{sec}^{-1}$ ), so that the $\mathrm{NH}_{4}{ }^{+}$ions are then available in the brain free ammonia pool for metabolic processing. (It has also been suggested that an active transport mechanism for $\mathrm{NH}_{4}^{+}$across the $\mathrm{BBB}$ may exist.)

The differential equations describing this compartmental system have not been solved explicitly, and so the model results are compared with the experimental data through numerical integration of the differential equations by finite differentials. The driving function for the differential equations is the $13 \mathrm{NH}_{3}$ arterial concentration (total arterial $13 \mathrm{~N}$ corrected for the presence of $13 \mathrm{~N}$ metabolites), measured 225 times during the first 2.5 minutes after injection, then at $3,5,7,10,15$, and 20 minutes after injection. The total amount of $13 \mathrm{~N}$ present in the three pools as $13 \mathrm{NH}_{3}$ and $13 \mathrm{~N}$-metabolites, as predicted by the model, is compared with the total brain $13 \mathrm{~N}$ activity recorded by the TOKIM as a function of time. Figures 7 and 3 show two such comparisons for two subjects whose brain $13 \mathrm{~N}$ activity exhibited rather different short term behavior. While these model fits (solid curve) to the data are recognized as being unsatisfactory, they are seen to conform to the basic characteristics of the brain $13 \mathrm{~N}$ data. (points with error bars). Further progress with the model has been hampered by our current computer hardware; however, 
Figure 7. Brain ${ }^{13} \mathrm{~N}$ activity (shown as data points with error bars; arbitrary units) obtained with the TOKIM gamma camera, following IV administration of $13 \mathrm{~N}$-ammonia, versus time after injection (in minutes). Solid curve is fit to data generated by computer model.

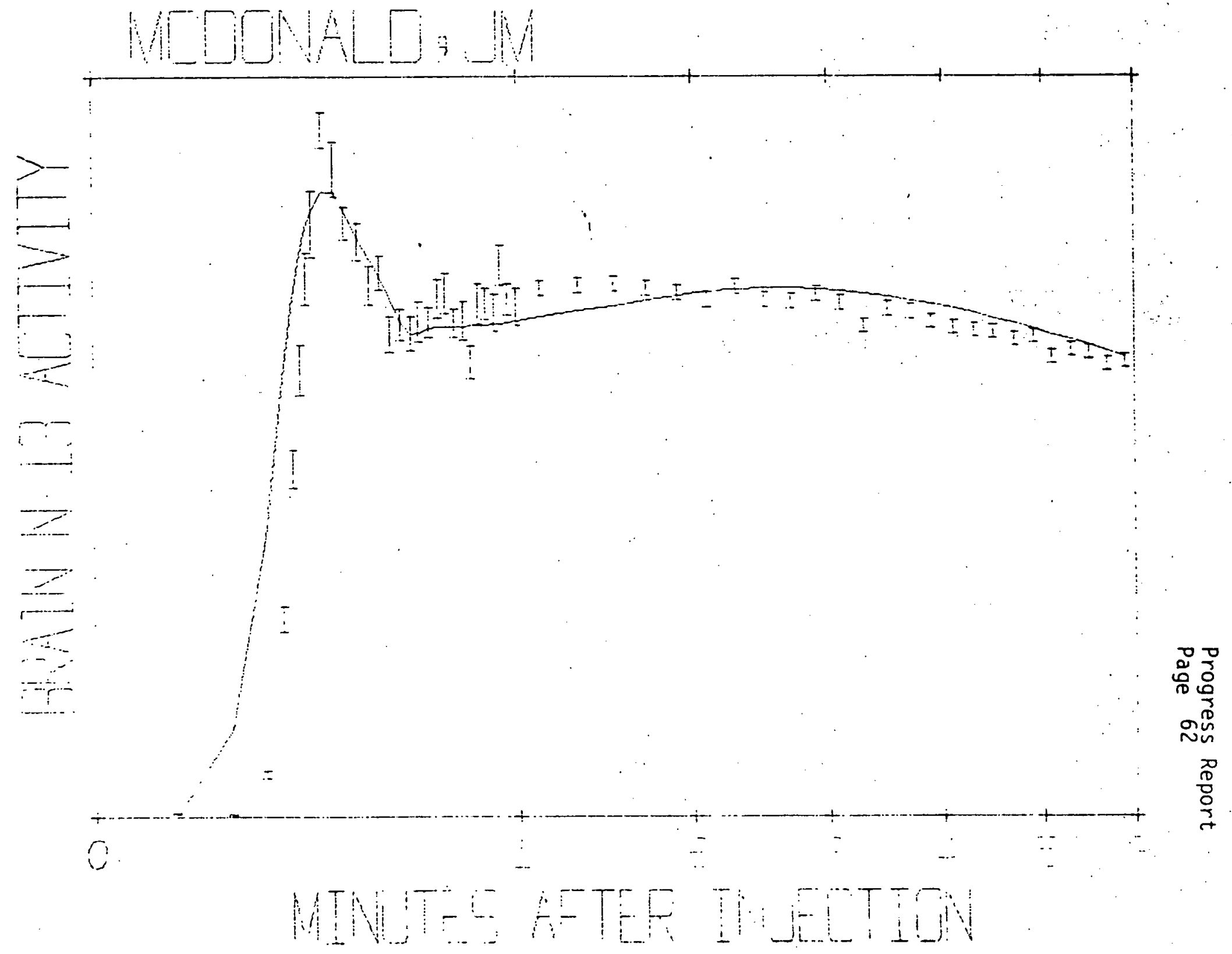


Figure 8. Brain ${ }^{13} \mathrm{~N}$ activity (shown as data points with error bars; arbitrary units) obtained with the TOKIM gamma camera, following IV administration of $13 \mathrm{~N}$-ammonia, versus time after injection (in minutes). Solid curve is fit to data generated by computer model. Lack of prominent initial spike in activity, compared to previous figure, may be due to slower injection of activity in this case.

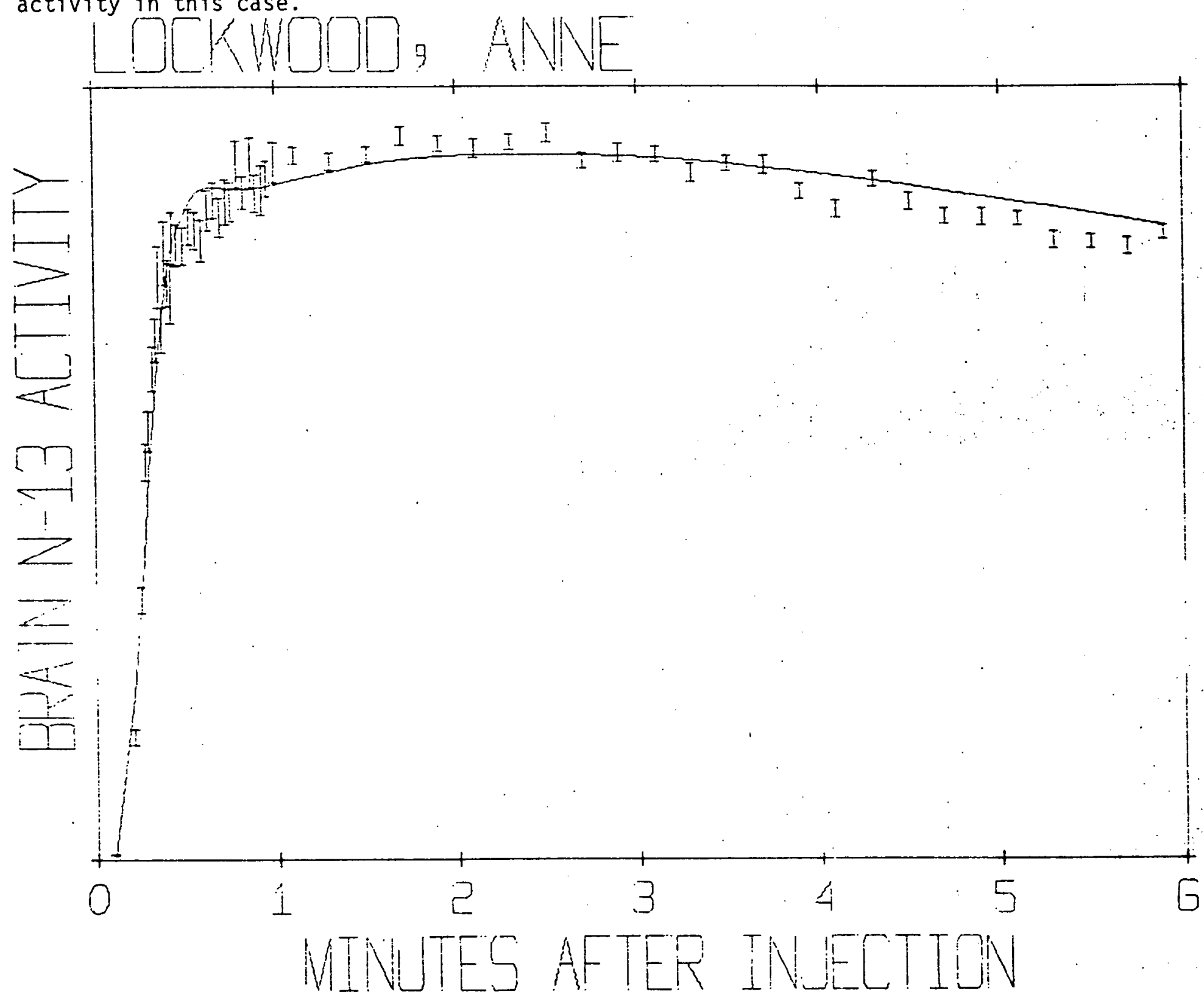


we will have use shortly of a just-delivered DEC PDP 11/70 computer, which, as an example, will decrease real number computation times by roughly a factor of 100 over the previous hardware. While these results are still very preliminary, one feature of these computer fits that appears consistently is that the size of the brain free ammonia pool is on the order of $20 \%$ or less of the estimated whole brain anmonia content, indicating a compartmentalization of this aspect of the brain's metabolism.

We have implemented two simple types of functional images into the framework of our TOKIM data analysis software. These are the persistence index and the time of maximum activity index.

The persistence index is based on a method introduced by Agress, et a1. (Applied Radiology, NM $4: 202-208$ ). We have supplied it to the analysis of $1 \mathrm{O}_{2}$ washout parameters. In that study, the subject is allowed to breathe the labelled gas continuously until a steady state is reached. At that point, the gas is turned off and the TOKIM begins to acquire data. Data accumulation continues until the counts reach background levels (see Figure 9). Upon analysis, the quantity PI is computed for each of the $4096(64 \times 64)$ resolution elements in the field. The persistence index PI is in units of time. It may be noted that if the washout function $C(t)$ is a simple monoexponential decay, i.e.

$$
C(t)=C_{0} * \exp (-\lambda t) \quad \text { then }
$$

the persistence index is simply the mean lifetime of the process, or

$$
\mathrm{PI}=\lambda^{-1}
$$

In practice, $P I$ is computed by a simple numerical integration of the discrete data points which make up the time curve at each picture element.

The maximum time index is computed by determining, for each picture element, the frame number in which the activity reached its maximum. value. The data can then be printed out frame by frame, indicating those resolution elements which reached their maximum value by a special symbol: It is thus possible to trace the path of a bolus injection through the image field.

The persistence index has enabled us to distinguish metastatic lung disease from normal lung tissue based on differences in washout times of $\mathrm{I}_{2} \mathrm{O}_{2}$ gas from chest images of normal dogs and dogs with spontaneous lung neoplasms. In normal dogs, most lung tissue clears with a PI of about 140 seconds, which is somewhat faster than the mean lifetime of the i.sotope (177 seconds). In an animal with lung tumor, the PI was of this value in most of the lung but was longer in regions identified with tumor (PI = about 205 seconds), indicating an influx of label, probably 
Progress Report

Page 65

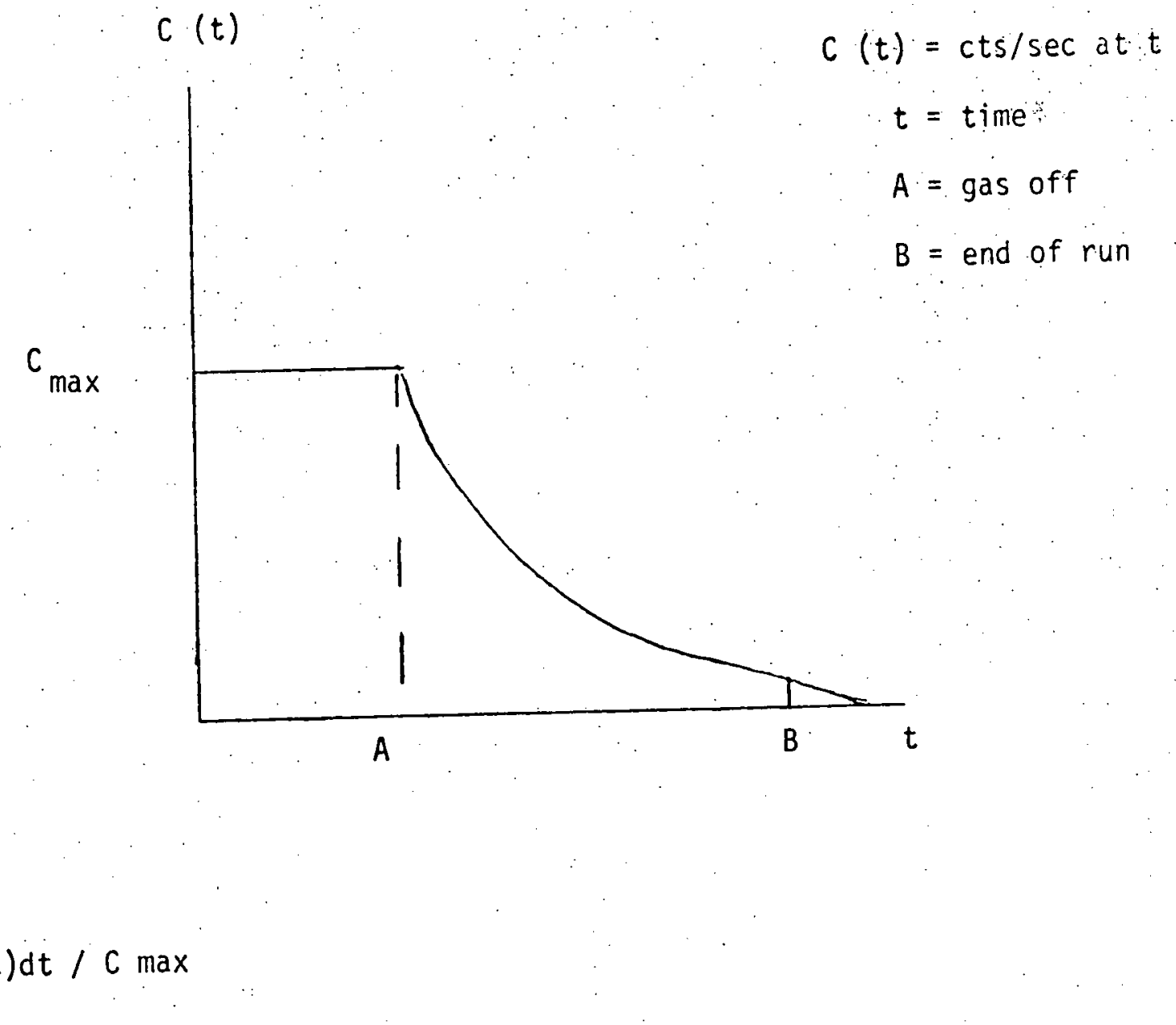

Figure 9. Computation of the persistence index (PI) for ${ }^{15} \mathrm{O}_{2}$ washout studies. 
attached to water into the tumor areas. "We plan to apply this method to the study of cerebral ischemia with $15 \mathrm{O}_{2}$ labeled gases.

In our experience, the maximum time index has not been of great utility compared to the more quantitative persistence index.

\section{DOSIMETRY FOR INTERNALLY DEPOSITED ISOTOPES IN ANIMALS AND MAN}

\section{OBJECTIVE:}

To evaluate the radiation hazard associated with the use of radionuclides and labeled compounds in animals and man.

\section{SCOPE OF INVESTIGATION:}

A key ingredient in the intelligent choice of a radionuclide or labeled compound for any proposed use in humans is an evaluation of the radiation hazards associated with its use. Such evaluation can begin with an analysis of the existing metabolic data for a preliminary radiation dose estimate. Where such data is lacking, specific studies of the distribution and dynamics of the agent of interest must be performed in a selected model system to provide the parameters required for radiation dose estimates.

An analysis of the expected radiation dose in man was performed for studies in which molecular oxygen labeled with oxygen-15 (1502) is administered continuously by inhalation and in which carbon monoxide labeled with carbon-11 is administered by inhalation in one or more breaths.

The relationship between the time distribution of radiation dose in external beam radiation therapeutic applications wi.th the time distribution of radiation dose from internally deposited radionuclides was studied to provide a better method for evaluating the biologic effects of radiation received in association with administered radionuclides and labeled compounds.

\section{RESULTS AND CONCLUSIONS:}

\section{A. Biologic Effects of Systemic Radionuclides}

The normal standard dose (NSD) concept, which is widely used by radiotherapists for the purpose of comparing treatment regimens which differ in time, dose, and fractionation patterns has been extended to internally deposited radionuclides to allow an evaluation of the biologic effects of their administration $(1,2)$. The manner in which current methods of 
Progress Report

Page 67

internal radiation dosimetry can be fitted into the formalism of external beam radiotherapy is the subject of a detailed presentation titled "Relationships of External Radiation Doses to Internal Dosimetry" appearing in the proceedings of the Symposium on Therapy in iluclear Medicine, Hartford, March 17-19, 1977 and will not be discussed here (1). To date, five radionuclides have been evaluated by this method for predicting the biologic effects following systemic administration.

\section{131 I Sodium Iodide Therapy for Metastatic Thyroid Cancer}

The experience of the Memorial Sloan-Kettering Cancer Center from 1946 to 1960 in treating patients with metastatic thyroid cancer showed that the majority of these patients had previously received a total surgical thyroidectomy (3). The administered amount of 131 I sodium iodide was chosen for the majority of patients to result in a dose of 300 rads to the blocd with the assumption that this was the largest dose patients could tolerate in relative safety. Next to nausea, bone marrow depression was the most frequent complication of treatment.

marrow of 131. Time and dose factor (TDF) estimates for the effect on retention data included in Table 15 assuming the isotope concentration of red marrow equal to blood. TDF of 1.3 was found for this treatment procedure as indicated in Table 16.

2. ${ }^{125}$ I Sodium Iodide Therapy for Metastatic Thyroid Cancer

The administered dose and red marrow radiation dose for ${ }^{125} \mathrm{I}$ sodium iodide treatment resulting in an equal TDF were calculated for two purposes. The first was to illustrate the possible predictive value of such estimates in evaluating the potential of substituting other radioactive isotopes of a given radionuclide for treatment or diagnosis. The second purpose was to point out that such estimates cannot be relied upon if the model assumed for the first isotope is not appropriate for the second isotope. Before this procedure could be expected to provide a reliable estimate of the effect on red marrow of 125I. sodium iodide therapy, cellular level distribution studies should be carried out for red marrow. A microscopic model may be needed for a reasonable estimate of the hazard associated with the use of 125I due to the short range of its emissions.

3. ${ }^{32} \mathrm{P}$ EHDP Treatment for Metastatic Osteogenic Sarcoma The possibility of using ${ }^{32} \mathrm{P}$ EHDP or ${ }^{33} \mathrm{P}$ EHDP as an adjuvant in the prophylactic or palliative treatment of osteogenic sarcoma is under active investigation at the sloan-Kettering Institute $(4,5)$. Data obtained from patient studies were used to derive the biologic parameters for 32p EHDP appearing in Table 15. At an administered dose level of $0.3 \mathrm{mCi} / \mathrm{kg}$ body weight $(6)$, the dose results in a TDF of 2.7 in humans as indicated in Table 16. 


\section{TABLE 15}

Biologic Parameters for Single IV Administrations of Three Radiolabeled Compounds

\begin{tabular}{|c|c|c|c|c|c|c|c|}
\hline \multirow{2}{*}{$\begin{array}{l}\text { Radiolabeled } \\
\text { Compound }\end{array}$} & \multirow[b]{2}{*}{ Body Tissue } & \multicolumn{3}{|c|}{$\begin{array}{l}\text { Fraction of Administered } \\
\text { Activity Per Organ } \\
\end{array}$} & \multicolumn{3}{|c|}{$\begin{array}{c}\text { Biologic Disappearance } \\
\text { (Constants }\left(h^{-1}\right)\end{array}$} \\
\hline & & $\alpha_{1}$ & $\alpha_{2}$ & $\alpha_{3}$ & $\lambda_{1}$ & $\lambda_{2}$ & $\lambda_{3}$ \\
\hline \multirow{3}{*}{ 131. I-iodine } & Total-Body & 0.35 & 0.18 & 0.47 & 0.158 & 0.06 & $5.9 \times 10^{-3}$ \\
\hline & Marrow & $9.6 \times 10^{-2}$ & $-6.5 \times 10^{-3}$ & $9.7 \times 10^{-3}$ & 0.313 & 0.027 & 0.0 \\
\hline & Trabecular Bone & $1.62 \times 10^{-1}$ & $4.37 \times 10^{-2}$ & --- & $2.57 \times 10^{-3}$ & $0: 0$ & --- \\
\hline \multirow[t]{2}{*}{${ }^{32} \mathrm{P}-\mathrm{EHDP}$} & Cortical bone & $2.17 \times 10^{-1}$ & $5.83 \times 10^{-2}$ & --- & $2.57 \times 10^{-3}$ & 0.0 & --- \\
\hline & Marrow & $9.23 \times 10^{-2}$ & $2.15 \times 10^{-2}$ & $6.65 \times 10^{-4}$ & $1.61 \times 10^{0}$ & $3.39 \times 10^{-1}$ & $1.73 \times 10^{-2}$ \\
\hline${ }^{35}$ s-sulfate & Marrow & $1.22 \times 10^{-2}$ & $2.79 \times 10^{-2}$ & $2.8 \times 10^{-5}$ & $3.15 \times 10^{-1}$ & $4.81 \times 10^{-3}$ & $1.28 \times 10^{-3}$ \\
\hline
\end{tabular}


TABLE 16

Time-Dose Factor (TOF) Estimate of Damage to Normal Red Marrow by Internally Deposited. Radionuclides and Labeled Compounds.

\begin{tabular}{|c|c|c|c|c|}
\hline Radionuclide & $\begin{array}{c}\text { Chemical } \\
\text { Form }\end{array}$ & $\begin{array}{c}\text { Administered } \\
\text { Dose } \\
\text { mCi/kg } \\
\text { Body Weight }\end{array}$ & $\begin{array}{c}\text { Radiation Dose } \\
\text { to Marrow } \\
\text { (rad) }\end{array}$ & TDF \\
\hline $131 \mathrm{I}$ & $\begin{array}{l}\text { Sodium } \\
\text { Iodide }\end{array}$ & 4.5 & 300 & 1.3 \\
\hline${ }^{125} I$ & $\begin{array}{l}\text { Sodium } \\
\text { Iodide }\end{array}$ & 8.0 & 630 & 1.3 \\
\hline${ }^{32} p$ & EHDP* & 0.3 & 600 & 2.7 \\
\hline${ }^{33} \mathrm{p}$ & EHDP* & .2 .6 & 670 & 2.7 \\
\hline${ }^{35} \mathrm{~s}$ & Sulfate & 30. & 750 & 4.4 \\
\hline
\end{tabular}

^EHDP = Ethane-1-hydroxy-1, 1-diphosphonate. 


\section{4. $33_{P}$ EHDP Treatment for Metastatic Osteogenic Sarcoma}

Another example of investigating the predictive value of radioactive isotope substitution (33p for. $32 p$ ) by means of TDF estimations applies to the case of 32P-EHDP. This case differs from the iodine case in that distribution data are available showing that EHDP is taken up on bone surfaces. The present MIRD model assumes a uniform uptake within bone tissue (volume uptake). The relatively long range of the $1.7 \mathrm{MeV}$ (maximum) beta particle emitted by $32 \mathrm{p}$ relative to red marrow trabecular bone spacing (7) suggests that either a surface or volume uptake assumption would lead to essentially the same dose and TDF result for 32p. The $0.25 \mathrm{MeV}$ (maximum) beta particle emitted by $33 \mathrm{p}$ has a much stronger range. Clearly, before the 2.7 TDF estimate derived from $32 \mathrm{p}$ data can be used to predict the administered dose of $33 \mathrm{p}$ required for equal effect a calculation based upon the microscopic distribution is required.

\section{5. ${ }^{35}$ S-Sulfate Treatment}

Distribution data shown in Table 15 for ${ }^{35} \mathrm{~S}$-sulfate were derived from clinical studies performed at the Memorial Sloan-Kettering Cancer Center $(8,9)$. Two TDF estimates for red marrow were obtained. The first assumes a single administration of $30 \mathrm{mCi}$ per kilogram body weight, which results in a TDF of 4.4 and is included in Table 16 for comparison to the other TDF estimations. The second is according to a multiple dose administration treatment plan used in one case. In the latter case, the increase of TDF with item is illustrated in Figure 10 and of dose with time in Figure 11. TDF and radiation dose for the treatment plan are 3.3 and 990 rads respectively. This and other like treatments resulted in sufficiently severe marrow toxicity to contraindicate its use in patients.

The result of the time and dose factor calculations in Table 16 and the multiple administration protocol with $35 \mathrm{~s}$ suggest that any treatment resulting in TDF of no higher than about 2 to normal bone marrow is probably safe, whereas, treatments above. 3 are likely to result in unacceptable results. However, at present considerable caution must be exercised in the use of any predictions of effects on normal tissues derived from TDF calculations. The data used to establish the TDF inethod for implant brachytherapy did not extend below 30 rads per hour and no empirical proof of the validity of the relationship for variable dose-rate procedures has been given (10). Figure 12 shows that the dose rates from which TDF calculations presented here were derived are well below 30 rads per hour at time of administration and they decrease rapidly thereafter. The validity for the use of the NSD concept in nuclear medicine procedures can and should be provided by a thorough analysis of currently existing treatment experience. 


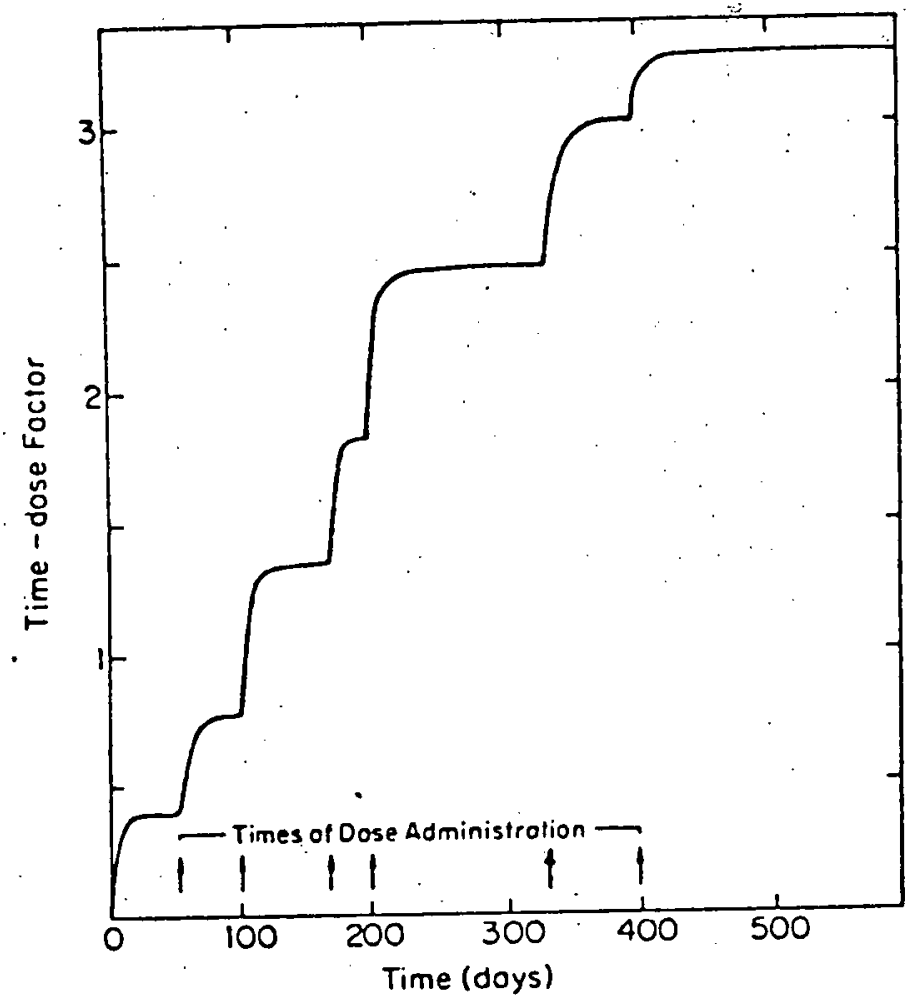

Figure 10. Graph of the radiation dose versus time for a ${ }^{32}$ S-sodium sulfate patient treatment plan, where multiple administrations have been performed. 


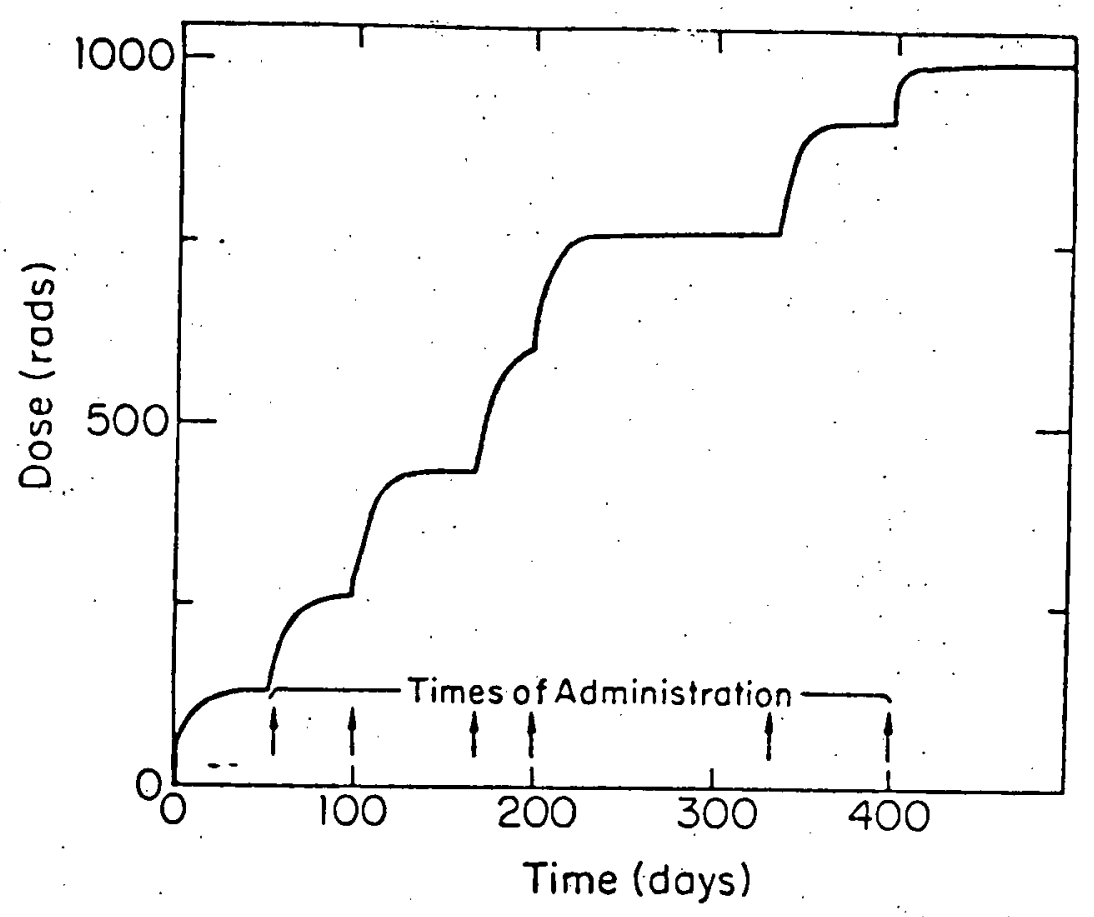

Figure 11. Graph of the radiation dose versus time for a ${ }^{35}$ S-sodium sulfate patient treatment plan, where multiple administrations have been performed. 


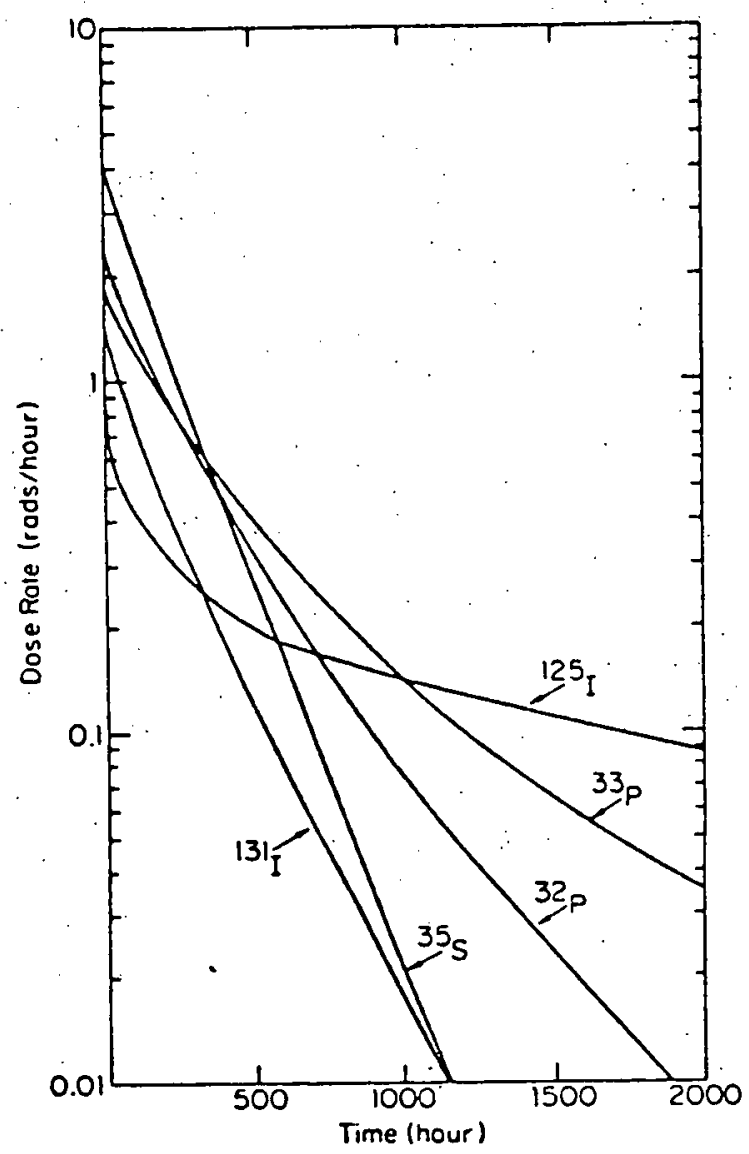

Figure 12. Graph of dose rate versus time for single administrations to humans of the radiolabeled compounds discussed in the text. 
B. Radiation Dosimetry for Short Lived Radioactive Agents for Inhalation

Two active studies at the Memorial Sloan-Kettering Cancer Center involving radioactive gases have required an evaluation of radiation dose prior to initiation of clinical trials. In both cases, the agent was $\mathrm{I5O}_{2}$ which required continuous inhalation until a steady state level of activity in the system was attained. A recently proposed study required a single breath or at most a few breaths of the longer 1ived 1.1C0. The dosimetry for these agents have, each for its own methodology, been estimated and reports submitted to the $\mathrm{Cl}$ inical Investigations Committee, Memorial Hospital for approval to begin clinical trials.

1. Radiation Dosimetry for the Continuous Inhalation of ${ }^{15}{ }_{02}$

The cumulative ${ }^{15} \mathrm{O}_{2}$ activity within the total body for a constant administration of activity. was estimated, using the model shown in Figure 13.

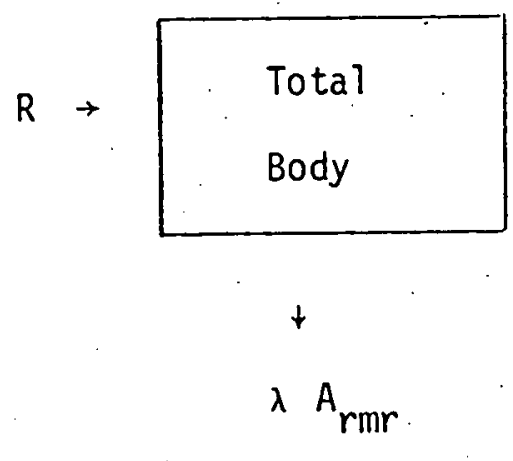

Figure 13. Total body model for constant administration of radioactive gas. $R=$ delivery rate of radioactive gas $(\mathrm{mCi} / \mathrm{hr}), \lambda=$ physical decay constant $(h r-1), A_{r m r}=$ activity in the resting metabolic state.

This is a one component steady-state model for the time distribution of activity within the metabolic compartment of the wholebody. Molecular oxygen labeled with 150 is administered at a constant rate $R$ to the patient by inhalation. The differential equation describing such a system is the following: 


$$
\frac{d A_{r m r}}{d t}=R-\lambda A_{r m r}
$$

where $A_{r m r}=$ Activity in resting metabolic state, $\lambda=$ radioactive decay constant. The general solution for this equation is

$$
A_{r m r}=\frac{R}{\lambda}\left(1-e^{-\lambda t}\right)
$$

where $t$ is the time from start of activity administration. At long times this expression becomes.

$$
A_{r m r}=\frac{R}{\lambda} \text {, }
$$

which is the level of activity at the steady-state.

The cumulative activity during the period of administration can be obtained by integration of Equation 1

$$
\AA_{\text {rmr }} \text { (uptake) }=\frac{R}{\lambda}\left\{t_{\max } \cdot-\frac{1}{\lambda}\left(1-e^{-\lambda t \max }\right)\right\}
$$

where $t_{\max }$ is the time at which activity administration is stopped.

The cumulative activity during the period following cessation of administration can be evaluated using the expression

$$
\AA_{\text {rmr }} \text { (clearance) }=\frac{A_{\text {rmr }} \text { (uptake) }}{\lambda} e^{-\lambda\left(t-t_{\max }\right)}
$$

The cumulative activity due to the reduction of oxygen is then the sum of the uptake and clearance cumulative activities

$$
\AA_{r m r}=\AA_{r m r} \text { (uptake) }+\AA_{\text {rmr }} \text { (clearance) }:
$$


Progress Report

Page 76

The total cumulative activity in each source organ is obtained from the following expression:

$$
\tilde{A}_{r}=\tilde{A}_{r m r}+\tilde{A}_{b 1 d}+\tilde{A}_{\text {Tun }}(\mu C i-h)
$$

where

$$
\begin{aligned}
& \tilde{A}_{r m r}=\frac{A_{0} R_{r}}{\lambda} t_{\max }+\frac{1}{\lambda}\left(e^{-\lambda t_{\max }-1}\right)+\left(1-\mathrm{e}^{-\lambda \cdot t_{\max }}\right)\left(\frac{1}{\lambda} \mathrm{e}^{-\lambda t_{\max }}\right), \\
& \AA_{b l d}=0_{b l d_{r}} \cdot S A \cdot t_{\max } \cdot A_{0}
\end{aligned}
$$

and

$$
A_{\text {lu }}=0_{\text {lu }} \cdot S A \cdot t_{\max } \cdot A_{0}
$$

Where

$$
\begin{aligned}
& A_{0}=\text { Administered activity. } \\
& \AA_{\text {nmr }}=\text { Cumulative activity due to resting oxygen } \\
& \text { utilization in the source organ } r .(\mu \mathrm{C} i-h) \\
& \tilde{A}_{\text {ald }}=\begin{array}{l}
\text { Cumulative activity due to molecular oxygen in } \\
\text { solution in the blood }(\mu \mathrm{C} i-h)
\end{array} \\
& \tilde{A}_{\text {un }}=\underset{\text { gas }(\mu C i-h)}{\text { Cumulative activity due to molecular oxygen in lung }} \\
& R_{r}=\text { Resting oxygen utilization rate }\left(m 0_{2}-h^{-1}\right) \\
& \lambda=\text { Physical decay constant }\left(h^{-1}\right) \\
& t_{\max }=\text { Maximum duration of }{ }^{15} 0 \text { gas flow }(h) \\
& 0_{\text {blt }}=\text { oxygen in blood in source organ }(\mathrm{ml}) \\
& \mathrm{SA}=\text { Specific activity of oxygen }=4.7755 \mu \mathrm{Ci} / \mathrm{ml} \mathrm{O}_{2} \\
& \left.0_{\text {lon }}=\text { oxygen in lung gas ( } m 1\right)
\end{aligned}
$$


The values assumed for the oxygen content of the blood and the resting metabolic oxygen content at steady state are given in. Table 17. Table 18 includes the resulting cumulative activities derived by application of these data to Eqs. 7-10. A summary of the radiation dose estimates for various total activity administration periods is given in Table 19.

2) Radiation Dosimetry for a Single Breath. Inhalation of ${ }^{11} \mathrm{CO}$

Cumulative activity estimates for carbon-11 labeled carbon monoxide $\left({ }^{11} \mathrm{CO}\right)$ are based upon the following assumptions: (1) No more than $10 \mathrm{mCi}$ of carbon monoxide labeled with carbon-11 per 70 kilogram body weight will be administered. (2) Activity will be maintained for no longer than $30 \mathrm{sec}$ within the lungs. (3) Activity within the body will be distributed only in blood with activity loss occuring only by physical decay.

Taking the blood mass to be $5400 \mathrm{~g}$, the activity in the blood will have an initial value of 1.85 microcuries per gram $(\mu \mathrm{Ci} / \mathrm{g})$. Table 20 shows the blood mass and resulting activity in a number of body organs.

The following formula is used to calculate the cumulated activity due to blood:

$$
\AA_{r}=1.44 A_{r} T_{p}
$$

where $A_{p}(\mu \mathrm{C} i)$ is the activity in each source organ $r$, and $T_{p}$ is the physical half-life in hours. These results are included in Table 20. For the lung an additional contribution arises from the gas activity. The $10 \mathrm{mC} i$ is assumed constant for 30 seconds which leads to a $83 \mu \mathrm{Ci}$ addition to the lung cumulated activity (total 373).

The radiation absorbed dose estimates for the above assumptions are given in Table 21. 
TABLE 17

Total Oxygen Residing in Various Body Organs

\begin{tabular}{|c|c|c|c|c|c|c|c|}
\hline Organ & $\begin{array}{l}\text { Blood } \\
\text { Volume } \\
\text { (ml) }\end{array}$ & $\begin{array}{l}\text { Blood } \\
\text { mass } \\
(\mathrm{g})\end{array}$ & $\begin{array}{l}\text { Organ } \\
\operatorname{mass} \\
(\mathrm{g})\end{array}$ & $\begin{array}{c}\mathrm{O}_{2} \\
\text { in } \mathrm{Blood} \\
765.6 \mathrm{ml} \\
\mathrm{O}_{2} \\
\text { Total. }\end{array}$ & $\begin{array}{c}\mathrm{O}_{2} \text { in } \\
\underset{(\mathrm{ml})}{\text { ung gas }}\end{array}$ & $\begin{array}{c}\mathrm{O}_{2} \text { Resting } \\
\text { Metabolic rate } \\
(\mathrm{ml})\end{array}$ & $\begin{array}{c}\text { Total } \\
0_{2} \\
\text { (ml) }\end{array}$ \\
\hline Liver & 235 & 260 & 1809 & 37.48 & & 349.07 & 386.55 \\
\hline Spleen & 72 & 82 & 173.6 & 11.48 & & 0 & 11.48 \\
\hline Lungs & 282 & 320 & 999.2 & 45.0 & 416.15 & 98.17 & 559.32 \\
\hline Kidneys & 68 & 76 & 284.2 & 10.85 & & 76.36 & 87.21 \\
\hline Brain & 16 & 18 & 1470 & 2.55 & & 229.07 & 231.62 \\
\hline Heart & 518. & 580 & 603 & 82.62 & & 109.08 & 191.70 \\
\hline Rem & 3609 & & 64541 & 575.62 & & 22.9 .07 & 804.69 \\
\hline Total & 4800 & & 69880 & 765.6 & 416.15 & 1090.83 & 2272.58 \\
\hline
\end{tabular}


TABLE 18

$$
\begin{aligned}
& \text { Tota1. Cumulative Activity for } 1 \mathrm{mCi} / 1-{ }^{15} \mathrm{O}_{2} \text { Administered } \\
& \text { Continuously in the Breathing Supply }
\end{aligned}
$$

\begin{tabular}{|c|c|c|c|c|}
\hline Organ & $\begin{array}{l}6 \text { Min. } \\
\text { Uptake } \\
+ \\
\text { Washout }\end{array}$ & $\begin{array}{c}10 \text { Min. } \\
\text { Uptake } \\
+ \\
\text { Washout }\end{array}$ & $\begin{array}{c}6 \text { Min Uptake } \\
+ \\
15 \text { Min Scan }^{+} \\
\text {Washout }\end{array}$ & $\begin{array}{l}10 \text { Min Uptake } \\
++ \\
15 \text { Min Scan } \\
+ \\
\text { Washout }\end{array}$ \\
\hline Liver & 123 & 231 & 564 & 687 \\
\hline Spleen & 5.48 & 9.14 & 19.2 & 22.8 \\
\hline Lungs & 250 & 424 & 912 & 1090 \\
\hline Kidneys & 28.1 & 52.7 & 128 & 156 \\
\hline Brain & 70.0 & 134 & 334 & 407 \\
\hline Heart & 72.1 & 129 & 295 & 356 \\
\hline REM & 344 & 590 & 1290 & 1550 \\
\hline Total Body & 693 & 960. & 2850 & 3440 \\
\hline
\end{tabular}


Progress Peport

Page 80

TABLE 19

Absorbed Radiation Dose for Continuous Breath Administration 1 mCi of ${ }^{15} \mathrm{O}_{2}$ per Liter of Air for Various Time Periods

\begin{tabular}{lcccc}
\hline \multirow{2}{*}{ Organ } & \multicolumn{3}{c}{ Dose (m rads) for Time Periods (min) } \\
\cline { 2 - 5 } & 6 & 10 & 21 & 25 \\
\hline Lungs & 420 & 710 & 1540 & 1840 \\
Heart & 240 & 420 & 960 & 1160 \\
Kidneys & 170 & 310 & 750 & 910 \\
Liver & 140 & 260 & 630 & 770 \\
Brain & 91 & 170 & 430 & 530 \\
Spleen & 64 & 110 & 230 & 270 \\
Total Body & 23 & 32 & 93 & 113 \\
\hline
\end{tabular}


TABLE 20

Biologic Data

\begin{tabular}{|c|c|c|c|}
\hline Organ & $\begin{array}{l}\text { Blood Mass* } \\
\text { (g) }\end{array}$ & $\begin{array}{c}\text { Activity } \\
(\mu \mathrm{C} i)\end{array}$ & $\begin{array}{l}\text { Cumulative } \\
\text { Activity } \\
\left({ }_{1} \mathrm{Ci}-\mathrm{h}\right)\end{array}$ \\
\hline . & & 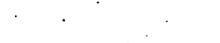 & $\therefore$ \\
\hline Liver & 260 & 482 & 235 \\
\hline Spleen & 82 & 152 & 74 \\
\hline Lungs & 320 & 593 & 290. \\
\hline Kidneys & 76 & 141 & 69 \\
\hline Red Marrow & 200 & 370 & 181 \\
\hline
\end{tabular}

${ }^{\star}$ Reference 11. 
TABLE 21

Summary of Radiation Dose Estimates to Humans for a $10 \mathrm{mCi}$ Bolus Breath Administration of ${ }^{11} \mathrm{CO}$

Organ $\begin{gathered}\text { Dose } \\ \text { (mrad) }\end{gathered}$

Spleen

Lung

Kidneys

Liver

Red Marrow

Ovaries

Testes 


\section{REFERENCES:}

1. Bigler, R.E. Relationship of external radiation doses to internal dosimetry. Therapy in Nuclear Medicine, Spencer, R.P. ed. Grune and Stratton, 1977 (In Press).

2. Bigler, R.E. Dosimetry for the evaluation of the biologic effects of radionuclides and labeled compounds. Proc. Radiopharmaceutical Dosimetry Symp., Oak Ridge, Tennessee, April, 1976. pp. 221-229 (Eds. R.J. Cloutier, J.L. Coffee, W.S. Snyder, and B.B. Watson) HEW Publ. FDA 7608044.

3. Benua, R.S., Cicale, N.R., Sonenberg, M., and Rawson, R.W. The relation of radioiodine dosimetry to results and complications in the treatment of metastatic thyroid cancer. Am. J. Roentgeno1. 87: $171-182,1962$.

4. Bigler, R.E., Rosen, G., Tofe, A.J.., Russ, G.A., Francis, M.D., Benua, R.S., and Woodard, H.Q. Distribution of 32p diphosphonate in patients with osteogenic sarcoma. Proc. Am. Assoc. Cancer Res. 17:103, 1976.

5. Bigler, R.E., Rosen, G., Tofe, A.J., Russ, G.A., Francis, M.D., Benua, R.S., Woodard, H.Q., and Kostick, J.A. Comparative distribution of $32 \mathrm{p}$ and $99 \mathrm{mT} \mathrm{c}$ diphosphonates in patients with osteogenic sarcoma. J. Nucl. Med. 17:548, 1976.

6. Francis, M.D., Slough, C.L. and Tofe, A.J. Distribution and effect of $\mathrm{P}-32$ EHDP in normal and bone tumor bearing dogs. J. Nucl. Med. $17: 548,1976$.

7. Spiers, F.W. Radionculijes and bone from ${ }^{226} \mathrm{Ra}$ to ${ }^{90} \mathrm{Sr}$. Brit. J. Radiol. 47:833-844, 1974.

8. Woodard, H.Q., Pentlow, K.S., Mayer, K., Laughlin, J.S., and Marcove, R.C. Distribution and retention of $35 \mathrm{~S}$-sodium sulfate in man. J. Nucl. Med. 17:285-289, 1976.

9. Woodard, H.?. Private Communication, 1977.

10. Orton, C.G. Time-dose factors (TDF's) in brachytherapy. Brit. J. Radiol. 47:603-607, 1974.

11. Cloutier, R.J., Watson, E.E. Radiation dose from radioisotopes in the blood. In: Medical Radionuclides: Radiation Dose and Effects, ed. by $\bar{R}$.J. Cloutier, C.L. Edwards and W.S. Snyder, Proc. Symposium, Dec. 8-11, 1969. Oak Ridge, Tennessee, Lib. Cong. Cat. No. 70-606556, 1970. 


\section{CYCLOTRON RESEARCH AND DEVELOPMENT}

\section{OBJECTIVE:}

To maintain and improve cyclotron operating efficiency and reliability, to improve personnel and equipment safety and protection; and to simplify and standardize cyclotron operation.

\section{SCOPE OF INVESTIGATION:}

The research programs utilizing the sloan-Kettering cyclotron demand a high degree of reliability and versatility from the cyclotron. Different particles and different beam currents on tight scheduling require daily and half daily particle change over and cyclotron retuning, much more so than similar cyclotrons in other institutions. Also, the limited particle energy of our cyclotron requires long term stable high and low beam currents for production of some isotopes and neutrons. To meet these demands we have concentrated on developing simple and standard cyclotron operation and maintenance methods, stable and reproducible beam currents, optimum extraction efficiencies and extended life times for perishable components.

\section{RESULTS AND CONCLUSIONS:}

\section{Beam Current Stability}

The quality and quantity of the internal beam and its effect on the extraction efficiency and external beam depends on the configuration of the first turn orbit, which in turn heavily depends on

components of the central region: the ion source, puller and first turnshield; as well as the isochronous magnetic field, RF system and accelerating voltage. When high beam currents are run, components may become misaligned due to overheating, copper components may be subject to ablation and the accelerating voltage power supply may overload and interrupt its power and thus the beam in a process called crowbarring. All of this contributes to an unsteady internal or external beam. We have continued to investigate the puller configuration and have adopted a design that yields satisfactory collimation of the first turn orbit. This is a compromise design, since we learned that the optimum first turn orbits of different particles have different configurations. Lining certain surfaces of the central region components with high density carbon has halted the ablation. Together, these improvements have lead to significantly steadier beam currents. 


\section{Cyclotron Operation, Maintenance and Safety}

In order to make the cyclotron easier to operate and less easily damaged by user-operators, a number of devices and interlocks have been installed. A Beam Current Monitoring Board that displays the beam current at eight critical points along the beam path for a new total of ten has been installed to supplement our beam profile scanner, to give the operator greater control over the beam extraction efficiency, quality and quantity. Interlocks to turn off the deflector at low main magnet currents and to run in the internal probe during the off periods of high beam current runs, are expected to greatly reduce deflectior. maintenance, thus reducing a principal source of cyclotron staff radiation exposure and costly replacement parts:

In order to extend the accessibility and versatility of our cyclotron, a Cyclotron Operator Proficiency Grading System has been created for all personnel with access to the cyclotron, see Appendix. User-operators have been encouraged to seek appropriate instruction to reduce reliance on the cyclotron staff.

\section{Control Systems and Protective Devices}

52 206 As mentioned above, targets for certain isotopes such as ${ }^{52} \mathrm{Fe},{ }^{206} \mathrm{Bi}$ and ${ }^{48} \mathrm{Cr}$. require long irradiation times. The necessary upgrading and debugging of automatic devices previously installed has been completed and long period unattended cyclotron operation is now reliable and safe. As a result, an Automatic Shutdown System has been installed so that self-terminating after-hours target irradiation may be made, thus making more efficient use of the 1 imited schedule, space and staff available.

The harsh winter just past severely affected the city water service used to cool the cyclotron external targets. The interruption of water service by frozen pipes and scale from a street main break damaged one target and interrupted the cyclotron schedule several times. connecting the targets to the closed loop cyclotron cooling water, with appropriate water flow and vacuum interlocks, has eliminated the problem. 
APPENDIX

\section{CYCLOTRON SUPERVISOR}

1. Responsible for general maintenance and operation of the cyclotron including the spare parts inventory.

2. Responsible for scheduling, assignment of operators, handling of radiation monitors and other administrative duties as need attention.

3. May suggest and make cyclotron and equipment modifications with Laboratory Head approval.

\section{SENIOR CYCLOTRON OPERATOR}

1. Can set up, tune and run the cyclotron unsupervised.

2. May be asked to train other cyclotron operators.

3. Can perform minor troubleshooting unsupervised.

4. May perform maintenance or major troubleshooting on the cyclotron under a Cyclotron Supervisor only and constitutes further training.

5. May run high beam currents with Cyclotron Supervisor approval only. SINGLE PARTICLE OPERATOR

1. Can set up, tune and run the cyclotron unsupervised for the particle assigned oniy.

2. May set up, tune and run the cyclotron under supervision of a Senior Operator or Cyclotron Supervisor as further training in other particle.

3. Can perform minor troubleshooting unsupervised for particle assigned only.

4. May run high beam currents with Cyclotron Supervisor approval only.

\section{CYCLOTRON MONITOR}

1. Can monitor cyclotron while in operation and call a Senior Operator or Cyclotron Supervisor if trouble should occur.

2. Can turn on and off the cyclotron by the "ABC" or "Preset" controls unsupervised.

3. May set up and run the cyclotron under supervision of a Senior Operator or Cyclotron Supervisor as further training. 


\section{PUBLICATIONS AND. IN PRESS}

1. Bigler, R.E., Davis, R., Jr., Evans, J.C. and Laughlin, J.S. Estimation of skeletal calcium in humans by exhaled 37 Ar measurement - Evaluation of the fast neutron dose requirements. Int. J. Nucl. Med. Biol. 3:105-110, 1976 .

2. Bigler, R.E., Kostick, J.A., Woodard, H.Q., and Laughl in, J.S. Use of a collimated source of fast neutrons to measure malignant tumor electrolyte exchange kinetics: IEEE Transactions on Nuclear Science NS24, No. 1,559-562, 1976.

3. Digenis, G.A., Pettit, W.A., Tilbury, R.S., Helson, L.R., Russ, G.A., and Zedeck, M.S. Preparation of $N-13-B C N U$ and its tissue distribution in rats and mice with tumors. APHA Academy of Pharmaceutical Sciences, 1977. (Abstract)

4. Freed, B.R. The tissue distribution of ${ }^{47} \mathrm{Sc}$ generated by decay of 47Ca in vivo. Health Physics 32:165-178, 1977.

5. Gelbard, A.S., Christie, T.R., Clarke, L.P., and Laughlin, J.S: Imaging of spontaneous canine tumors with $13 \mathrm{~N}-1$ abeled ammonia.and L-glutamine. J. Nucl. Med. 18:718-723, 1977.

6. McDonald, J.C., Kuo, T.Y.T., Freed, B.R., and Laughl in, J.S. Dosimetric measurements in the neutron field produced by a deuterium gas target with a compact medical cyclotron. Med. Phys. 4:319-321, 1977.

7. Pentlow, K.S., Beattie, J.W. and Laughl in, J.S. Parameters and design considerations for tomographic transmission scanners. In: RECONSTRUCTION TOMOGRAPHY IN DIAGNOSTIC RADIOLOGY AND NUCLEAR MEDICINE. Baltimore, M.D.: University Park Press, 1977, pp. 267-279.

8. Russ, G.A., Bigler, R.E., Tilbury, R.S., McDonald, J.M., and Laughlin, J.S. Distribution of oxygen-15. in the dog at the steadystate. Int. J. Nucl. Med. Biol. $3: 121-125,1976$.

9. Tilbury, R.S. and Dahl, J.R. ${ }^{13} \mathrm{~N}$ species produced by proton irradiation of water; Effect of dose and additives. Rad. Res. 70: 646, 1977. (Abstract)

10. Woodard, H.Q., Bigler, R.E., Freed, B., and Russ, G.A. Reply to Notations for tissue radionuclide distributions. Letter to the Editor: J. Nucl. Med. 17:1110-11111, 1976.

i1. Zeitz, L., Kim, S.H., Kim, J.H., and Detko, J.F. Determination of relative biological effectiveness (RBE) of soft $X$-rays. Rad. Res. 70:552-563, 1977 . 
IN PRESS

1. Bigler, R.E. Relationship of external radiation doses to internal dosimetry. Therapy in Nuclear Medicine, Ed. Spencer, R.P., New York: Grune \& Stratton, 1977.

2. Kuo, T.Y.T. and Laughlin, J.S. Improvement in beanl current performance of the biomedical cyclotron at Memorial Sloan-Kettering Cancer Center. To be published in: Proc. 4th Medical Cyclotron Users Conference, March 24-27, $1 \overline{976 .}$

3. Lockwood, A.H., McDonald, J.M., Reiman, R.E., Gelbard, A.S., Laughlin, J.S., Duffy, T.E., and Plum, F. The dynamics of ammonia metabolism in man. Gastroenterology. (Abstract)

4. Tilbury, R.S. The Memorial Sloan-Kettering Biomedical Cyclotron Facility: 1) Program Overview. To be published in: Proc. 4th Medical Cyclotron Users Conference, March 24-27, 1976.

5. Tilbury; R.S. The Memorial Sloan-Kettering Biomedical Cyclotron Facility: 2) Radioisotope Production and Labeled Compounds. To be published in: Proc. 4th Medical Cyclotron Users Conference, March 24-27, $197 \overline{6 .}$ 